\title{
The actin nucleation factors JMY and WHAMM enable a rapid Arp2/3 complex-mediated intrinsic pathway of apoptosis
}

\author{
Virginia L. King $₫$, Nathan K. Leclair $₫$, Alyssa M. Coulter $\odot$, Kenneth G. Campellone $\oplus^{*}$ \\ Department of Molecular and Cell Biology, Institute for Systems Genomics, University of Connecticut, Storrs, \\ Connecticut, United States of America \\ * kenneth.campellone@uconn.edu
}

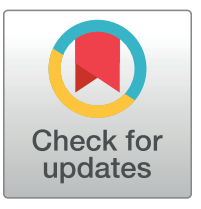

\section{G OPENACCESS}

Citation: King VL, Leclair NK, Coulter AM, Campellone KG (2021) The actin nucleation factors JMY and WHAMM enable a rapid Arp2/3 complexmediated intrinsic pathway of apoptosis. PLoS Genet 17(4): e1009512. https://doi.org/10.1371/ journal.pgen.1009512

Editor: Irene Chiolo, University of Southern California, UNITED STATES

Received: June 22, 2020

Accepted: March 28, 2021

Published: April 19, 2021

Peer Review History: PLOS recognizes the benefits of transparency in the peer review process; therefore, we enable the publication of all of the content of peer review and author responses alongside final, published articles. The editorial history of this article is available here: https://doi.org/10.1371/journal.pgen.1009512

Copyright: ๑ 2021 King et al. This is an open access article distributed under the terms of the Creative Commons Attribution License, which permits unrestricted use, distribution, and reproduction in any medium, provided the original author and source are credited.

Data Availability Statement: All relevant data are within the manuscript and its Supporting Information files.

\section{Abstract}

The actin cytoskeleton is a well-known player in most vital cellular processes, but comparably little is understood about how the actin assembly machinery impacts programmed cell death pathways. In the current study, we explored roles for the human Wiskott-Aldrich Syndrome Protein (WASP) family of actin nucleation factors in DNA damage-induced apoptosis. Inactivation of each WASP-family gene revealed that two of them, JMY and WHAMM, are necessary for rapid apoptotic responses. JMY and WHAMM participate in a p53-dependent cell death pathway by enhancing mitochondrial permeabilization, initiator caspase cleavage, and executioner caspase activation. JMY-mediated apoptosis requires actin nucleation via the Arp2/3 complex, and actin filaments are assembled in cytoplasmic territories containing clusters of cytochrome $c$ and active caspase-3. The loss of JMY additionally results in significant changes in gene expression, including upregulation of the WHAMM-interacting G-protein RhoD. Depletion or deletion of RHOD increases cell death, suggesting that RhoD normally contributes to cell survival. These results give rise to a model in which JMY and WHAMM promote intrinsic cell death responses that can be opposed by RhoD.

\section{Author summary}

The actin cytoskeleton is a collection of protein polymers that assemble and disassemble within cells at specific times and locations. Cytoskeletal regulators called nucleation factors ensure that actin polymerizes when and where it is needed, and many of these factors are members of the Wiskott-Aldrich Syndrome Protein (WASP) family. Humans express 8 WASP-family proteins, but whether the different factors function in programmed cell death pathways is not well understood. In this study, we explored roles for each WASPfamily member in apoptosis and found that a subfamily consisting of JMY and WHAMM is critical for a rapid pathway of cell death. JMY-mediated actin assembly in the cytoplasm is necessary for its pro-apoptotic function. Furthermore, the loss of JMY results in changes in gene expression, including a dramatic upregulation of the small G-protein RhoD, which appears to contribute to cell survival. Collectively, our results point to the 
Funding: KGC was supported by National Institutes of Health grants R01-GM107441 and K02AG050774 (www.nih.gov). The funders had no role in study design, data collection and analysis, decision to publish, or preparation of the manuscript.

Competing interests: The authors have declared that no competing interests exist. importance of JMY and WHAMM in driving intrinsic cell death responses plus a distinct function for RhoD in maintaining cell viability.

\section{Introduction}

Apoptosis is a programmed form of cell death crucial for many organismal processes, including development, tissue turnover, and tumor suppression [1,2]. It is driven by intrinsic mitochondria-mediated and extrinsic receptor-mediated death pathways that converge on a terminal execution program [3-6]. Cell rounding, shrinkage, membrane blebbing, and fragmentation into apoptotic bodies are common morphological features of apoptosis, and are controlled by a loss of actin-associated adhesions, rearrangements of actin filaments, and actin depolymerization $[7,8]$. While this reorganization and disassembly of the cytoskeleton during apoptosis is well described, the extent to which the actin assembly machinery actively contributes to the initiation or progression of apoptotic pathways is not understood.

Actin polymerization into filaments has been extensively characterized during cell morphogenesis, intracellular trafficking, cytokinesis, and motility [9,10]. To assemble branched actin networks during these processes, the heptameric Arp2/3 complex cooperates with nucleationpromoting factors from the Wiskott-Aldrich Syndrome Protein (WASP) family [11,12]. The mammalian WASP family is composed of WASP, N-WASP, WAVE1, WAVE2, WAVE3, WASH, WHAMM, JMY, and WHIMP $[13,14]$. Several of these factors are found in multi-protein complexes themselves, including all three WAVE isoforms and WASH, which constitute the WAVE and WASH complexes, respectively $[15,16]$. Each WASP-family member uses a conserved C-terminal domain that binds actin monomers and the Arp2/3 complex to stimulate polymerization, while their divergent $\mathrm{N}$-terminal domains interact with a variety of small G-proteins and phospholipids which direct their different localizations and functions within cells $[9,13]$. N-WASP, WAVE1-3, and WHIMP drive plasma membrane protrusion; N-WASP and WASH control endocytosis and endosomal cargo sorting; WHAMM and JMY promote anterograde membrane transport and autophagy. Additionally, during most of these processes, the atypical nucleation-promoting factor Cortactin binds actin filaments and the Arp $2 / 3$ complex to modulate actin branchpoint stability [17].

Compared to their well-established roles in such vital cellular functions, the extent to which WASP-family proteins participate in cell death pathways is largely uncharacterized. WAVE1 is perhaps the most studied member in relation to apoptosis, where it can influence the localization or modification of Bcl-2-family proteins, which control mitochondrial outer membrane permeabilization and the release of apoptogenic proteins $[6,18,19]$. In hepatocytes, WAVE1 associates with the pro-apoptotic protein Bad [20], while in neuronal cells WAVE1 engages the anti-apoptotic protein $\mathrm{Bcl}-\mathrm{xL}$ to promote mitochondrial recruitment of the pro-apoptotic permeabilization factor Bax [21]. In contrast, in leukemia cells, WAVE1 interacts with the anti-apoptotic protein Bcl-2 such that WAVE1 overexpression inhibits death signaling, whereas WAVE1 depletion increases apoptosis in response to chemotherapeutic agents $[22,23]$. Thus, WAVE1 appears to have cell type specific effects on apoptotic processes.

In addition to WAVE1, JMY has been reported to function in apoptosis. JMY was discovered as a cofactor that affects the function of p53 [24], a central tumor suppressor protein and transcription factor [25,26]. Under normal cellular growth conditions, JMY is regulated in the cytoplasm through interactions with the ubiquitin ligase Mdm2 [27] as well as autophagyrelated proteins [28]. Upon genotoxic damage, JMY binds importins and accumulates in the nucleus [29,30], where it associates with the stress-response protein Strap, the histone 
acetyltransferase p300, and p53 [24,31]. Co-overexpression of JMY and p300 in p53-proficient epithelial cells increases the transcription of $B A X[24,29]$, while introduction of a JMY siRNA in p53-overexpressing cells decreases the amount of $B A X$ induction [29]. These data indicate that JMY can promote cell death by enhancing the transcription of at least one pro-apoptotic gene. Consistent with this conclusion, an siRNA targeting JMY reduces the amount of sub-G1 (presumably apoptotic) cells after UV treatment [27]. Although, under other conditions, RNAi of JMY can increase the number of sub-G1 cells [32].

Collectively, these studies on WAVE1 and JMY reveal an interesting dynamic between actin assembly proteins and apoptosis-associated processes, and suggest that the relationships between nucleation factors and cell death pathways merit further investigation. In the current study, using a systematic gene knockout approach, we tested roles for all WASP-family members in DNA damage-induced apoptosis. We discovered that JMY and WHAMM are key regulators of a rapid p53-dependent and Arp2/3-mediated cell death pathway, but that their proapoptotic functions are opposed by the small G-protein RhoD.

\section{Results}

\section{The WASP-family proteins JMY and WHAMM enable DNA damage- induced apoptosis}

To evaluate the impact of WASP-family members on apoptosis, we employed a panel of knockout (KO) HAP1 or eHAP fibroblast-like cell lines lacking N-WASP, WAVE1, WAVE2, WAVE3, the WAVE Complex, the WASH Complex, WHAMM, JMY, or Cortactin (S1 Table and S1 Fig). The parental cells, derived from a chronic myeloid leukemia patient [33], are useful for studying apoptosis because they harbor a well-defined immortalizing BCR-ABL fusion [34], have easily manipulatable nearly-haploid (HAP1) or fully-haploid (eHAP) genomes [33,35], and are p53-proficient [36]. To examine intrinsic apoptotic responses, the parental and $\mathrm{KO}$ cells were treated with etoposide, a topoisomerase II inhibitor that induces dsDNA breaks. To monitor cell death, each sample was then imaged using fluorescent Annexin V $(\mathrm{AnnV})$ to identify the apoptotic hallmark of phosphatidylserine externalization, propidium iodide (PI) to assess membrane permeability, and hoechst to visualize nuclear fragmentation (Figs $1 \mathrm{~A}$ and $\mathrm{S} 1$ ).

After $6 \mathrm{~h}$ of etoposide treatment, approximately $33 \%$ of parental HAP1 or eHAP cells were apoptotic, as determined by AnnV-positive staining, compared to only 3\% of DMSO-treated controls (Fig 1B). The proportion of cells displaying AnnV staining was not significantly different across the majority of the etoposide- or DMSO-treated WASP-family knockout lines compared to the parental lines (Figs 1B and S1). In one of three etoposide experiments, a statistically significant increase in AnnV-positive cells was observed for the WAVE1 ${ }^{\mathrm{KO}}$ line (Fig 1B), a phenotype reminiscent of previous studies in which WAVE1 depletion in leukemia cells increased apoptosis $[22,23]$. In contrast, across all three etoposide experiments, two cell linesthe JMY ${ }^{\mathrm{KO}}$ and the $\mathrm{WHAMM}^{\mathrm{KO}}$ - exhibited significantly lower percentages of AnnV-positive cells (Fig $1 \mathrm{~A}$ and $1 \mathrm{~B}$ ). The JMY ${ }^{\mathrm{KO}}$ and $\mathrm{WHAMM}^{\mathrm{KO}}$ cells also showed substantially less frequent PI staining and nuclear fragmentation compared to parental cells (Figs 1A and S2). These results indicate that among a set of cell lines lacking WASP-family members, only those missing JMY or WHAMM have significantly impaired apoptotic responses to DNA damage.

JMY and WHAMM are approximately 35\% identical and 50\% similar to one another [37], and comprise a subgroup within the WASP family. Since both appear to be important for apoptosis, we sought to more thoroughly compare the effects of JMY or WHAMM inactivation on cell death. For this, we characterized three independent $J M Y$ mutant cell lines derived from HAP1 cells and two independent WHAMM mutant cell lines derived from eHAP cells (Figs 


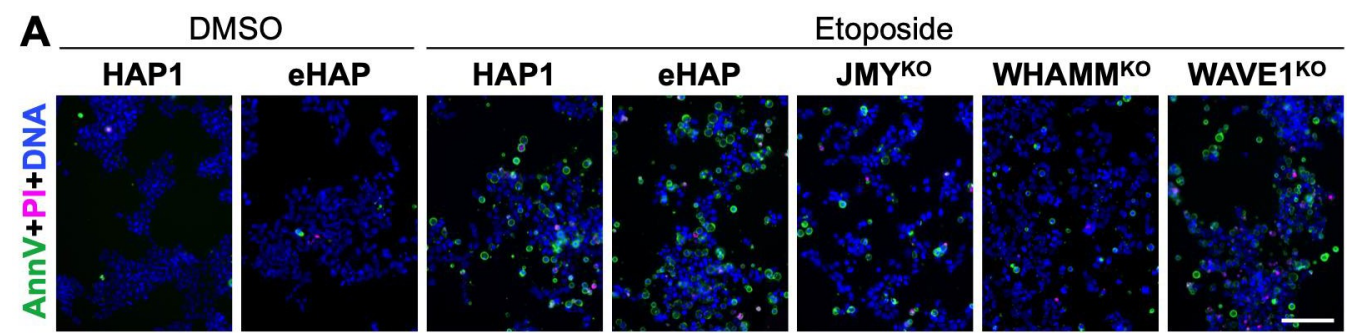

B

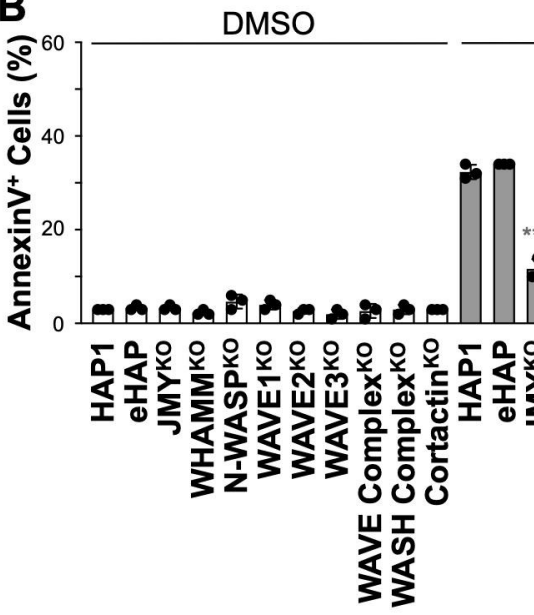

D

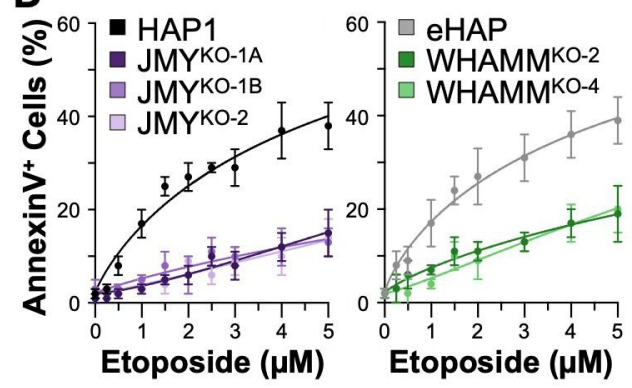

Etoposide
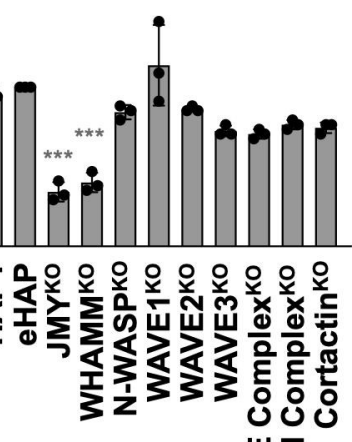

C

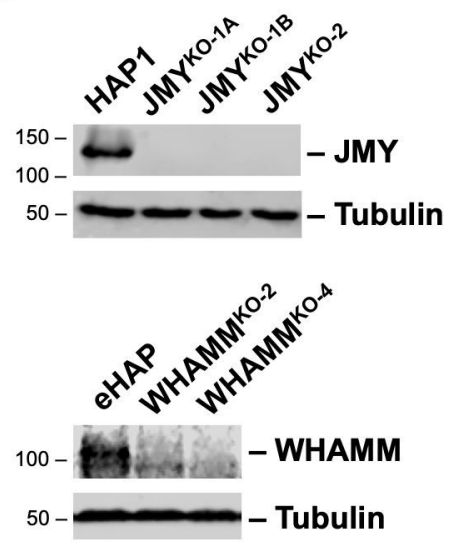

E

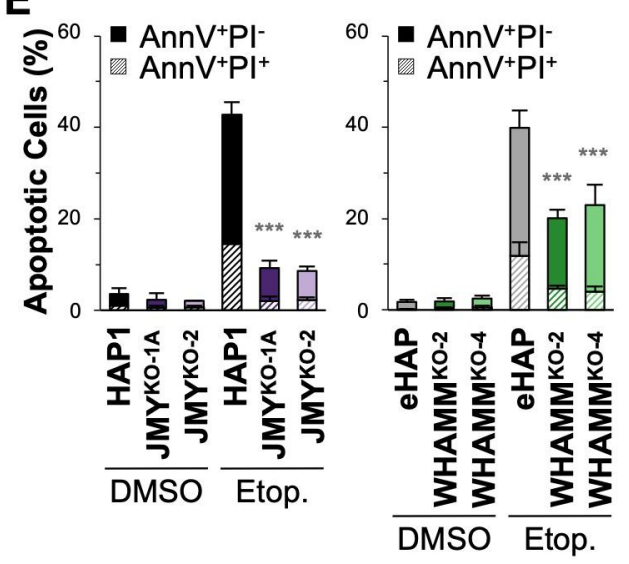

Fig 1. Cells lacking the WASP-family members JMY or WHAMM undergo less apoptosis following DNA damage. (A) Parental (HAP1, eHAP) and WASP-family knockout $\left(\mathrm{JMY}^{\mathrm{KO}-1 \mathrm{~A}}, \mathrm{WHAMM}^{\mathrm{KO}-2}, \mathrm{~N}-\mathrm{WASP}{ }^{\mathrm{KO}}, \mathrm{WAVE} 1^{\mathrm{KO}}\right.$, $\mathrm{WAVE}^{\mathrm{KO}}$, WAVE $3^{\mathrm{KO}}$, WAVE Complex ${ }^{\mathrm{KO}}$, WASH Complex ${ }^{\mathrm{KO}}$, Cortactin $^{\mathrm{KO}}$ ) cells were treated with DMSO or $5 \mu \mathrm{M}$ etoposide for $6 \mathrm{~h}$ and stained with Alexa488-AnnexinV (AnnV; green), Propidium Iodide (PI; magenta), and Hoechst (DNA; blue). Scale bar, $100 \mu \mathrm{m}$. (B) The \% of AnnV-positive cells was calculated in ImageJ by dividing the number of cells that displayed AnnV staining by the total number of cells identified by nuclear Hoechst staining. Each point represents the mean from 3 fields-of-view in 3 separate experiments, and the bar represents the mean \pm SD of those experiments ( $\mathrm{n}=391-1,303$ cells per point; $\mathrm{n}=1,772-3,619$ cells per bar). The uppermost $\mathrm{WAVE}{ }^{\mathrm{KO}}$ point was significantly different from HAP1 cells in one experiment. (C) HAP1, JMY ${ }^{\mathrm{KO}}$, eHAP, and WHAMM ${ }^{\mathrm{KO}}$ cell lysates were immunoblotted with antibodies to JMY, WHAMM, and tubulin. (D) HAP1, JMY ${ }^{\mathrm{KO}}$, eHAP, and WHAMM ${ }^{\mathrm{KO}}$ cells were treated with a range of etoposide concentrations for $6 \mathrm{~h}$ and then stained with Alexa488-AnnV and Hoechst. The \% of AnnV-positive cells was calculated in ImageJ. Each point represents the mean \pm SD from 3-6 fields-of-view pooled from 1-2 experiments ( $n=1,699-4,996$ cells per experiment). Nonlinear regressions were performed with a baseline set to 0.02 and a maximum response set to 0.85 . EC50 values were significantly different for parental vs KO samples (Mean EC50s: Parental $=6.2 \mu \mathrm{M}$; $\mathrm{JMY}^{\mathrm{KO}}=26.4 \mu \mathrm{M}, \mathrm{p}<0.001$; $\mathrm{WHAMM}^{\mathrm{KO}}=20.9 \mu \mathrm{M}, \mathrm{p}<0.001$ ). (E) Cells were treated with DMSO or $5 \mu \mathrm{M}$ etoposide for $6 \mathrm{~h}$ and stained with Alexa488-AnnV, PI, and Hoechst. The \% of AnnV-positive cells is displayed as the fraction of AnnVpositive/PI-negative $\left(\mathrm{AnnV}^{+} \mathrm{PI}^{-}\right)$or $\mathrm{AnnV} / \mathrm{PI}$ double-positive $\left(\mathrm{AnnV}^{+} \mathrm{PI}^{+}\right)$cells. Each bar represents the mean $\pm \mathrm{SD}$ from 3 experiments ( $n=2,338-9,846$ cells per bar). All significance stars are for comparisons to the etoposide-treated HAP1 or eHAP cells. ${ }^{* * *} \mathrm{p}<0.001$ (ANOVA, Tukey post-hoc tests). 
1C and S3). Etoposide treatment caused similarly high levels of DNA damage across all of the parental and knockout samples, as evidenced by increased phosphorylated histone H2AX $(\gamma \mathrm{H} 2 \mathrm{AX})$ protein levels and greater numbers of $\gamma \mathrm{H} 2 \mathrm{AX}$ foci at DNA breaks within nuclei (S4 Fig). Both the parental cell lines, as well as the JMY ${ }^{\mathrm{KO}}$ and the $\mathrm{WHAMM}^{\mathrm{KO}}$ lines, showed etoposide dose-dependent increases in AnnV-positive apoptotic cells, but the mutants displayed significantly lower percentages at virtually every concentration (Fig 1D). At the highest concentrations $(4-5 \mu \mathrm{M})$, nearly $40 \%$ of parental cells, but only $8-12 \%$ of JMY ${ }^{\mathrm{KO}}$ cells and $15-20 \%$ of WHAMM ${ }^{\mathrm{KO}}$ cells, were AnnV-positive (Fig 1D).

To assess early versus late apoptosis, the percentage of AnnV-positive cells without versus with PI staining was quantified (S2 Fig). Among the $~ 40 \%$ of parental cells exhibiting AnnV staining, about $25 \%$ were AnnV-positive and PI-negative, indicating early apoptosis, while $15 \%$ were AnnV and PI double-positive, signifying late apoptosis (Fig 1E). In comparison, all of the JMY ${ }^{\mathrm{KO}}$ and WHAMM ${ }^{\mathrm{KO}}$ samples contained significantly fewer cells in both early and late apoptosis, with the JMY ${ }^{\mathrm{KO}}$ cells exhibiting $8 \%$ early and $2 \%$ late, and the WHAMM ${ }^{\mathrm{KO}}$ cells displaying $15 \%$ early and $5 \%$ late (Fig $1 \mathrm{E}$ ). These results indicate that JMY and WHAMM each play important roles in apoptosis, but the more extreme phenotypes observed when JMY is mutated suggest that JMY is more prominent in enabling cell death.

\section{Inactivation of JMY or WHAMM impairs multiple steps of intrinsic apoptotic signaling}

Since the loss of JMY or WHAMM decreased the final apoptotic readouts of phosphatidylserine externalization and membrane permeability, we next wanted to determine if the inactivation of JMY or WHAMM affected earlier aspects of apoptotic signaling. Intrinsic pathways of apoptosis are characterized by the export of apoptogenic proteins from mitochondria into the cytosol upstream of the initiation of a caspase cleavage cascade. So we examined whether the loss of JMY or WHAMM affected the release of cytochrome $c$ (cyto $c$ ), a protein that is maintained in the mitochondrial intermembrane space under normal conditions, but is exported to trigger the cytosolic assembly of macromolecular structures called apoptosomes, which serve as platforms for the activation of initiator caspases during intrinsic apoptosis $[38,39]$. In parental HAP1 and eHAP cells, as expected, mitochondrial-independent cyto $c$ localization became apparent following etoposide treatment (Fig 2A and 2B). Categorization of cyto $c$ localization as discrete mitochondrial versus diffuse cytosolic was confirmed by plotting the fluorescence intensity profiles of mitochondria and cyto $c$ (Fig 2C and 2D). It was also notable that diffuse cytosolic cyto $c$ staining was sometimes accompanied by non-mitochondrial clusters of cyto $c$ puncta (described in a later section). Consistent with the previously-observed amounts of AnnV-positive cells, $>30 \%$ of parental cells exhibited cytosolic cyto $c$ localization patterns following $6 \mathrm{~h}$ of etoposide treatment (Fig 2E). In contrast, the JMY ${ }^{\mathrm{KO}}$ and $\mathrm{WHAMM}^{\mathrm{KO}}$ cell lines had significant delays in cyto $c$ release, and by $6 \mathrm{~h}$ only $10 \%$ of JMY ${ }^{\mathrm{KO}}$ and around $15 \%$ of $\mathrm{WHAMM}^{\mathrm{KO}}$ cells showed cytosolic cyto $c$ staining (Fig 2E). These findings suggest that JMY and WHAMM are necessary for an efficient intrinsic apoptosis pathway, and that part of their contributions to apoptotic responses may occur prior to and/or during the accumulation of cyto $c$ in the cytosol.

After mitochondrial cyto $c$ release, apoptotic signaling is typified by the multimerization and proteolytic processing of initiator caspases in the apoptosome that cleave and activate executioner caspases, which in turn target multiple proteins in the cytosol and nucleus $[40,41]$. We next sought to measure the effects of JMY and WHAMM on the caspase cascade by examining both the expression and cleavage of representative initiator and executioner caspase proteins via immunoblotting. Control DMSO-treated parental, JMY ${ }^{\mathrm{KO}}$, and $\mathrm{WHAMM}^{\mathrm{KO}}$ cells 
A
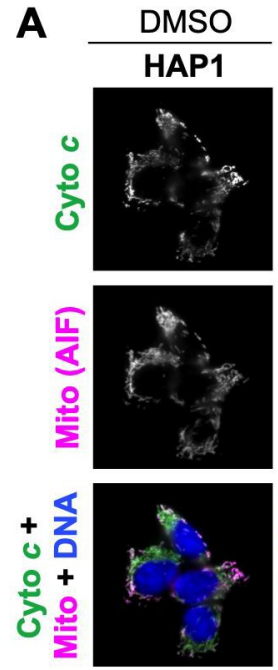

C
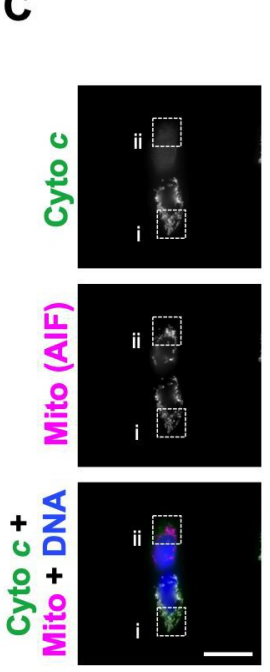

Etoposide
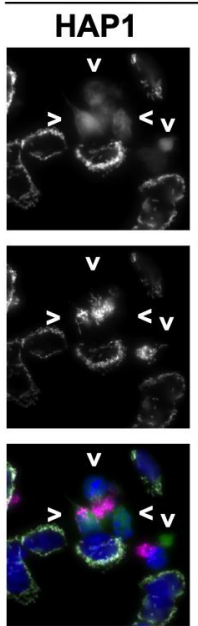

Cytochrome $c$
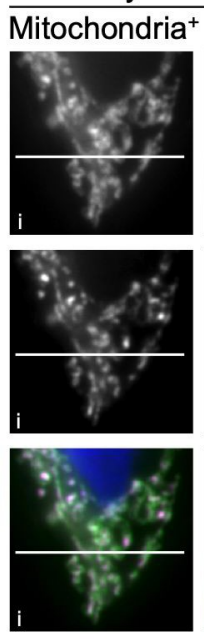
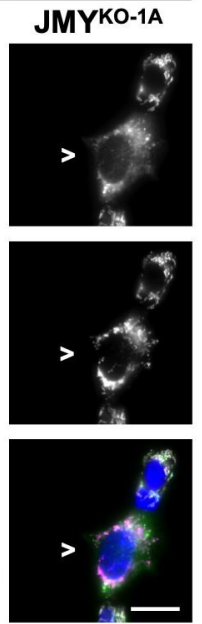

\section{Cytosol $^{+}$}
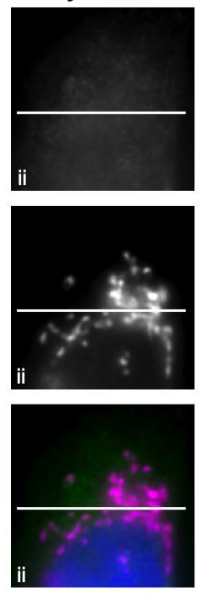

B
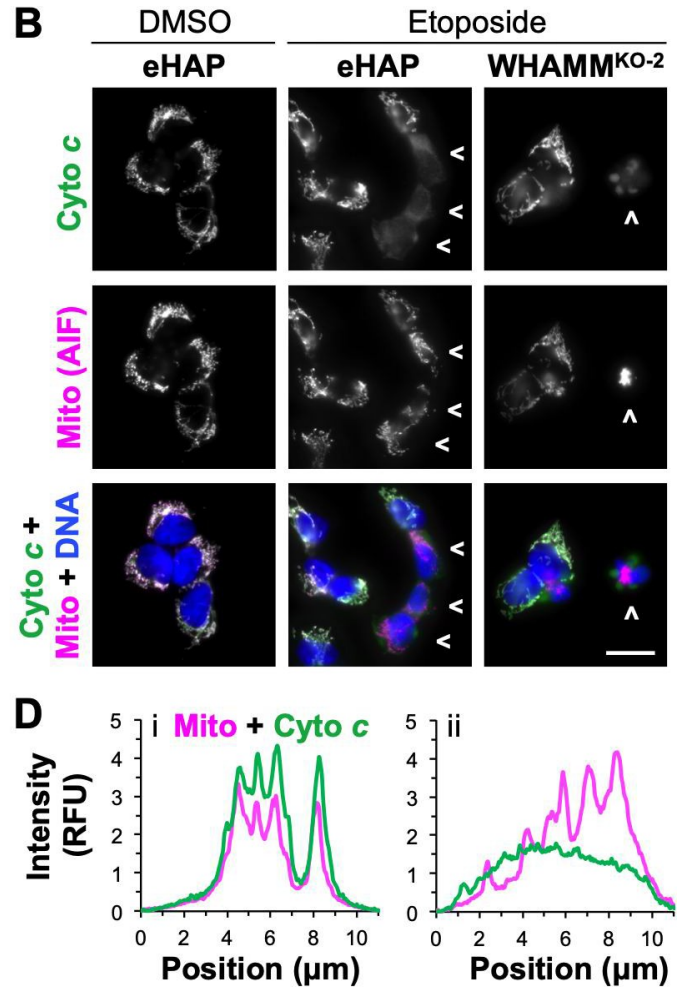

E

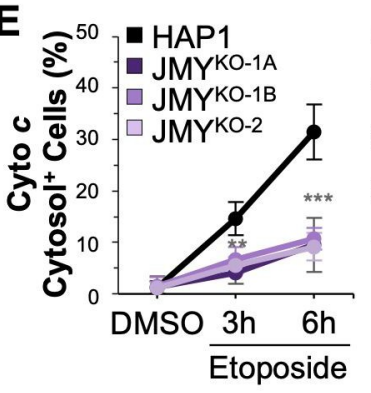

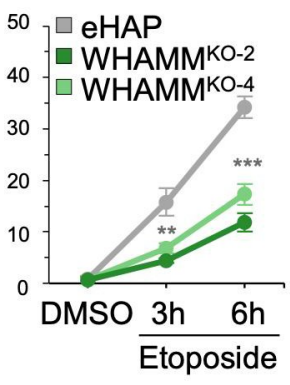

Fig 2. Cytochrome $c$ release is delayed when JMY or WHAMM is deleted. (A-B) HAP1, JMY ${ }^{\mathrm{KO}}$, eHAP, and

WHAMM $^{\mathrm{KO}}$ cells were treated with DMSO for $6 \mathrm{~h}$ or $5 \mu \mathrm{M}$ etoposide for $3 \mathrm{~h}$ or $6 \mathrm{~h}$ before being fixed and stained with a cytochrome $c$ antibody (Cyto $c$; green), AIF antibody (Mito; magenta), and DAPI (DNA; blue). Images are from the $6 \mathrm{~h}$ timepoint. Arrowheads highlight examples of cells with diffuse cytosolic cyto $c$ staining. Scale bars, $25 \mu \mathrm{m}$. (C) A representative image of HAP1 cells with magnifications depicts cyto $c$ in the mitochondria (i) or diffuse in the cytosol (ii). (D) Lines were drawn through the magnified images using ImageJ to measure the pixel intensity profiles for cyto $c$ and mitochondria, highlighting the differences in scoring mitochondrial versus cytosolic cyto $c$ localization. (E) The $\%$ of cells with cytosolic cyto $c$ staining was calculated in ImageJ by counting cells that exhibited cytosolic rather than mitochondrial cyto $c$ staining and dividing by the total number of DAPI-stained nuclei. Each point represents the mean $\% \pm$ SD from 3-4 experiments ( $n=533-856$ cells per point). Significance stars refer to comparisons of parental to KO samples at the depicted timepoints. ${ }^{* *} \mathrm{p}<0.01 ;{ }^{* * *} \mathrm{p}<0.001$ (ANOVA, Tukey post-hoc tests).

https://doi.org/10.1371/journal.pgen.1009512.g002

expressed indistinguishable levels of inactive initiator procaspase- 9 and inactive executioner procaspase-3 (Fig 3A and 3B), suggesting that the mutant cell lines did not have any inherent deficits in the steady-state abundance of these core components of the apoptotic machinery. However, upon etoposide treatment for $3 \mathrm{~h}$ and $6 \mathrm{~h}$, the parental, JMY ${ }^{\mathrm{KO}}$, and $\mathrm{WHAMM}^{\mathrm{KO}}$ cell lines displayed very different kinetics in the conversion of inactive procaspases to cleaved caspases. Whereas HAP1 and eHAP cells began to show processing of procaspases to cleaved caspases by $3 \mathrm{~h}$ of etoposide treatment, the cleaved caspases were generally not detectable in the 


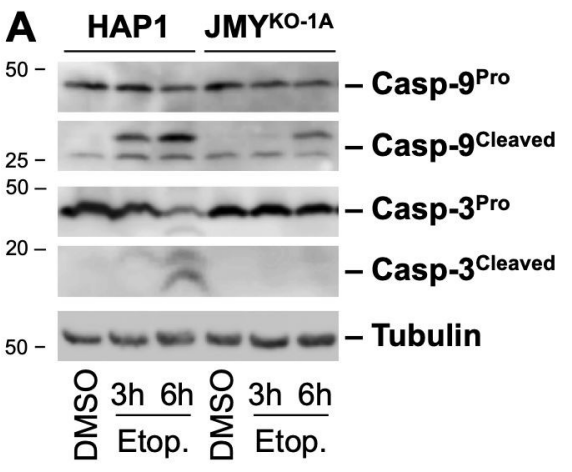

D

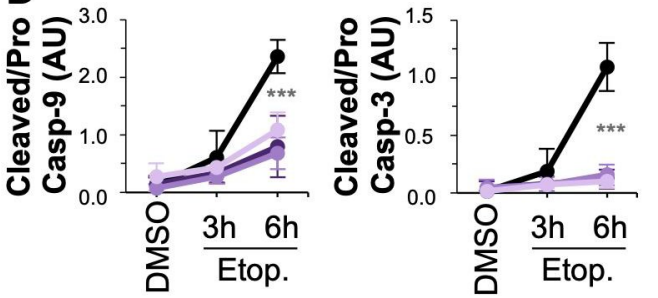

F
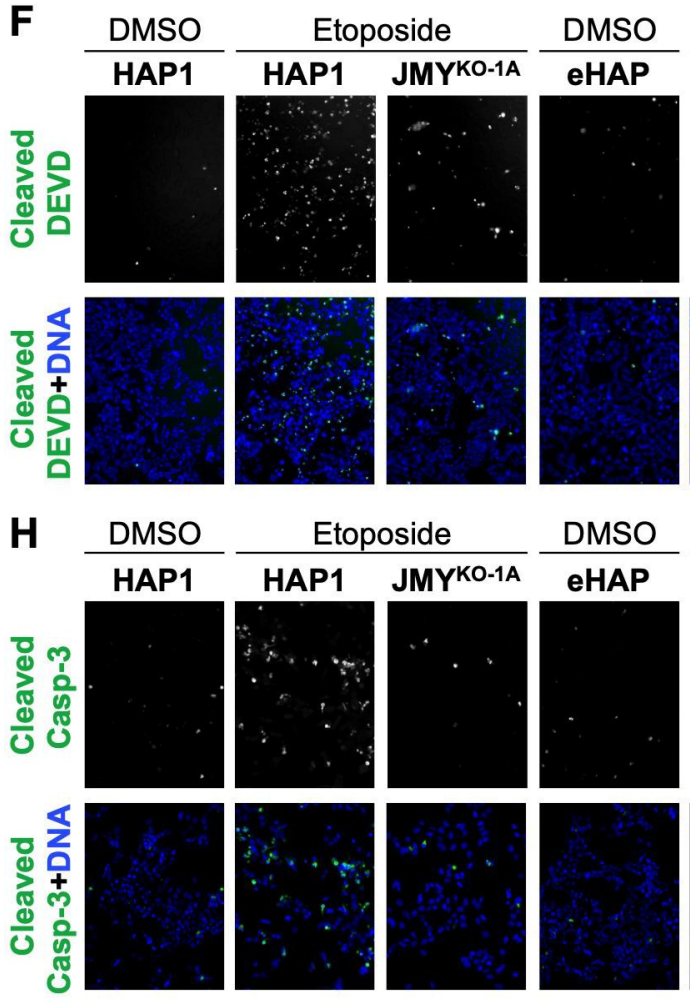

\section{DMSO}
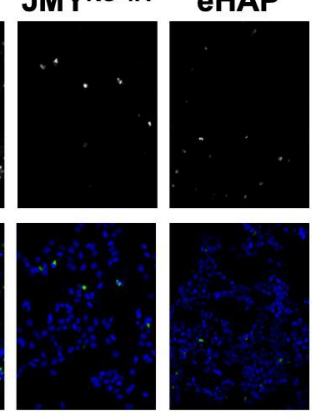

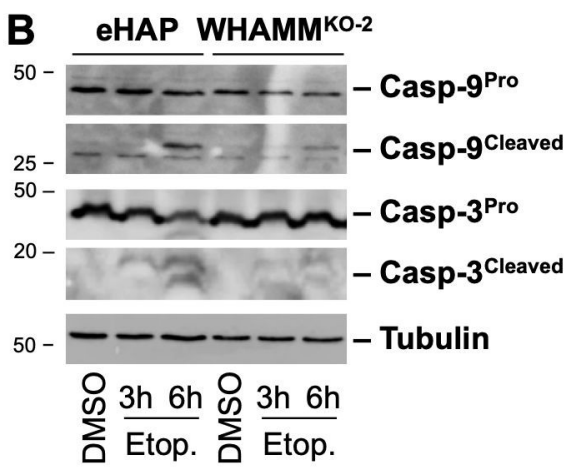

C

- HAP1

- JMYKO-1A

口 JMYKO-1B

$\square$ JMYKO-2

$\square$ eHAP

- WHAMMKO-2

- WHAMM ${ }^{\mathrm{KO}-4}$

E
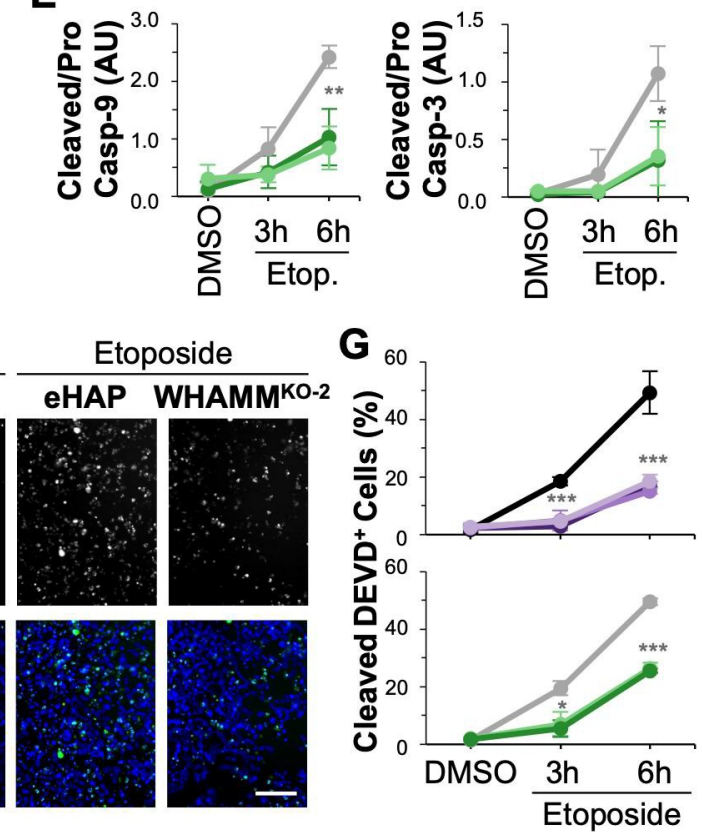

Fig 3. Initiator and executioner caspase cleavage is inefficient in the absence of JMY or WHAMM. (A-B) HAP1, JMY ${ }^{\mathrm{KO}}$, eHAP, and WHAMM ${ }^{\mathrm{KO}}$ cells were treated with DMSO for $6 \mathrm{~h}$ or $5 \mu \mathrm{M}$ etoposide for $3 \mathrm{~h}$ or $6 \mathrm{~h}$, and extracts were immunoblotted with antibodies to caspase- 9 (Casp- $9^{\text {Pro }}$ and Casp- $-9^{\text {Cleaved }}$ ), caspase-3 (Casp- $3^{\text {Pro }}$ and Casp- $3^{\text {Cleaved }}$ ), and tubulin. (C) Key for color-coded samples in panels (D-I). (D-E) For quantification, the caspase cleavage ratio was calculated by dividing the cleaved band intensity by the procaspase band intensity. Each point represents the mean ratio \pm SD from 3 experiments. AU = Arbitrary Units. (F) Cells were treated with DMSO or etoposide, and stained with caspase-3/7 green detection reagent to label cleaved DEVD (green) and Hoechst to stain DNA (blue). Images are from the $6 \mathrm{~h}$ timepoint. Scale bars, $100 \mu \mathrm{m}$. (G) The \% of cleaved DEVD-positive cells was calculated in ImageJ by counting cells that exhibited green nuclear fluorescence and dividing by the total number of Hoechst-stained nuclei. Each point represents the mean $\pm S \mathrm{D}$ from 3 experiments $(n=2,741-6,646$ cells per point). $(\mathbf{H})$ Cells treated as above were fixed and stained with an antibody that 
recognizes caspase-3 cleaved at Asp175 (Cleaved Casp-3; green) and DAPI (DNA; blue). Images are from the 6h timepoint. (I) The \% of cleaved caspase-3-positive cells was calculated in ImageJ by counting cells that contained bright clusters of green fluorescence and dividing by the total number of DAPI-stained nuclei. Each point represents the mean \pm SD from 3 experiments ( $\mathrm{n}=1,136-7,844$ cells per bar). Significance stars refer to comparisons of parental to KO samples. ${ }^{*} \mathrm{p}<0.05$; ${ }^{* *} \mathrm{p}<0.01 ;{ }^{* * *} \mathrm{p}<0.001$ (ANOVA, Tukey post-hoc tests).

https://doi.org/10.1371/journal.pgen.1009512.g003

$\mathrm{JMY}^{\mathrm{KO}}$ and WHAMM ${ }^{\mathrm{KO}}$ cells until $6 \mathrm{~h}$ (Fig $3 \mathrm{~A}$ and $3 \mathrm{~B}$ ). Even at the later timepoint, caspase-9 cleavage was 2-3-fold lower in both JMY ${ }^{\mathrm{KO}}$ and WHAMM ${ }^{\mathrm{KO}}$ cells compared to the parental cell lines (Fig 3C-3E). For caspase-3, cleavage was 10-fold less efficient in JMY ${ }^{\mathrm{KO}}$ cells and 3-fold less efficient in WHAMM ${ }^{\mathrm{KO}}$ cells relative to their parental lines (Fig 3C-3E). Together, these results show that following acute genotoxic damage, JMY and WHAMM are each required for the rapid activation of caspase cleavage cascades.

During the terminal execution stage of apoptosis, caspase- 3 and caspase- 7 cleave the motif Asp-Glu-Val-Asp (DEVD) [41], so we used a DEVD substrate peptide conjugated to a fluorescent reporter to quantify the amount of cells with active caspase-3/7 following treatment with etoposide. Caspase-3/7 activation was readily detectable in parental cells at $3 \mathrm{~h}$, but did not become clearly apparent in the knockout cells until the $6 \mathrm{~h}$ timepoint, when $50 \%$ of parental cells versus only $15-25 \%$ of JMY ${ }^{\mathrm{KO}}$ or WHAMM ${ }^{\mathrm{KO}}$ cells were positive for cleaved DEVD (Fig $3 \mathrm{~F}$ and $3 \mathrm{G}$ ). To further validate these results, we stained cells with antibodies that specifically recognize the active cleaved form of caspase-3. Immunofluorescence microscopy revealed that nearly $40 \%$ of parental cells contained bright clusters of active caspase- 3 staining, whereas $<10 \%$ of the $\mathrm{JMY}^{\mathrm{KO}}$ and $<20 \%$ of the WHAMM ${ }^{\mathrm{KO}}$ cells stained positive for active caspase- 3 (Fig $3 \mathrm{H}$ and 3I). Therefore, the apoptotic deficiencies arising from JMY or WHAMM mutations include significantly delayed and less potent activation of executioner caspases, with JMY knockout cells exhibiting more extreme defects, particularly in caspase- 3 activation.

\section{Cells lacking JMY and/or WHAMM are defective at apoptosis in several cellular contexts}

Because the loss of either JMY or WHAMM results in multiple apoptotic deficits, we next sought to determine the extent to which apoptosis would proceed in cells lacking both proteins. So we derived two independent WHAMM/JMY double knockout (DKO) cell lines from WHAMM $^{\mathrm{KO}-2}$ cells (S3 Fig). Similar to the other knockout cells, both WHAMM/JMY ${ }^{\mathrm{DKO}}$ cell lines had low levels of DNA damage when exposed to DMSO, but more numerous DNA breaks when incubated with etoposide (S4 Fig). After etoposide exposure and staining with fluorescent AnnV, significantly fewer WHAMM/JMY ${ }^{\text {DKO }}$ cells were apoptotic compared to control cells, as only $10 \%$ of WHAMM/JMY ${ }^{\mathrm{DKO}}$ cells were AnnV-positive (Fig 4A and 4B). This frequency of apoptosis was noticeably lower than that of the single WHAMM knockouts and more closely resembled that of the single JMY knockouts (Fig 1E).

To directly compare the efficiency of apoptosis in the parental cells, single JMY or WHAMM mutants, and WHAMM/JMY double mutants, we stained each of these cell populations for active cleaved caspase- 3 . While nearly $40 \%$ of parental HAP1 or eHAP cells contained active caspase- 3 after etoposide treatment, $20 \%$ of WHAMM ${ }^{\mathrm{KO}}$ cells and $<10 \%$ of JMY ${ }^{\mathrm{KO}}$ or WHAMM/JMY ${ }^{\text {DKO }}$ cells showed active caspase-3 staining (Fig 4C and 4D). Thus, inactivation of $J M Y$ in a WHAMM-deficient background does not result in any synthetic or synergistic death phenotypes, but simply reduces apoptosis levels down to that of a single JMY mutant. This frequency, typically $8-10 \%$ of the population, seems to be the lowest achievable amount of apoptotic death in HAP1 derivatives under the genotoxic conditions used in our experiments. 

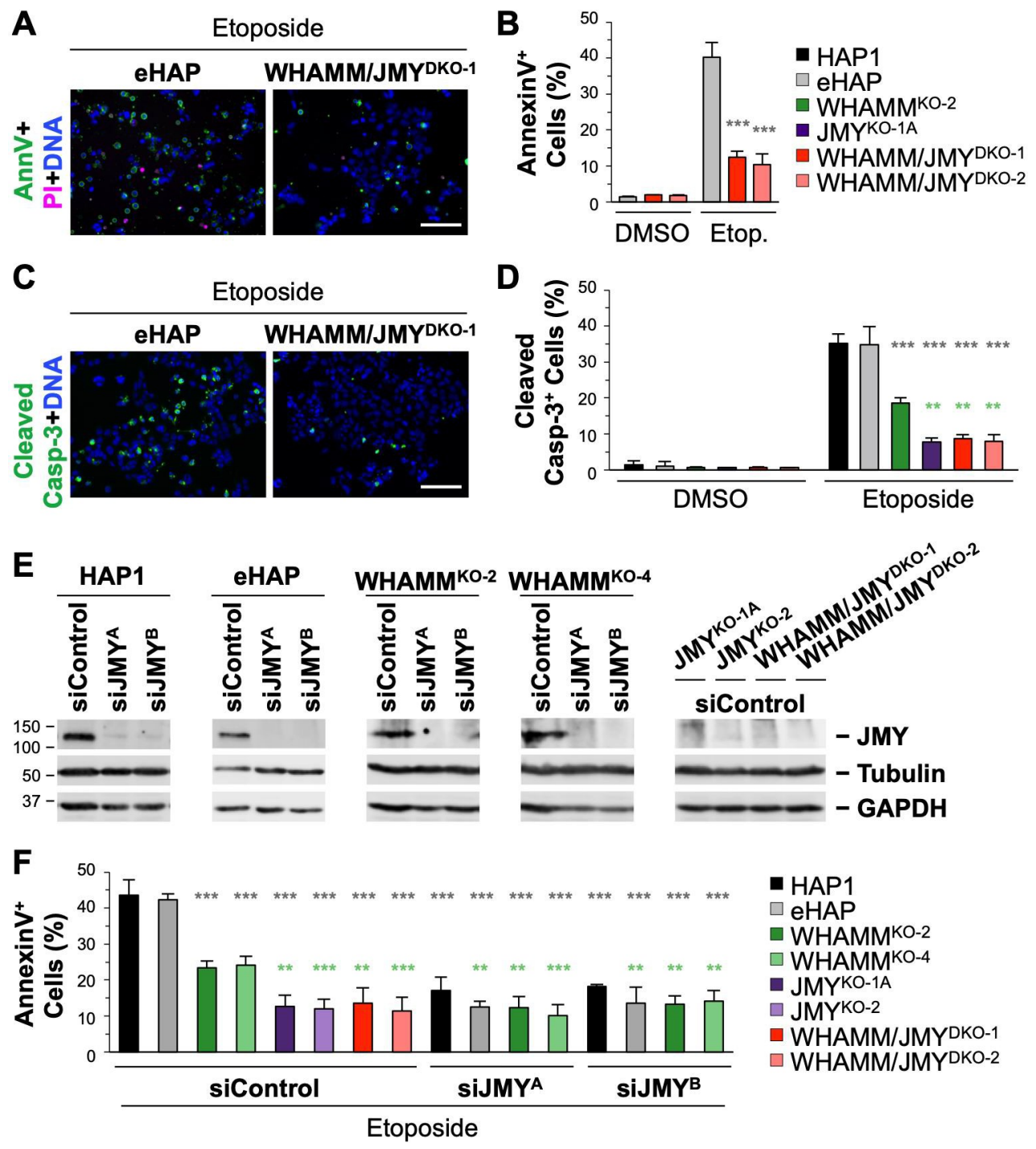

Fig 4. Deletion or depletion of JMY reduces apoptosis in WHAMM-deficient cells. (A) eHAP and WHAMM/ $\mathrm{JMY}^{\mathrm{DKO}}$ cells were treated with DMSO or $5 \mu \mathrm{M}$ etoposide for $6 \mathrm{~h}$ and stained with Alexa488-AnnV, PI, and Hoechst. Scale bars, $100 \mu \mathrm{m}$. (B) The $\%$ of AnnV-positive cells was calculated, and each bar represents the mean $\pm \mathrm{SD}$ from 3 experiments ( $\mathrm{n}=3,035-7,080$ cells per bar). (C) eHAP and WHAMM/JMY ${ }^{\text {DKO }}$ cells were treated with DMSO or etoposide before being fixed and stained with an antibody that recognizes caspase- 3 cleaved at Asp175 (Cleaved Casp3; green) and DAPI (DNA, blue). (D) The \% of cleaved caspase-3-positive cells was calculated, and each bar represents the mean \pm SD from 3 experiments ( $n=2,962-7,844$ cells per bar). Gray significance stars refer to comparisons to the parental samples and green significance stars refer to comparisons to the WHAMM ${ }^{\mathrm{KO}}$ samples. (E) HAP1, eHAP, and $\mathrm{WHAMM}^{\mathrm{KO}}$ cells were treated with control siRNAs or independent siRNAs for the JMY gene, while JMY ${ }^{\mathrm{KO}}$ and WHAMM/JMY ${ }^{\text {DKO }}$ cell lines were treated with control siRNAs before immunoblotting with antibodies to JMY, tubulin, and GAPDH. (F) Etoposide-treated cells were stained with Alexa488-AnnV, PI, and Hoechst. The \% of AnnV-positive cells was calculated and each bar represents the mean \pm SD from 3 experiments ( $n=2,485-4,596$ cells per bar). Gray significance stars refer to comparisons to the parental siControl samples and green significance stars refer to comparisons to the WHAMM ${ }^{\mathrm{KO}}$ siControl samples. ${ }^{* *} \mathrm{p}<0.01 ;{ }^{* * *} \mathrm{p}<0.001$ (ANOVA, Tukey post-hoc tests).

https://doi.org/10.1371/journal.pgen.1009512.g004

To next determine the extent to which transient depletion, rather than permanent deletion, of JMY, WHAMM, or both, affects apoptosis, we treated HAP1 and eHAP cells with two independent siRNAs targeting either JMY (Fig 4E) or WHAMM (S5 Fig). Consistent with the stable genetic knockout results, significantly fewer JMY- or WHAMM-depleted cells were AnnVpositive compared to parental cells after etoposide exposure (Figs 4F and S5). Moreover, 
RNAi-mediated depletion of JMY in WHAMM ${ }^{\mathrm{KO}}$ cells resulted in significantly fewer AnnVpositive cells compared to control siRNA treatments (Fig 4E and $4 \mathrm{~F}$ ), a phenotype resembling that of the WHAMM/JMY ${ }^{\mathrm{DKO}}$ lines. Overall, the more severe apoptotic deficiencies that arise when JMY is permanently deleted or transiently depleted suggest that JMY is the nucleation factor with the most influential role in programmed cell death.

For further gauging the effects of JMY on apoptosis in different human cell lines, we targeted JMY using siRNAs in U2OS osteosarcoma cells and HeLa adenocarcinoma cells (S5 Fig). As in HAP1 and eHAP cells (Figs 4E, 4F, 5A, and 5B), RNAi-mediated depletion of JMY resulted in significantly fewer AnnV-positive cells compared to control siRNA treatments (S5 Fig). Additionally, the level of JMY expressed in HAP1, U2OS, and HeLa cells showed a positive relationship with the proportion of AnnV-positive cells (Figs 5C and S5). These results demonstrate that JMY is required for efficient apoptosis across multiple cell types.

\section{JMY functions in p53-dependent apoptosis after a p21-associated proliferation arrest}

To begin to understand the underlying mechanisms that give rise to the apoptotic pathway defects in JMY- and WHAMM-deficient cells, we sought to determine the importance of p53 in the death of parental HAP1 and eHAP cells. First, to verify that apoptosis was dependent on p53, we treated these parental cell lines with three independent siRNAs targeting TP53 and measured the percentage of cells with AnnV staining. Compared to samples that were treated with a control siRNA, samples in which p53 levels were diminished contained significantly fewer AnnV-positive cells (Figs 5D, 5E, and S6). Moreover, greater degrees of p53 knockdown resulted in larger reductions in apoptosis, as the amount of $\mathrm{p} 53$ protein was positively correlated with the percentage of AnnV-positive cells (Figs 5F and S6). Extrapolation of the p53 trendline down to zero protein expression suggested that approximately $12 \%$ of HAP1 cells completely lacking p53 would undergo apoptosis (Figs 5F and S6), nearly matching the percentage observed for JMY-depleted samples (Fig 5C). These results demonstrate that the majority of etoposide-induced apoptosis in HAP1 cells requires both $\mathrm{p} 53$ and JMY.

For evaluating the impact of 53 levels on apoptosis in the absence of JMY or WHAMM, we then targeted TP53 in WHAMM ${ }^{\mathrm{KO}}$ and JMY ${ }^{\mathrm{KO}}$ cells. Depletion of $\mathrm{p} 53$ in WHAMM $\mathrm{WO}^{\mathrm{KO}}$ cells resulted in significantly fewer AnnV-positive cells (S6 Fig), consistent with the idea that WHAMM inactivation causes only a partial inhibition of p53-dependent apoptosis which can be rendered complete by the subsequent removal of p53. Conversely, depletion of p53 in the $J M Y$ mutant background revealed that the already low apoptosis levels following etoposide treatment could not be reduced below 10\% (Fig 5D-5F). Together, the JMY and p53 depletion studies support the conclusion that JMY and p53 function in the same intrinsic apoptotic death pathway.

The observation that HAP1 cells undergo apoptosis in a primarily p53-dependent manner, combined with the finding that JMY can associate with p53 and its acetyltransferase cofactor p300 [24], led us to next investigate the specific influence of JMY on p53 functions. Since apoptosis is typically accompanied by $\mathrm{p} 53$ protein stabilization, post-translational modification, and re-localization into the nucleus [25,26], we examined these properties. At steady-state, HAP1 and JMY ${ }^{\mathrm{KO}}$ cells expressed similar amounts of $\mathrm{p} 53$ protein (S7 Fig), indicating that the loss of JMY did not cause an overall decrease in p53 abundance. Treatment of HAP1 and $\mathrm{JMY}^{\mathrm{KO}}$ cells with etoposide resulted in a clear increase in $\mathrm{p} 53$ protein levels, its phosphorylation on serine-15 and serine-46, its acetylation on lysine-382, and its accumulation in the nucleus in the majority of cells (S7 Fig), suggesting that JMY functions downstream of such pro-apoptotic changes in p53 stability and modification. 
A

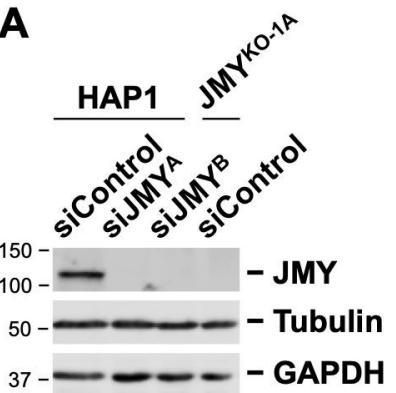

D
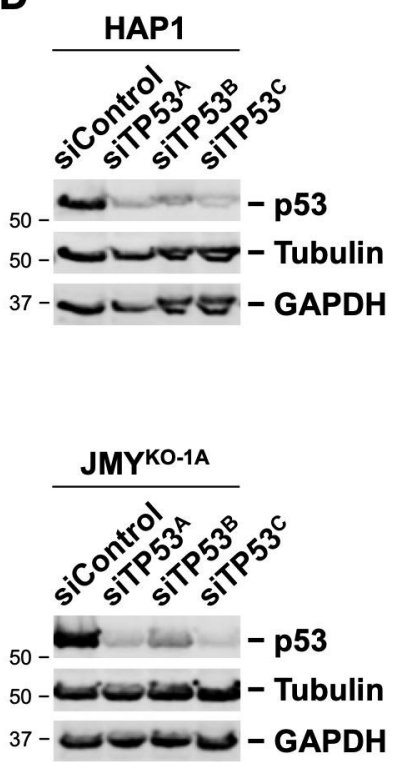

B

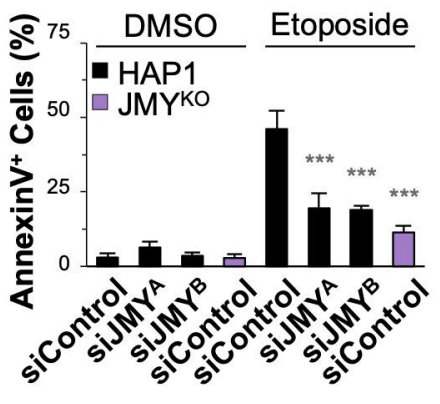

E
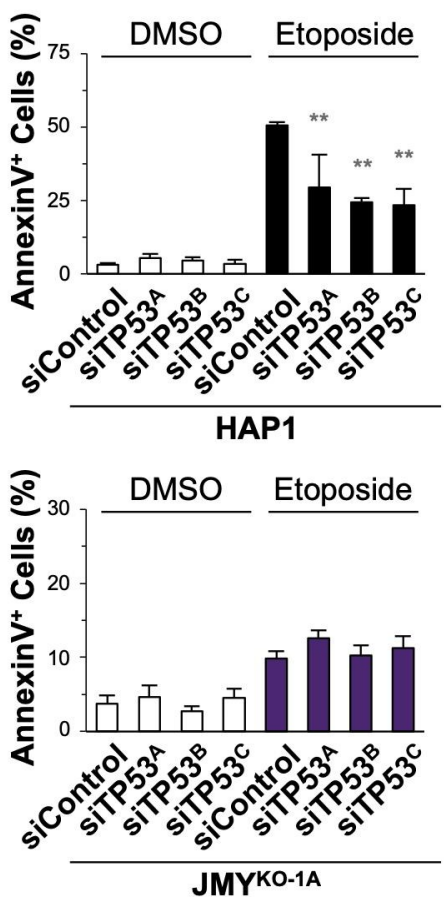

C

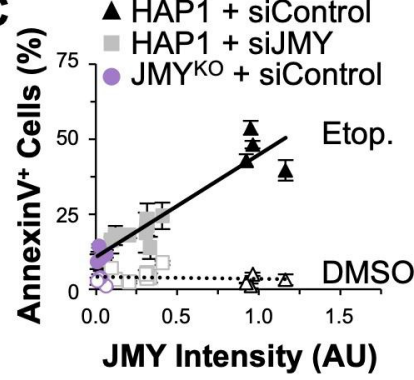

$\mathbf{F}$
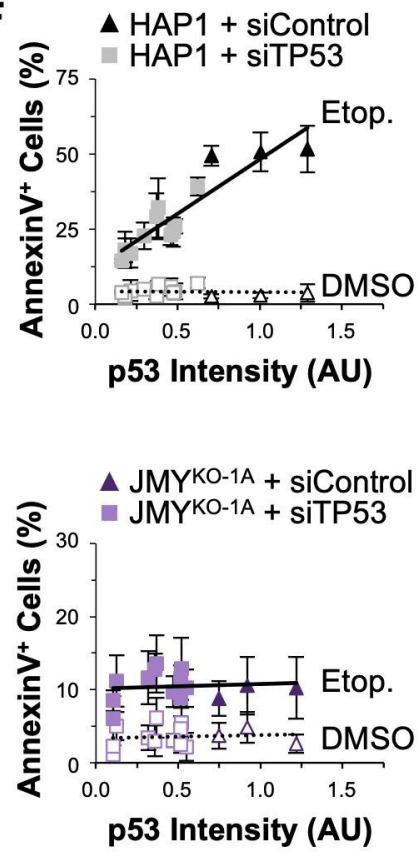

Fig 5. Cells transiently depleted of JMY or $\mathrm{p} 53$ have similar reductions in apoptosis. (A) HAP1 cells were treated with control siRNAs or independent siRNAs for the JMY gene, while a JMY ${ }^{\mathrm{KO}}$ cell line was treated with control siRNAs before immunoblotting with antibodies to JMY, tubulin, and GAPDH. (B) Cells were treated with DMSO or $5 \mu \mathrm{M}$ etoposide for $6 \mathrm{~h}$ and stained with Alexa488-AnnV, PI, and Hoechst. The \% of AnnV-positive cells was calculated, and each bar represents the mean $\pm \mathrm{SD}$ from 4 experiments ( $\mathrm{n}=4,508-7,626$ cells per bar). (C) JMY band intensities on immunoblots were normalized to tubulin intensities and plotted against the \% of AnnV-positive cells. Each point represents the mean \pm SD from 3 fields-of-view in a given experiment ( $n=564-2,587$ cells per point). The slope in the linear trendline regression equation for etoposide-treated samples $(\mathrm{Y}=34.56 \mathrm{X}+10.52)$ was significantly non-zero $\left(\mathrm{p}<0.001, \mathrm{R}^{2}=0.86\right)$. (D) HAP1 and JMY ${ }^{\mathrm{KO}-1 \mathrm{~A}}$ cells were treated with control siRNAs or independent siRNAs for the TP53 gene before immunoblotting with antibodies to p53, tubulin, and GAPDH. (E) Cells were treated and stained as in panel (B). The \% of AnnV-positive cells was calculated, and each bar represents the mean \pm SD from 3 experiments $(n=2,194-5,237$ cells per bar). (F) p53 band intensities on immunoblots were normalized to tubulin intensities and plotted against the $\%$ of AnnVpositive cells. Each point represents the mean \pm SD from 3 fields-of-view in a given experiment $(n=273-2,217$ cells per point). The slope in the linear trendline regression equation for HAP1 etoposide-treated samples $(\mathrm{Y}=33.47 \mathrm{X}+12.48)$ was significantly non-zero $\left(\mathrm{p}<0.001, \mathrm{R}^{2}=0.74\right)$. Significance stars refer to comparisons to the HAP1 siControl samples. ${ }^{* *} \mathrm{p}<0.01 ;{ }^{* * *} \mathrm{p}<0.001$ (ANOVA, Tukey post-hoc tests).

https://doi.org/10.1371/journal.pgen.1009512.g005

In response to genotoxic damage, nuclear p53 alters transcription and can trigger cell cycle arrest, DNA repair, apoptosis, senescence, and other stress responses [42,43]. Because a proliferation arrest is usually an early response to DNA damage, we compared the growth and death rates of HAP1 and JMY ${ }^{\mathrm{KO}}$ cultures after exposure to etoposide. For these experiments, we treated each cell line with DMSO or etoposide for $6 \mathrm{~h}$, removed the solvent or drug and 
replaced them with fresh media, and then quantified the numbers of total cells (live and dead) at regular intervals up to a $48 \mathrm{~h}$ endpoint. While $\mathrm{HAP} 1$ and JMY $\mathrm{KO}^{\mathrm{KO}}$ cells multiplied at equivalent rates after treatment with DMSO, both cell types stopped proliferating after treatment with etoposide (S8 Fig). In contrast, when apoptotic cell quantities were measured using AnnV staining, the proportion of cells undergoing apoptosis was significantly higher in the HAP1 samples at every timepoint (S8 Fig). For parental samples, $>35 \%$ were AnnV-positive by $6 \mathrm{~h}, 50 \%$ were apoptotic by approximately $10 \mathrm{~h}$, and the frequency of apoptosis had reached about $90 \%$ of cells by $48 \mathrm{~h}$ (S8 Fig). JMY ${ }^{\mathrm{KO}}$ samples never hit the $50 \%$ apoptosis mark, as only $35 \%$ were AnnV-positive at 48h (S8 Fig). Thus, without JMY, cells remain stuck in an arrested condition and fail to shift into a proper death signaling state.

One of the key p53 targets that triggers cell cycle arrest is $C D K N 1 A$, which encodes the cyclin-dependent kinase inhibitor, p21 [44]. To determine if CDKN1A expression is affected by $J M Y$ inactivation in the absence or presence of etoposide, we used RT-PCR for comparing CDKN1A transcript levels. Consistent with the proliferation assays described above, CDKN1A was expressed at low levels in DMSO-treated HAP1 and JMY ${ }^{\mathrm{KO}}$ cells, and significantly upregulated in both cell lines following a $6 \mathrm{~h}$ exposure to etoposide (S8 Fig). Similarly, small amounts of $\mathrm{p} 21$ protein were found in HAP1 and JMY ${ }^{\mathrm{KO}}$ cells at steady-state, while treatment with etoposide resulted in a 3-fold increase in the abundance of nuclear p21 in both sets of cells (S8 Fig). Collectively, these experiments suggest that JMY specifically promotes a cell suicide program and is not required for several other aspects of nuclear p53 modification or function, including the transcriptional responses that lead to a proliferation arrest.

\section{Expression of the small G-protein RhoD is turned on in JMY-knockout cells}

While inactivation of JMY did not prevent arrest or CDKN1A upregulation, it could still impact other aspects of transcriptional programming. Indeed, given that JMY can enhance the expression of the pro-apoptotic p53 target $B A X[24,29]$, one plausible explanation for the apoptotic defects in JMY ${ }^{\mathrm{KO}}$ cells could be that they possess different gene expression patterns than normal cells such that they are less 'equipped' to die. To characterize the transcriptomic changes that took place upon knocking out $J M Y$, we performed differential gene expression analyses using RNA-sequencing (RNA-seq) on HAP1 cells and on one of the JMY knockout cell lines $\left(\mathrm{JMY}^{\mathrm{KO}-1 \mathrm{~A}}\right)$. When comparing the JMY ${ }^{\mathrm{KO}-1 \mathrm{~A}}$ cells to parental HAP1 cells, $<0.36 \%$ of protein-coding genes displayed expression differences of at least 2 -fold and with a significance q-value of $<0.05$ (Figs $6 \mathrm{~A}$ and S9). Expression of the genes encoding p53, caspases, Bax and other Bcl-2-family members, additional key modulators of apoptosis, or JMY-interacting proteins such as p300, Strap, and Mdm2 were not significantly different (S10 Fig). Moreover, genes for WASP-family members and other actin nucleation factors were not substantially changed (S10 Fig). Therefore, mutating JMY does not appear to adversely affect the basal expression of canonical apoptosis regulators or factors that are structurally or functionally related to JMY.

Since important differences in gene expression might not become evident until cells experience a pro-apoptotic stimulus, we next compared the transcriptomic changes that occurred in HAP1 and JMY ${ }^{\mathrm{KO}}$ cells after etoposide exposure. When comparing etoposide-treated to control samples, $<0.37 \%$ of protein-coding genes in either cell line displayed expression differences of at least 2 -fold and with a significance q-value of $<0.05$ (Figs 6B, 6C, and S9). Of the 67 total genes that met such criteria, 48 were shared between the HAP1 and JMY ${ }^{\mathrm{KO}}$ cells (S9 Fig). The mutually-upregulated factors included the CDKN1A cell cycle inhibitor described above, NFKB signaling components, and AP-1 transcription factors (S9 Fig). Substantial changes in 
A

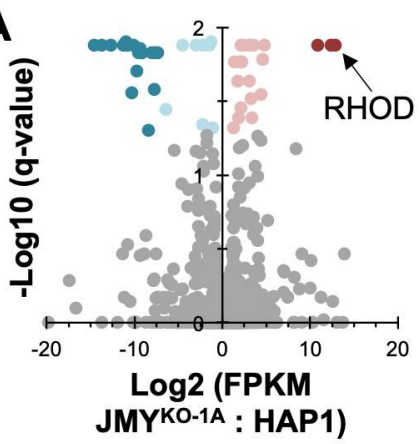

D

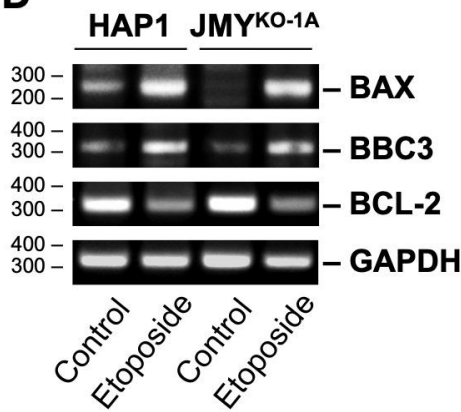

B

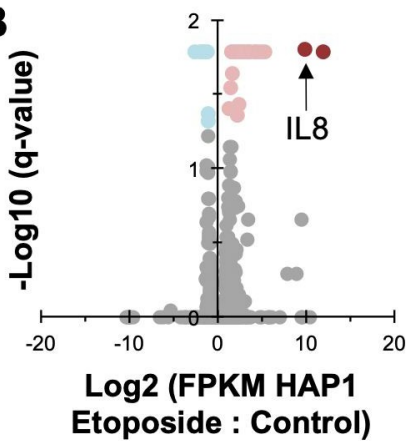

E

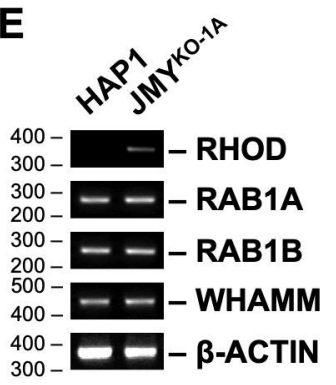

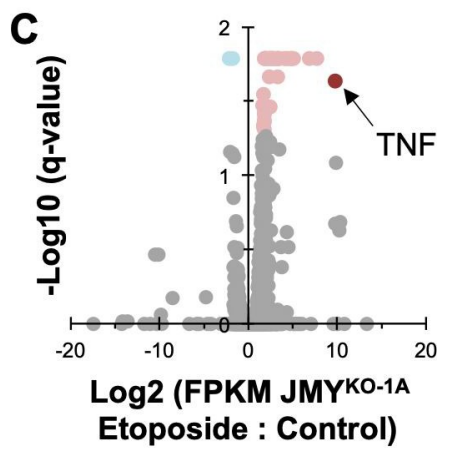

$F$

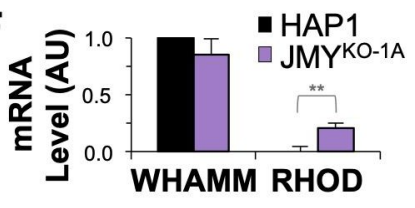

G

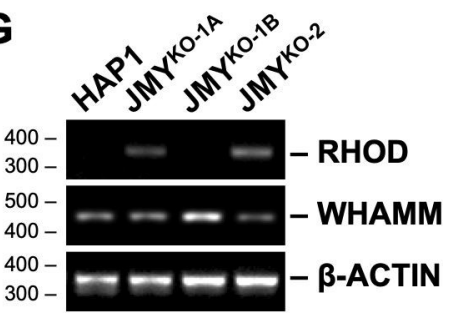

Fig 6. Expression of RHOD, but not canonical apoptosis regulators, is turned on in JMY-knockout cells. (A) RNA collected from HAP1 and JMY ${ }^{\mathrm{KO}-1 \mathrm{~A}}$ cells was subjected to mRNA sequencing analysis. A volcano plot represents FPKM (Fragments Per Kilobase of transcript per Million mapped reads) values plotted against -log10(q-values) of all individual genes for JMY ${ }^{\mathrm{KO}-1 \mathrm{~A}}$ vs HAP1 cells. Genes with expression differences of at least 2-fold and with a significance q-value of $<0.05$ are shown in dark red (turned on), pink (up-regulated), light blue (down-regulated), or dark blue (turned off), while genes that do not meet these criteria are depicted in gray (unchanged). Each point represents the mean value from 3 independent RNA samples per genotype. (B-C) RNA collected from HAP1 and JMY ${ }^{\mathrm{KO}-1 \mathrm{~A}}$ cells treated with $5 \mu \mathrm{M}$ etoposide for $6 \mathrm{~h}$ was subjected to mRNA sequencing. Volcano plots represent FPKM values plotted against - $\log 10$ ( $\mathrm{q}$-values) of all individual genes for etoposide vs control media-treated HAP1 (B) or JMY ${ }^{\mathrm{KO}}$ (C) cells. Genes with expression differences of at least 2 -fold and with a significance q-value of $<0.05$ are shown as in A. Each point represents the mean value from two independent RNA samples per genotype, except for $I L 8$, which was only detected in one experiment. (D-E) RNA from HAP1 and JMY ${ }^{\mathrm{KO}}$ cells was subjected to RT-PCR using primers to $B A X, B B C 3, B C L-2, G A P D H, R H O D, R A B 1 A, R A B 1 B$, $W H A M M$, and $\beta$-ACTIN, and visualized on agarose gels. (F) Gel band intensities were quantified in ImageJ, and values for RHOD and WHAMM were normalized to $\beta$-ACTIN. AU $=$ Arbitrary Units. Each bar represents the mean \pm SD from 3 experiments. (G) RNA from HAP1, JMY KO-1A JMY $^{\mathrm{KO}-1 \mathrm{~B}}$, and JMY $\mathrm{KO}^{\mathrm{KO}}$ cells were subjected to RT-PCR and visualized on agarose gels. ${ }^{* *} \mathrm{p}<0.01$ (t-test).

\section{https://doi.org/10.1371/journal.pgen.1009512.g006}

expression of genes that encode p53, caspases, Bcl-2 family members, or other prototypical apoptotic modulators were again not detected. Among the 19 genes that showed statistical differences between the parental and knockout cells, 16 displayed similar trends in either up- or down-regulation. The only sizable discrepancies between the two cell lines were in the cytokine genes IL8 and TNF, as IL8 was strongly upregulated in one of the HAP1 samples and TNF was greatly upregulated in the JMY ${ }^{\mathrm{KO}}$ samples (Figs 6B, 6C, and S9). These results imply that HAP1 and JMY ${ }^{\mathrm{KO}}$ cells are sufficiently equipped with enough potentially-apoptotic factors to be able to execute an intrinsic death program without a major increase in the abundance of pro-apoptotic transcripts.

A closer inspection of known p53 targets in the RNA-seq datasets indicated that $B A X$ transcript levels were unchanged after etoposide treatment in both HAP1 and JMY KO cells (S10

Fig). Under the same genotoxic conditions, the BBC3 transcript, which encodes the p53 
upregulated modulator of apoptosis PUMA, was increased 2.5-fold in HAP1 cells and 5-fold in the JMY ${ }^{\mathrm{KO}}$, although neither of these values reached statistical significance (S10 Fig). To more specifically test whether changes in the amounts of particular transcripts could be detected by a targeted approach, we performed RT-PCRs for $B A X$ and $B B C 3$, as well as the anti-apoptotic factor $B C L$-2. Compared to untreated steady-state conditions, etoposide exposure resulted in slightly increased $B A X$ and $B B C 3$ transcript levels and decreased $B C L-2$ levels in both HAP1 and JMY ${ }^{\mathrm{KO}-1 \mathrm{~A}}$ cells (Fig 6D). Therefore, mutating JMY does not appear to drastically affect the expression patterns of canonical p53 target genes, further suggesting that transcriptional reprogramming is not the principal driver of death signaling under the conditions used in our experiments.

In light of these observations, we sought to better understand how unanticipated factors might be contributing to cell survival or death in the presence and absence of JMY. When examining the 51 genes whose expression differed in the $\mathrm{JMY}^{\mathrm{KO}}$ line at steady state, it was notable that the most upregulated gene was RHOD (Figs 6A and S9), which encodes a small Gprotein that was previously shown to interact with WHAMM [45,46]. Transcript levels for other small G-proteins were virtually the same between parental and KO cells (S10 Fig), implying that the change for RHOD might be functionally meaningful. Moreover, RT-PCR experiments confirmed that RHOD transcript levels were almost undetectable in HAP1 cells and significantly turned on in the JMY ${ }^{\mathrm{KO}}$ cells (Fig $6 \mathrm{E}$ and $6 \mathrm{~F}$ ). The expression of WHAMM and $R A B 1 A / R A B 1 B$, the latter of which encode small G-proteins known to bind WHAMM directly [47], were unchanged between the parental and JMY ${ }^{\mathrm{KO}}$ cells (Figs 6E and S10). RT-PCR further showed that one of the other two independently derived $J M Y$ knockout cell lines also had increased $R H O D$ transcript levels (Fig 6G), suggesting that RHOD upregulation may be a frequent, but not universal, response to the inactivation of $J M Y$. These experiments reveal that although the loss of JMY may not cause any obvious compensatory changes in the transcription of actin nucleation factors, it can result in increased expression of a G-protein known to affect cytoskeletal dynamics.

\section{RhoD promotes cell survival in the absence or presence of JMY}

RhoD is a Rho-family GTPase that regulates many cellular functions, including actin assembly during filopodia formation, cell migration, endosome dynamics, and Golgi trafficking [4556]. Additionally, RhoD appears to participate in other processes that affect cell proliferation, such as cell cycle regulation and cytokinesis [49,57]. Since JMY is involved in proteostasis and genotoxic stress responses through its activities in autophagy and apoptosis, we reasoned that the increase in $R H O D$ expression in JMY ${ }^{\mathrm{KO}}$ cells might be part of a compensatory pro-survival mechanism that allows the cells to better tolerate the loss-of-function mutation in JMY. To explore this possibility, we targeted RhoD for depletion using two independent siRNAs in $J_{M Y}{ }^{\mathrm{KO}}$ cells. RT-PCRs verified that each RhoD siRNA reduced RHOD transcript levels (S11 Fig). DMSO- or etoposide-treated JMY ${ }^{\mathrm{KO}}$ cells were then subjected to AnnV, PI, and Hoechst staining for measuring apoptosis and for evaluating necrosis (S11 Fig). Compared to control siRNA-treated samples, RHOD-depleted samples that were exposed to just DMSO showed modest increases in the fraction of cells with AnnV staining (S11 Fig), consistent with the possibility that cells are slightly more prone to apoptosis when RHOD levels are decreased. For the samples that were treated with etoposide, the low frequency of AnnV staining of JMY ${ }^{\mathrm{KO}}$ cells was equivalent whether or not RHOD was silenced (S11 Fig). Since diminishing RHOD expression in these experiments did not restore apoptosis to normal levels, the intrinsic apoptotic defects in JMY ${ }^{\mathrm{KO}}$ cells must not be due simply to the upregulation of RHOD. Perhaps more importantly, the percentage of AnnV-negative cells that were PI-positive, or considered to be 
necrotic, was significantly higher when $R H O D$ was depleted (S11 Fig). This latter result supports the idea that RhoD normally promotes cell survival.

Because of the complexities in studying RhoD activities during apoptosis in $\mathrm{JMY}^{\mathrm{KO}}$ cells, which appear to be fundamentally defective in their intrinsic apoptotic responses, we next wanted to characterize the effects of transiently depleting or permanently inactivating $R H O D$ in otherwise healthy JMY-proficient cells. While RHOD transcript is below the limit of detection in the HAP1 cell line, it is expressed at measurable levels in eHAP cells (Fig 7A). So eHAP samples were treated with siRNAs for depleting RHOD (Fig 7B), exposed to DMSO or etoposide, and stained with AnnV and PI to assess the proportion of apoptotic and necrotic cells (Fig 7C). For the DMSO-treated populations, apoptotic death rose from $1 \%$ in cells receiving the control siRNA to 5\% in cells receiving either of the RhoD siRNAs (Fig 7D), suggesting that RhoD depletion in healthy cells leads to a higher incidence of death under normal growth conditions. For the etoposide-treated samples, $R H O D$ silencing caused apoptosis to occur in approximately $80 \%$ of eHAP cells, frequencies which were approximately double what was observed in cells treated with a negative control siRNA (Fig 7C and 7D). Moreover, the amount of RhoD transcript was inversely correlated with the percentage of AnnV-positive cells (Fig 7E). Necrotic death frequencies also rose, in this case from $2 \%$ in the presence of RHOD to $5 \%$ when it was silenced (Fig 7D). Thus, decreasing RHOD expression can increase stress-induced apoptosis and necrosis when normal JMY and p53 responses are present, further strengthening the conclusion that RhoD plays a basic pro-survival role in cells.

To assess the impact of a permanent loss of RHOD on cell survival and death, we next derived two independent $\mathrm{RhoD}^{\mathrm{KO}}$ cell lines from parental eHAP cells (S3 Fig). RT-PCRs verified that wild type RhoD mRNA was absent in the mutant cells (Fig 7F). Similar to other knockout cells, each of the RhoD ${ }^{\mathrm{KO}}$ cell lines had low levels of DNA damage when exposed to DMSO, but more numerous DNA breaks when incubated with etoposide (S4 Fig). Consistent with the transient depletion findings in etoposide-treated samples, apoptotic and necrotic death were more common in $\mathrm{RhoD}^{\mathrm{KO}}$ cells than in eHAP cells (Figs $7 \mathrm{G}$ and S11). Additionally, in dose-response experiments, at each etoposide concentration the $\mathrm{RhoD}^{\mathrm{KO}}$ cell lines showed a death frequency that was approximately twice that of parental cells (Fig 7H). These studies reveal that the permanent loss of RhoD makes cells more susceptible to dying during normal culture conditions and also enhances their apoptotic responses following acute DNA damage.

Since JMY and WHAMM are necessary for an efficient pathway of cyto $c$ release, initiator caspase cleavage, and executioner caspase activation, we tested if RHOD inactivation affected these aspects of intrinsic apoptosis. Following $3 \mathrm{~h}$ and $6 \mathrm{~h}$ of etoposide treatment, compared to the eHAP parental cell line, the Rho ${ }^{\mathrm{KO}}$ samples had significantly higher percentages of cells with diffuse cyto $c$ localization, greater levels of initiator caspase-9 processing, more cells undergoing cleavage of DEVD-containing substrates, and more cells staining positive for active caspase-3 (Figs 7I-7K and S11). Together, the above results show that knocking out RHOD has the opposite apoptotic phenotypes of knocking out JMY or WHAMM. Thus, while JMY and WHAMM are WASP-family proteins that have important pro-apoptotic roles in intrinsic pathways of cell death, such functions may be constrained by pro-survival or antiapoptotic activities of the small G-protein RhoD.

\section{The Arp2/3 complex is required for efficient intrinsic apoptosis}

The actions of Rho-family G-proteins and WASP-family nucleation factors converge on the activation of the Arp2/3 complex, which nucleates actin into filaments [58,59]. To better understand the contribution of the actin cytoskeleton in intrinsic apoptosis, we first tested the 

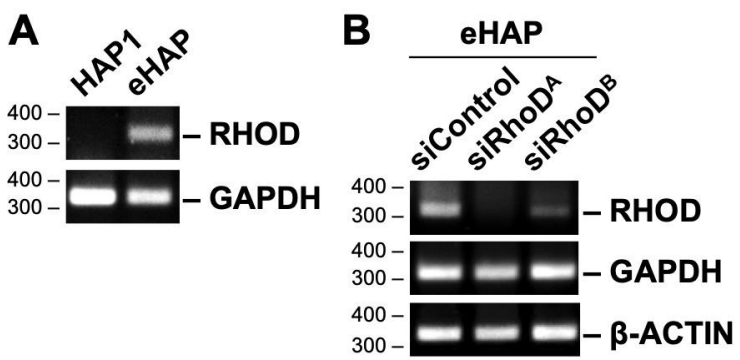
C

DHAP

eHAP
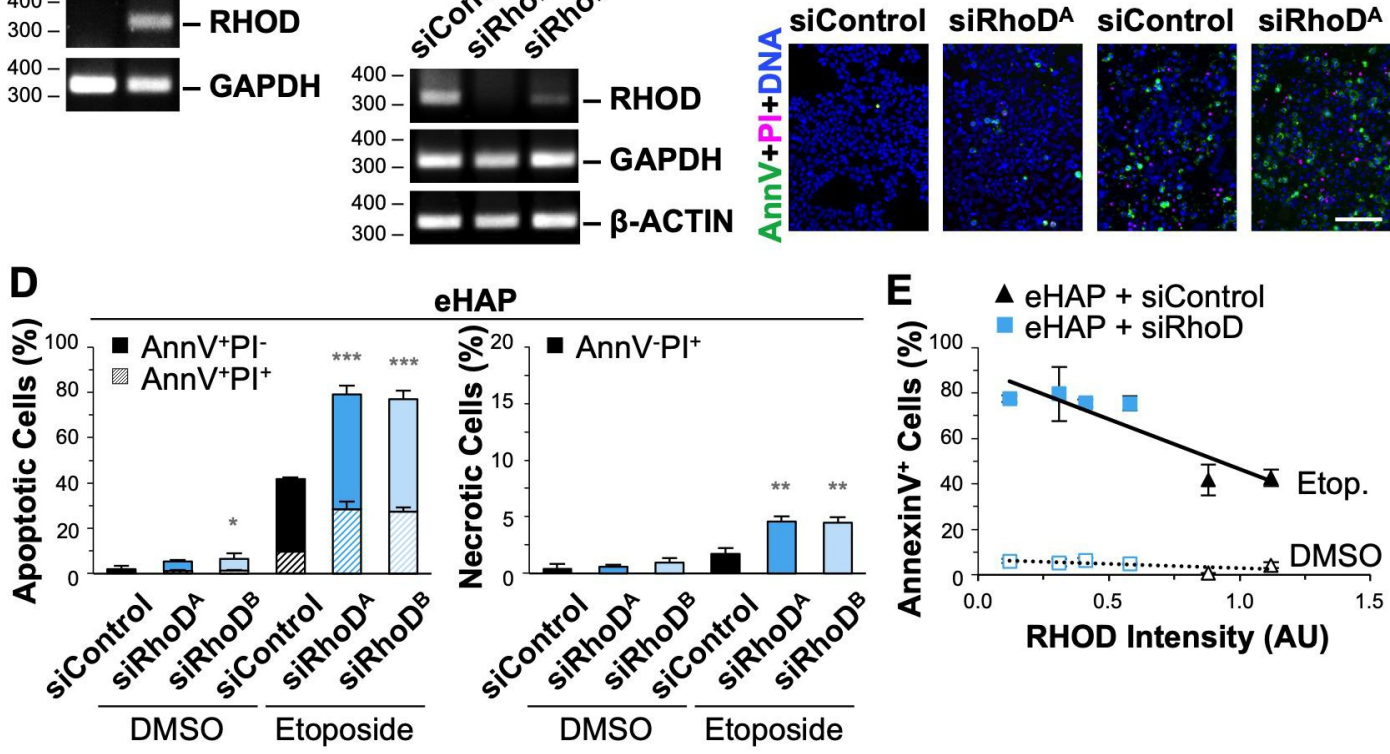

siControl siRhoDA
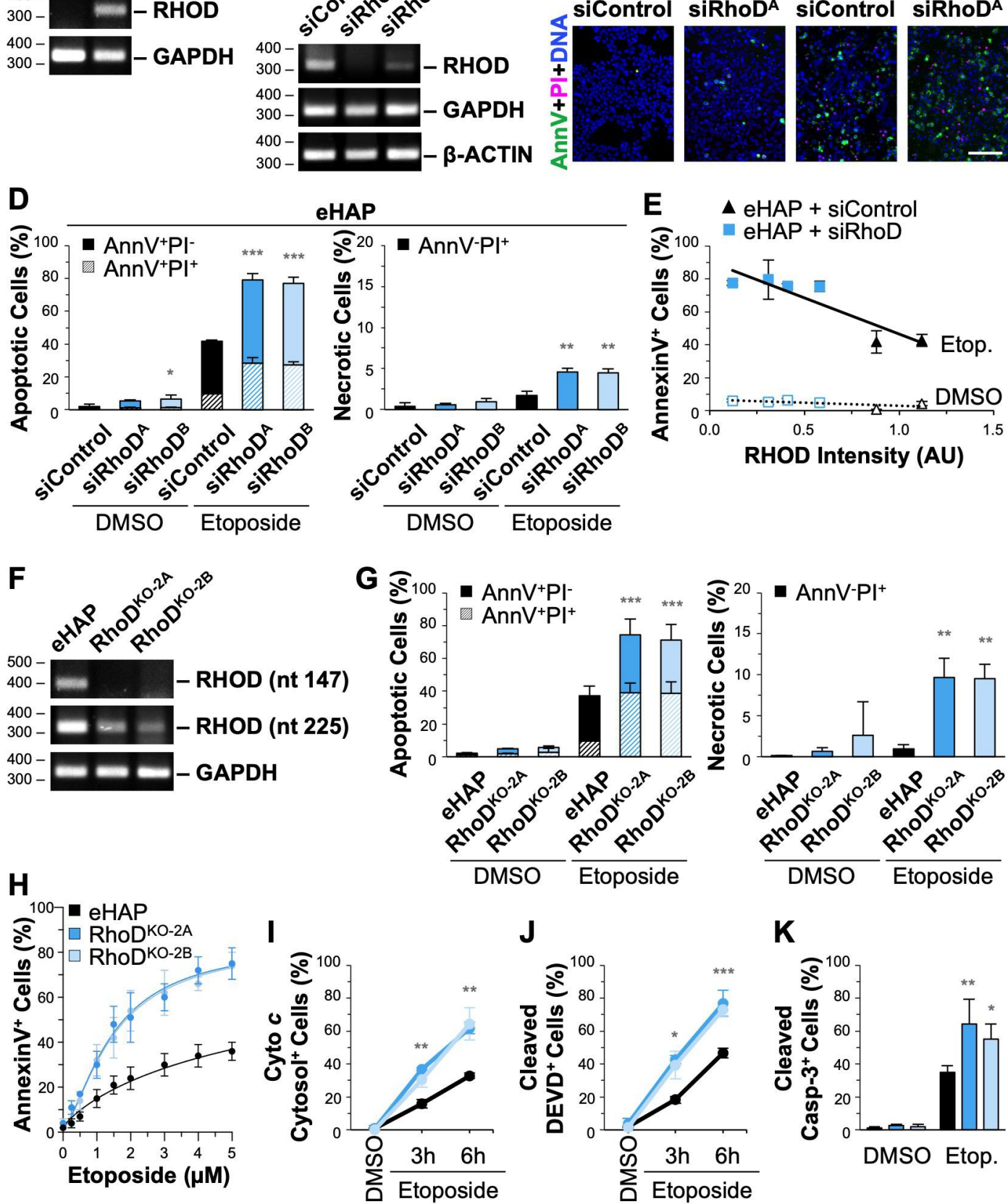

$\mathbf{J}$

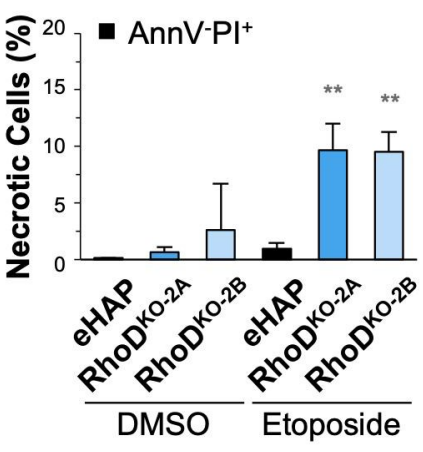

Fig 7. Depletion or deletion of RhoD results in greater levels of apoptotic and necrotic cell death. (A) RNA from HAP1 and eHAP cells was subjected to RT-PCR using primers to RHOD and GAPDH and visualized on agarose gels. (B) eHAP cells were treated with control siRNAs or independent siRNAs for the RHOD gene before performing RT-PCRs with primers to $R H O D, G A P D H$, and $\beta$-ACTIN. (C) Cells were treated with DMSO or $5 \mu \mathrm{M}$ etoposide for $6 \mathrm{~h}$ and stained with Alexa 488 -AnnV (green), PI (magenta), and Hoechst (blue). Scale bar, $100 \mu \mathrm{m}$. (D) The \% of apoptotic cells was calculated and displayed as the fraction of AnnV-positive/PI-negative $\left(\mathrm{AnnV}^{+} \mathrm{PI}^{-}\right)$or $\mathrm{AnnV} / \mathrm{PI}$ double-positive $\left(\mathrm{AnnV}^{+} \mathrm{PI}^{+}\right)$cells. Significance stars refer to comparisons of total $\mathrm{AnnV}^{+}$counts for siControl vs siRhoD samples. The $\%$ of AnnV-negative/PI-positive $\left(\mathrm{AnnV}^{-} \mathrm{PI}^{+}\right.$) necrotic cells was also quantified. Significance stars refer to comparisons of siControl vs siRhoD samples. Each bar represents the mean \pm SD from 3 experiments ( $\mathrm{n}=3,662-4,948$ cells per sample). (E) $R H O D$ band intensities were normalized to $\beta$ ACTIN and plotted versus the \% of AnnV-positive cells. Each point represents the mean \pm SD from 3 fields-of-view in a given experiment $(\mathrm{n}=980-1,728$ cells per point). The slopes in the linear trendline regression equations for etoposide-treated samples $(Y=-43.48 X+90.28)\left(p<0.001, R^{2}=0.75\right)$ and DMSO-treated samples $(Y=-3.46 X+6.47)\left(p<0.01, R^{2}=0.37\right)$ were 
significantly non-zero. (F) RNA from eHAP and $\mathrm{RhoD}^{\mathrm{KO}}$ cells was subjected to RT-PCR using primers to RHOD (forward primer: nt 124-147; reverse primer: nt 523-545), RHOD (forward primer: nt 225-247; reverse primer: nt 523-545), and GAPDH. Nucleotide 147 is predicted to be absent in mRNA from both knockouts, whereas nucleotide 247 should be present in both, albeit reflecting transcript levels that are lower than the parental control due to nonsense-mediated decay. Bands from this gel are also shown in panel (A). (G) eHAP and $\mathrm{RhoD}^{\mathrm{KO}}$ cells were treated and stained as in panel (D). The \% of apoptotic and necrotic cells were quantified and each bar represents the mean \pm SD from 3 experiments $(n=4,713-9,322$ cells per sample). (H) eHAP and $\mathrm{RhoD}^{\mathrm{KO}}$ cells were treated with a range of etoposide concentrations and stained with Alexa488-AnnV and Hoechst. The $\%$ of AnnV-positive cells was calculated and each point represents the mean \pm SD from 3-6 fields-of-view pooled from 1-2 experiments ( $\mathrm{n}=2,309-4,356$ cells per experiment). Nonlinear regressions were performed with a baseline set to 0.02 and a maximum response set to 0.85 . EC50 values were significantly different for parental vs KO samples (Mean EC50s: $\left.\mathrm{eHAP}=6.8 \mu \mathrm{M} ; \mathrm{RhoD}^{\mathrm{KO}}=1.5 \mu \mathrm{M}, \mathrm{p}<0.001\right)$. (I) Cells were treated with DMSO or etoposide, fixed, and stained with antibodies to detect cyto $c$ and AIF. The $\%$ of cells with cytosolic cyto $c$ staining was scored and each point represents the mean \pm SD from 3 experiments $(n=480-843$ cells per point). Significance stars refer to comparisons of parental to KO samples at the depicted timepoints. (J) Cells were stained with caspase-3/7 detection reagent, and the $\%$ of cleaved DEVDpositive cells was calculated. Each point represents the mean \pm SD from 3 experiments ( $n=1,746-3,580$ cells per point). (K) Cells were treated with DMSO or etoposide for $6 \mathrm{~h}$ before being fixed and stained with an antibody to cleaved caspase- 3 and DAPI. The $\%$ of cleaved caspase-3-positive cells was calculated, and each bar represents the mean \pm SD from 3 experiments $\left(\mathrm{n}=1,227-7,830\right.$ cells per bar). Representative images and immunoblots appear in (S11 Fig). ${ }^{*} \mathrm{p}<0.05,{ }^{* *} \mathrm{p}<0.01,{ }^{* * *} \mathrm{p}<0.001$ (ANOVA, Tukey post-hoc tests).

https://doi.org/10.1371/journal.pgen.1009512.g007

importance of the Arp2/3 complex by treating HAP1 and eHAP cells with siRNAs targeting two Arp2/3 subunits, ACTR3 and ARPC4, whose depletion results in loss of the entire complex [37]. Similar to the knockdowns of p53, JMY, or WHAMM described earlier, Arp2/3 depletions resulted in significantly fewer AnnV-positive cells (Fig 8A and 8B) and significantly fewer cells exhibiting active cleaved caspase-3 staining (Fig 8C). Further, in HAP1 and eHAP cells, greater degrees of Arp2/3 complex knockdown resulted in larger reductions in apoptosis, and the amount of Arp3 protein was positively correlated with the percentage of AnnV-positive cells (Fig 8D). To validate the apparent requirement for the Arp2/3 complex in apoptosis, we also performed etoposide treatments in the presence of the small molecule Arp2/3 inhibitor, CK666. Consistent with the RNAi experiments, CK666-treated samples contained fewer active caspase-3-positive cells than did DMSO-treated control samples (Fig 8C).

To determine the effect of the Arp2/3 complex on apoptosis in the absence of JMY or WHAMM, we similarly performed Arp2/3 depletions in $\mathrm{JMY}^{\mathrm{KO}}$ and WHAMM ${ }^{\mathrm{KO}}$ cells (Fig $8 \mathrm{~A})$. Analogous to the observation that knockdown of $\mathrm{p} 53$ in $\mathrm{JMY}^{\mathrm{KO}}$ cells did not further diminish apoptosis levels from their already low amount of $\sim 10 \%$ (Fig 5D-5F), the depletion of Arp2/3 in this knockout background did not affect AnnV or active caspase-3 staining frequencies (Fig 8B and 8C). In contrast, Arp2/3 silencing in WHAMM ${ }^{\mathrm{KO}}$ samples did result in significantly fewer apoptotic cells (Fig 8A-8C). One interpretation of these observations is that among the $20 \%$ of WHAMM-deficient cells that successfully execute apoptosis, approximately half rely on a death mechanism involving JMY and Arp2/3. Overall, it appears that the major intrinsic apoptotic pathway requires $\mathrm{p} 53$, JMY, and the Arp $2 / 3$ complex, and can be enhanced by WHAMM.

\section{JMY-driven actin assembly is associated with cyto $c$ clustering and caspase- 3 activation}

JMY activates the Arp $2 / 3$ complex using a C-terminal domain consisting of 3 actin-binding WASP-homology-2 (W) motifs and an Arp2/3-binding Connector-Acidic (CA) motif, and can also use its WWW segment to nucleate actin directly [60]. To investigate whether the actin polymerization capacity of JMY is important for its participation in apoptosis, we generated 3 GFP-tagged JMY derivatives for performing rescue experiments in JMY ${ }^{\mathrm{KO}}$ cells: a wild type JMY construct (JMY ${ }^{\mathrm{WT}}$ ); a JMY mutant missing all $3 \mathrm{~W}$ motifs (JMY ${ }^{\Delta \mathrm{WWW}}$ ) that can neither nucleate actin directly nor cooperate with the Arp2/3 complex; and a JMY mutant lacking the 

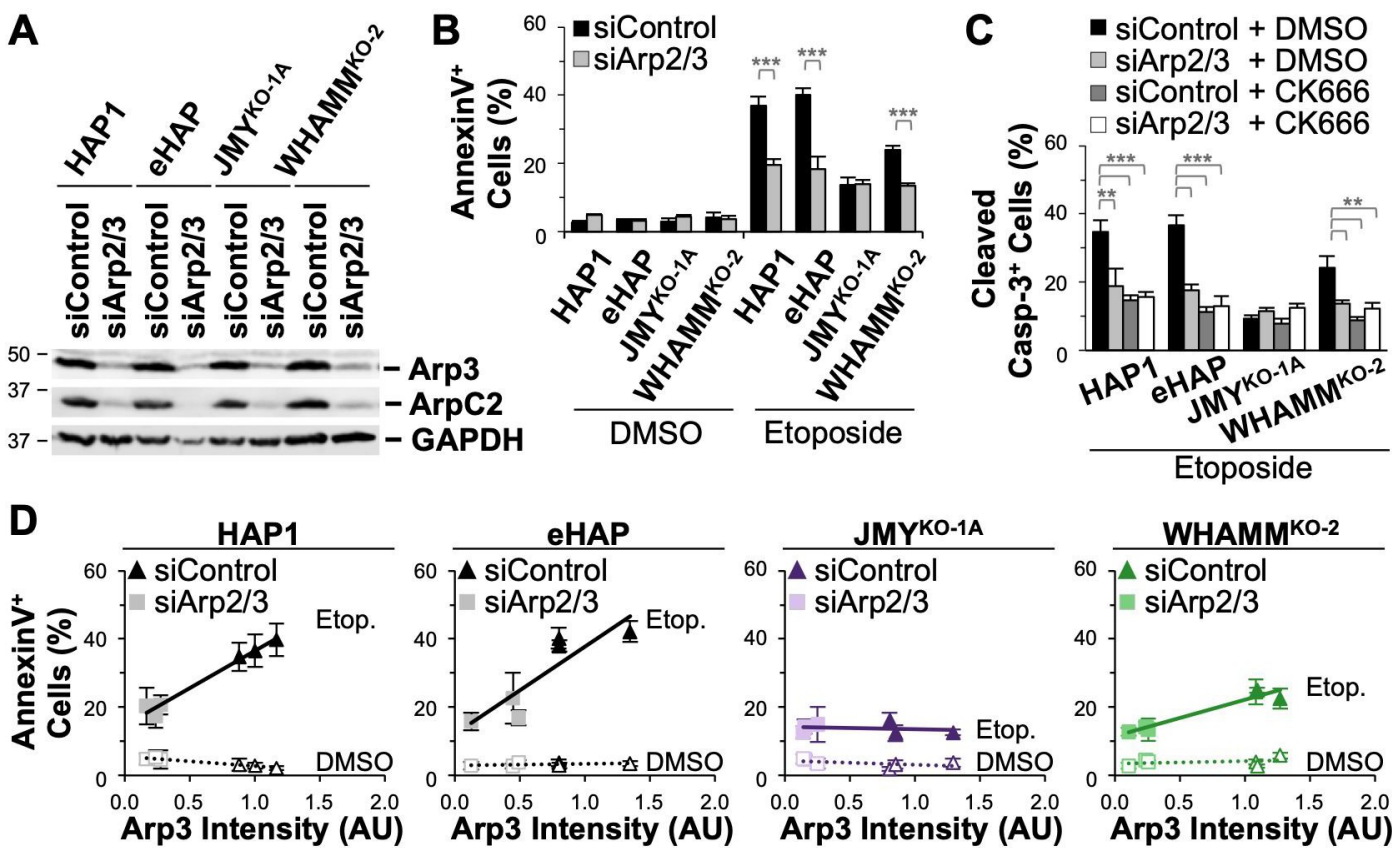

GAPDH
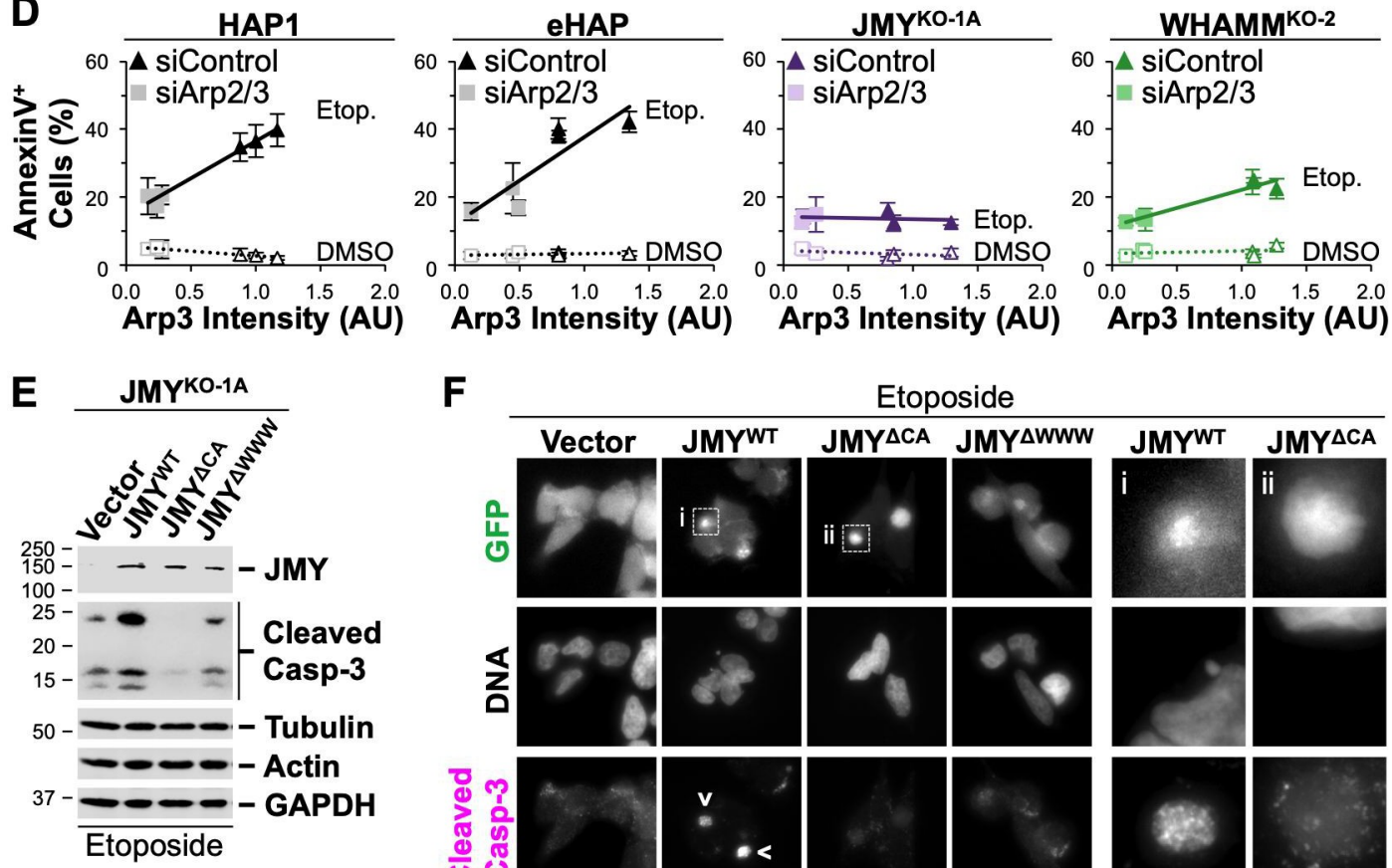

$\mathbf{F}$

Etoposide
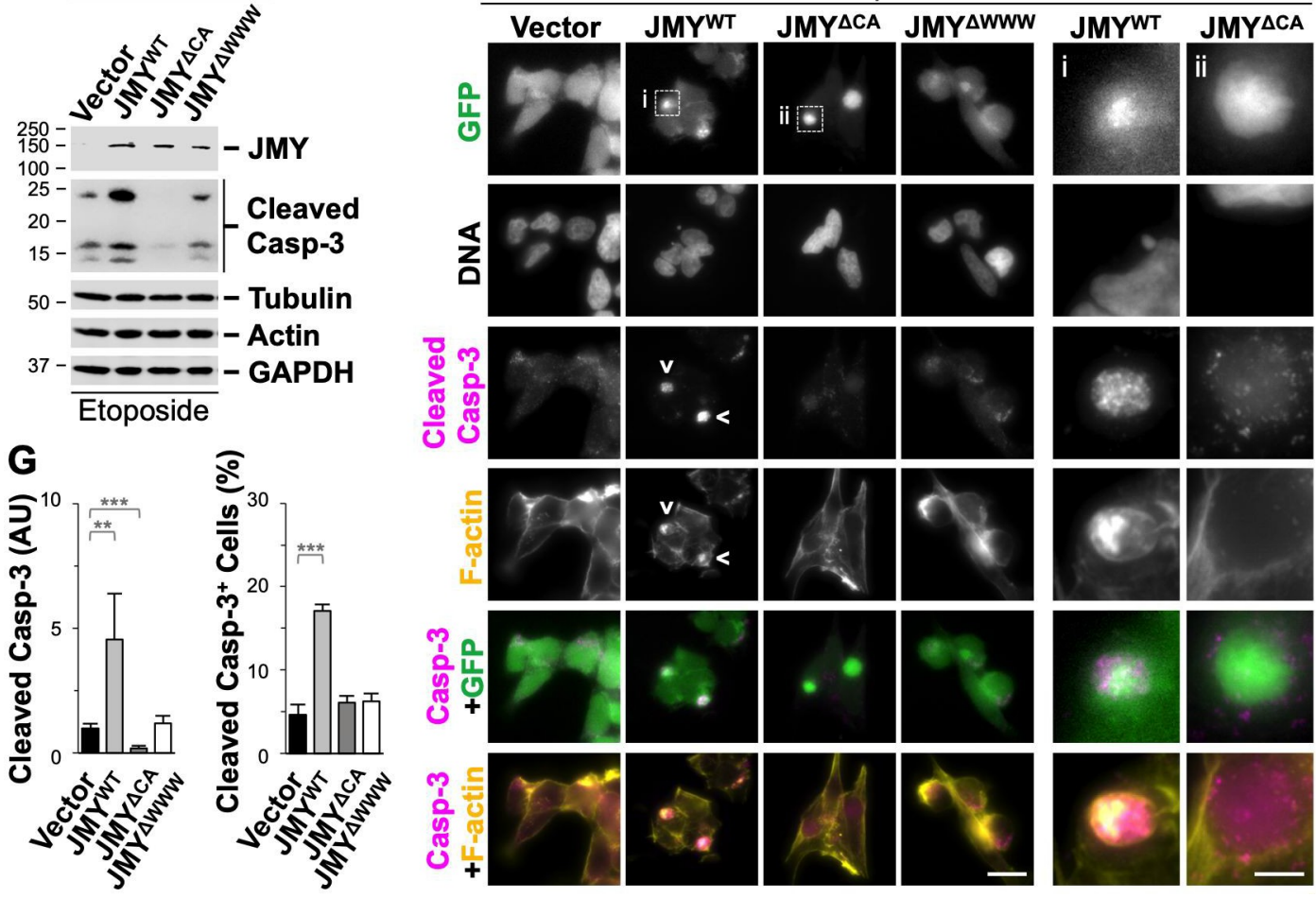

Fig 8. Intrinsic apoptosis and caspase- 3 activation require the Arp2/3 complex and actin assembly motifs in JMY. (A) HAP1, eHAP, JMY ${ }^{\mathrm{KO}}$, and WHAMM ${ }^{\mathrm{KO}}$ cells were treated with control siRNAs or with siRNAs for the ACTR3 and ARPC4 genes before immunoblotting with antibodies to Arp3, ArpC2, and GAPDH. (B) Cells were treated with DMSO or $5 \mu \mathrm{M}$ etoposide for $6 \mathrm{~h}$ and stained with Alexa488-AnnV, PI, and Hoechst. The \% of AnnV-positive cells was calculated and each bar represents the mean \pm SD from 3 experiments $(n=3,044-7,286$ cells per bar). (C) Cells were treated with etoposide in conjunction with DMSO or CK666 before being fixed and stained with an antibody that recognizes active caspase-3 cleaved at Asp175 and DAPI. The \% of cleaved caspase-3-positive cells was calculated and each bar represents the mean \pm SD from 3 experiments ( $\mathrm{n}=2,532-4,651$ cells per bar). (D) Arp3 band intensities on immunoblots were normalized to GAPDH intensities and plotted against the $\%$ of AnnV-positive cells. Each point represents the mean \pm SD from 3 fields-of-view in a 
given experiment ( $\mathrm{n}=974-2,499$ cells per point). The slopes in the linear trendline regression equations for HAP1, eHAP, and WHAMM $^{\mathrm{KO}}$ etoposide-treated samples (HAP1: $\mathrm{Y}=22.43 \mathrm{X}+14.39$; eHAP: $\mathrm{Y}=25.26 \mathrm{X}+12.411$; WHAMM ${ }^{\mathrm{KO}}: \mathrm{Y}=10.901 \mathrm{X}$ +11.31 ) were significantly non-zero $\left(\mathrm{p}<0.001, \mathrm{HAP} 1: \mathrm{R}^{2}=0.85 ;\right.$ eHAP: $\left.\mathrm{R}^{2}=0.71 ; \mathrm{WHAMM}^{\mathrm{KO}}: \mathrm{R}^{2}=0.82\right)$. AU = Arbitrary Units. (E) JMY ${ }^{\mathrm{KO}}$ cells transfected with plasmids encoding GFP (vector) or GFP-tagged JMY constructs (JMY ${ }^{\mathrm{WT}}$, JMY ${ }^{\Delta \mathrm{CA}}$, $\mathrm{JMY}^{\Delta \mathrm{WWW}}$ ) were treated with $10 \mu \mathrm{M}$ etoposide for $5 \mathrm{~h}$ before immunoblotting with antibodies to JMY, active cleaved caspase-3, tubulin, actin, and GAPDH. (F) GFP-expressing cells (green) treated as in (E) were also fixed and stained with DAPI to detect DNA, an antibody to visualize cleaved caspase-3 (magenta), and phalloidin to label F-actin (yellow). Arrowheads highlight examples of cleaved caspase-3-positive clusters. Magnifications represent examples of a JMY ${ }^{\mathrm{WT}}$ cluster that overlaps with a cleaved caspase- 3 cluster and is associated with an F-actin-rich territory (i), and a JMY ${ }^{\Delta C A}$ structure lacking both cleaved caspase-3 and F-actin enrichment (ii). Scale bars, $25 \mu \mathrm{m}, 10 \mu \mathrm{m}$. (G) For quantification of (E), the cleaved caspase- 3 band intensities were normalized to the loading control intensities and the vector sample was set to 1 . Each bar represents the mean intensity \pm SD from 4 experiments. $\mathrm{AU}=$ Arbitrary Units. For quantification of $(\mathrm{F})$, the $\%$ of cleaved caspase-3-positive cells was calculated and each bar represents the mean \pm SD from 3 experiments $(\mathrm{n}=3,447-6,084$ cells per bar $) .{ }^{* *} \mathrm{p}<0.01$, *** $\mathrm{p}<0.001$ (t-tests).

https://doi.org/10.1371/journal.pgen.1009512.g008

CA segment $\left(\mathrm{JMY}^{\Delta \mathrm{CA}}\right.$ ) that cannot activate Arp2/3 but retains its actin nucleating WWW region. The GFP-JMY plasmids, or a vector control, were introduced into the JMY ${ }^{\mathrm{KO}-1 \mathrm{~A}}$ line, which was then cultured in selective media, exposed to etoposide, and subjected to immunoblotting (Fig 8E) or immunostaining (Fig 8F) for active cleaved caspase-3. Compared to the vector-transfected knockout cells, which contained low levels of cleaved caspase-3, cells transfected with the wild type JMY construct showed a 4.5-fold increase in the amount of cleaved caspase-3 and a 3.5-fold increase in the cellular frequency of cleaved caspase-3 staining (Fig $8 \mathrm{G}$ ), indicating that full-length JMY can restore intrinsic apoptosis functions to JMY ${ }^{\mathrm{KO}}$ cells. In contrast, the JMY mutant with the WWW segment deleted failed to rescue apoptosis in the knockout cells, as cleaved caspase- 3 levels were indistinguishable from those of the vectortransfected controls (Fig 8E and 8G). The JMY mutant lacking the CA portion was also ineffective at increasing the frequency of cleaved caspase-3 staining (Fig 8G), and actually decreased the total levels of active caspase- 3 in JMY ${ }^{\mathrm{KO}}$ cells (Fig 8E and 8G). These results show that JMY requires its actin assembly activity, particularly its Arp2/3 complex binding segment, in order to drive intrinsic apoptosis.

JMY is primarily cytoplasmic in healthy cells $[27,28]$, and is typically redistributed into both the cytoplasm and nucleus upon exposure to apoptosis-inducing stressors [29,30]. Consistent with this expectation, GFP-JMY exhibited a fairly uniform localization in the cytosol and nucleus (Fig 8F). Interestingly, however, GFP-JMY additionally appeared in intense juxtanuclear clusters (Fig 8F), and those cytoplasmic structures overlapped with clusters of cleaved caspase-3 (Fig 8F). Further, staining with fluorescent phalloidin demonstrated that filamentous- (F-) actin also assembled throughout the caspase-3 region and was most intense adjacent to JMY (Fig $8 \mathrm{~F}$ ). JMY ${ }^{\Delta \mathrm{CA}}$ and JMY ${ }^{\Delta \mathrm{WWW}}$ could also be found in bright cytoplasmic spots, but cleaved caspase-3 staining was diffuse within these areas and F-actin was not enriched (Fig 8F). These findings highlight important relationships between JMY-mediated actin polymerization and the formation of cytoplasmic territories containing active caspase- 3 .

Because caspase- 3 activation is driven by apoptosomes, macromolecular platforms consisting of cyto $c$, procaspase-9, and other scaffolding factors [38,61,62], we revisited the potential connections among JMY, cyto $c$, and actin in the cytoplasm. Reminiscent of the GFP-JMY and cleaved caspase-3 clusters, punctate juxtanuclear structures of endogenous JMY were visible in a subset of etoposide-treated HAP1 cells (Fig 9A and 9B). The same type of staining pattern was also observed in $15-20 \%$ of U2OS cells, which are larger and easier to image (Fig 9A and 9B). Interestingly, in both HAP1 and U2OS cells, many of these JMY puncta colocalized with cyto $c$ puncta that were distinct from mitochondria (Figs 9C, 9D, and S12). They were also associated with bright clouds of the cleaved DEVD reporter (prior to its nuclear import), indicative of active caspase- 3 being present in proximity to these JMY- and cyto $c$-containing 


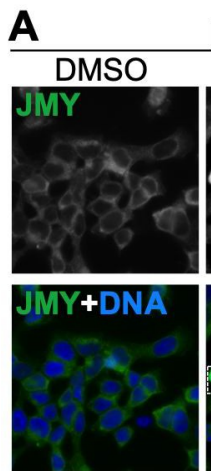

HAP1 Etoposide
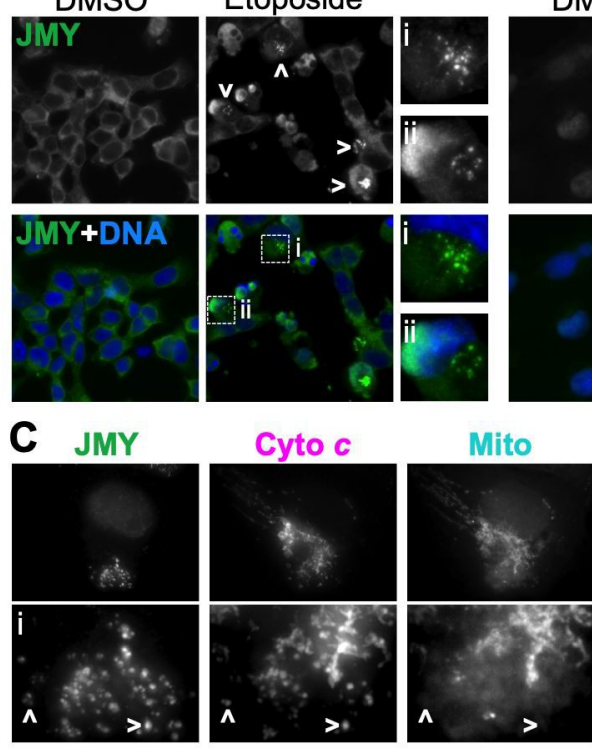

Cyto c+Mito JMY+Cyto c
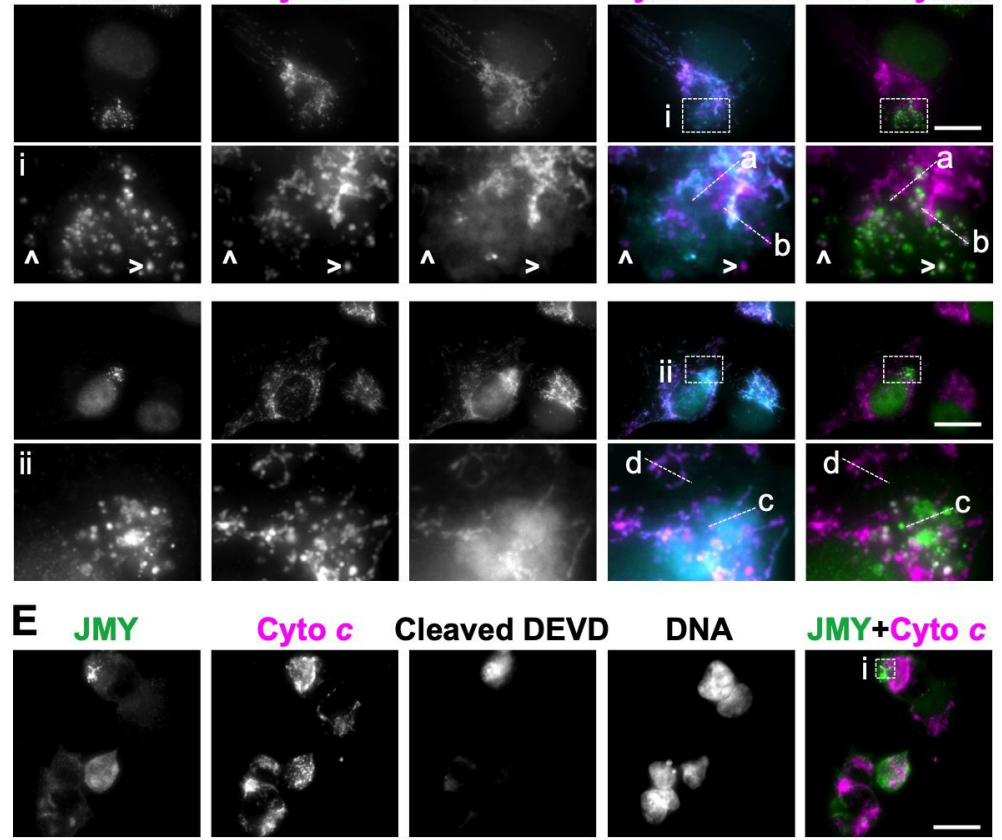

DNA

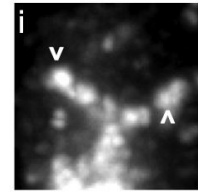

G

JMY

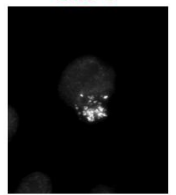

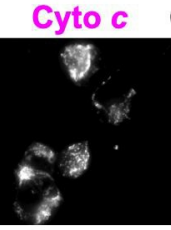
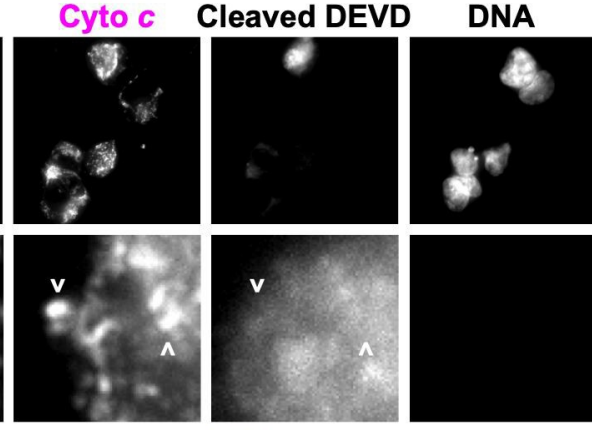

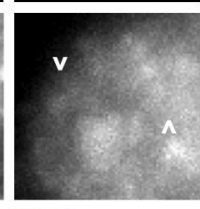

JMY+

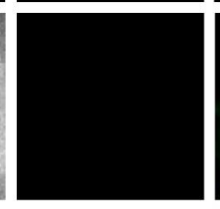

JMY+Cyto $c$
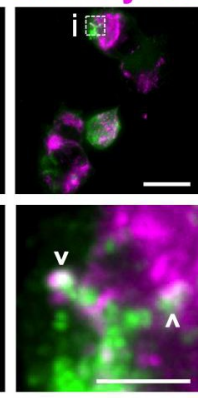

F-actin
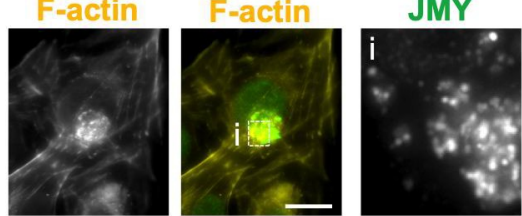

Cyto c
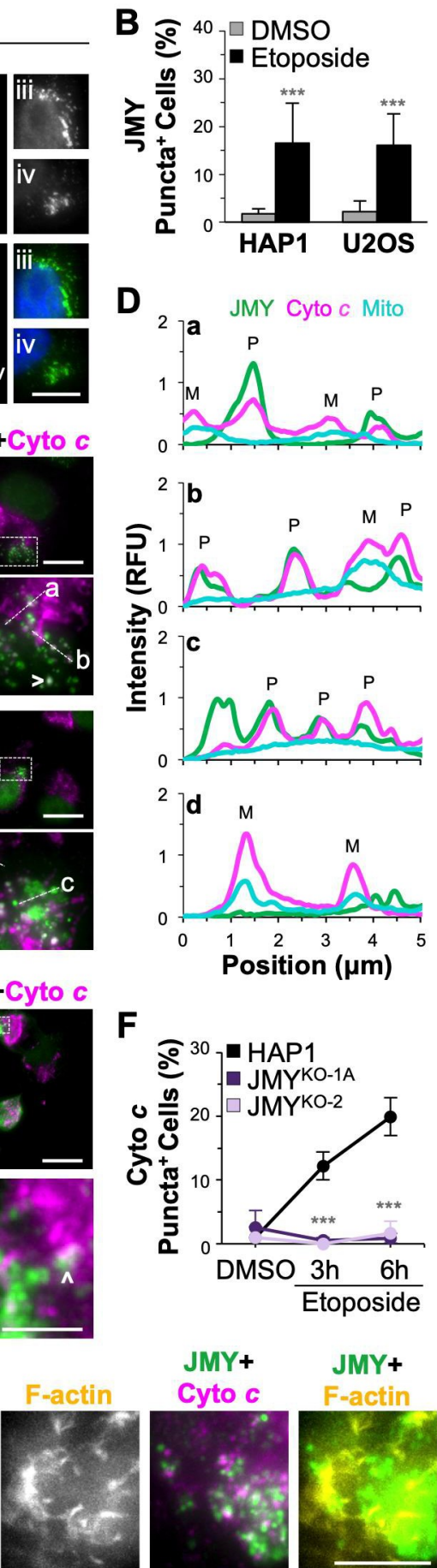

$\mathbf{F}$
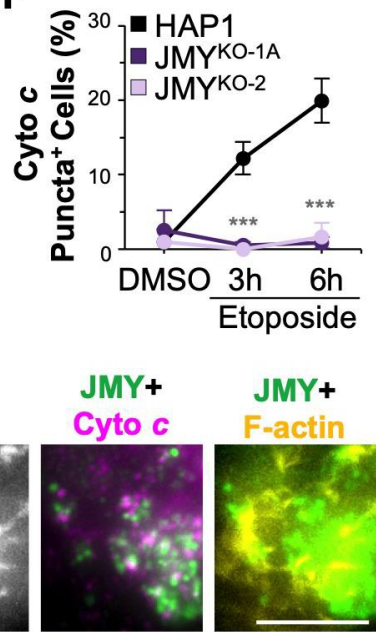

Fig 9. JMY colocalizes with cytochrome $c$ puncta and is required for their assembly into F-actin-associated cytoplasmic clusters. (A) HAP1 and U2OS cells were treated with DMSO, $5 \mu \mathrm{M}$ etoposide, or $10 \mu \mathrm{M}$ etoposide for $6 \mathrm{~h}$ before being fixed and stained with an antibody to JMY (green) and DAPI (DNA; blue). Arrowheads and magnifications (i-iv) highlight examples of cytosolic JMY puncta. Scale bars, $25 \mu \mathrm{m}, 10 \mu \mathrm{m}$. (B) The $\%$ of cells with JMY puncta was calculated in ImageJ by counting the cells containing JMY puncta and dividing by the total number of DAPI-stained nuclei. Each bar represents the mean $\% \pm S D$ from 3 experiments ( $n=1,149-1,576$ HAP1 cells per bar; $n=466-489$ U2OS cells per bar). Significance stars refer to comparisons between DMSO and etoposide treatments. (C) U2OS cells were treated with $10 \mu \mathrm{M}$ etoposide for $6 \mathrm{~h}$ and incubated with MitoTracker (Mito; cyan) before being fixed and stained with antibodies to JMY (green) and cyto $c$ (magenta). Arrowheads and magnifications (i,ii) show examples of cytosolic JMY and cyto $c$ puncta. Scale bars, $10 \mu \mathrm{m}$. (D) $5 \mu \mathrm{m}$ lines were drawn through the magnified images in (C) using ImageJ to measure the pixel intensity profiles for JMY, cyto $c$, and 
mitochondria, highlighting the differences in cyto $c$ maintained within mitochondria $(\mathrm{M})$ and cytosolic cyto $c$ that colocalizes with JMY puncta (P). (E) HAP1 cells were treated with $5 \mu \mathrm{M}$ etoposide for $6 \mathrm{~h}$, stained with caspase-3/7 green detection reagent to label cleaved DEVD, fixed, and stained with antibodies to JMY (green), cyto $c$ (magenta), and DAPI. Scale bars, $25 \mu \mathrm{m}$, $10 \mu \mathrm{m}$. Magnifications represent examples of JMY and cyto $c$ puncta that overlap with an area containing cleaved DEVD. (F) HAP1 and JMY ${ }^{\mathrm{KO}}$ cells were treated with DMSO or etoposide before being fixed and stained to visualize AIF and cyto $c$. The \% of cells with non-mitochondrial cyto $c$ puncta was calculated in ImageJ. Each point represents the mean $\% \pm$ SD from 3 experiments ( $\mathrm{n}=194-332$ cells per point). Significance stars refer to comparisons of parental to KO samples at the depicted timepoints. (G) U2OS cells were treated with etoposide, fixed, and stained with antibodies to JMY (green) and cyto $c$ (magenta), and with phalloidin (F-actin; yellow). Magnifications (i) depict clusters of JMY, cyto $c$, and F-actin. Scale bars, $25 \mu \mathrm{m}, 10 \mu \mathrm{m} .{ }^{* * *} \mathrm{p}<0.001$ (ANOVA, Tukey post-hoc tests).

https://doi.org/10.1371/journal.pgen.1009512.g009

clusters (Fig 9E). To test whether JMY was required for cells to form the distinct cytoplasmic cyto $c$ structures, we quantified the proportion of HAP1 and JMY ${ }^{\mathrm{KO}}$ cells containing mitochondria-independent cyto $c$ puncta. While the fraction of parental cells harboring cyto $c$ puncta increased during $3 \mathrm{~h}$ and $6 \mathrm{~h}$ exposures to etoposide, the JMY ${ }^{\mathrm{KO}}$ lines did not form cytosolic cyto $c$ puncta under any of these conditions (Fig 9F). In addition, inspection of U2OS cells revealed that the overlap of JMY and cyto $c$ puncta took place within F-actin-rich territories (Figs $9 \mathrm{G}$ and S12). F-actin appeared to be specifically reorganized, rather than globally polymerized or upregulated, as the inactivation of $J M Y$ did not significantly affect the overall levels of actin filaments, stained with phalloidin, or the total amounts of actin in the cytoplasm or nucleus, stained with an actin antibody (S12 Fig). These observations are consistent with a role for cytoplasmic JMY and F-actin during the period of apoptosis encompassing apoptosome assembly and executioner caspase-3 activation.

Finally, we investigated whether the formation of the cytosolic JMY puncta was impacted by WHAMM or RhoD. After etoposide treatment, $20 \%$ of HAP1 and eHAP cells contained clusters of JMY puncta while only $10 \%$ of WHAMM $^{\mathrm{KO}}$ cells but more than $35 \%$ of $\mathrm{RhoD}^{\mathrm{KO}}$ cells displayed such cytosolic JMY puncta (Fig 10A and 10B). These phenotypic differences are reminiscent of the reduced versus increased apoptotic characteristics previously observed in the WHAMM and RhoD knockout cells, respectively. To address how overexpression of RhoD might influence the formation and organization of the JMY-containing structures, we transiently transfected U2OS cells with constructs encoding GFP-tagged wild type RhoD (RhoD ${ }^{\mathrm{WT}}$ ) or a GDP-locked dominant negative mutant RhoD ( $\mathrm{RhoD}^{\mathrm{DN}}$ ) (Fig 10C). JMY puncta were formed at indistinguishable frequencies in cells expressing either GFP-RhoD ${ }^{\mathrm{WT}}$ or the GFP vector control (Fig 10D), suggesting that elevating RhoD protein levels does not inherently disturb this pattern of JMY localization during apoptotic signaling. In contrast, only half as many cells expressing the RhoD ${ }^{\mathrm{DN}}$ mutant contained JMY puncta (Fig 10D). Additionally, this dominant interfering RhoD protein increased JMY levels in the nucleus (Fig 10C-10E), signifying that the nucleotide-bound state of RhoD affects both the formation of the punctate cytosolic structures and the nuclear accumulation of JMY. Further examination of GFP-RhoD localization and Factin staining revealed that $\mathrm{RhoD}^{\mathrm{WT}}$ surrounded the clusters of JMY puncta and allowed actin polymerization (Fig $10 \mathrm{C}$ and $10 \mathrm{E}$ ). Conversely, $\mathrm{RhoD}^{\mathrm{DN}}$ did not localize in analogous juxtanuclear regions or permit actin filaments to form there (Fig 10C and 10E), suggesting that RhoD-GDP can act as an 'off switch' for JMY-mediated cytoskeletal rearrangements. Collectively, these results indicate that although JMY and RhoD exhibit opposing pro-apoptotic versus pro-survival activities, both proteins apparently function in the assembly and organization of cytoplasmic territories containing cyto $c$, active caspases, and F-actin.

\section{Discussion}

The polymerization, organization, and turnover of actin filaments have been thoroughly characterized during many cellular functions that maintain viability $[9,10]$. However, the 
A DMSO
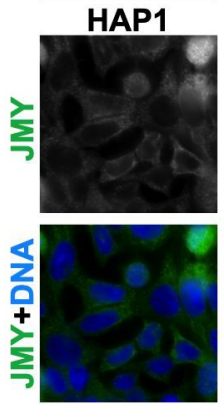

C
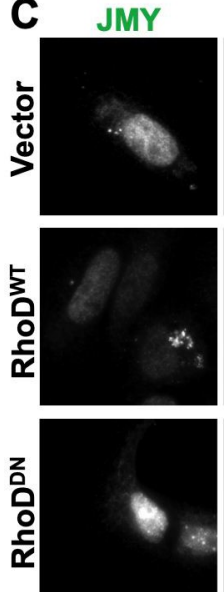

E
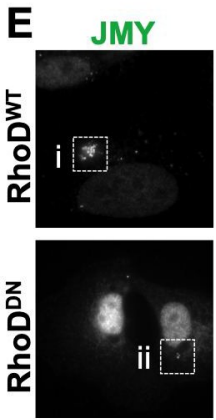

Etoposide
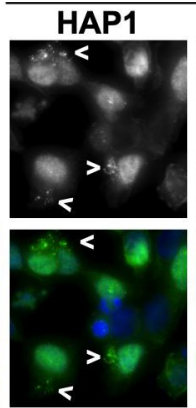

GFP
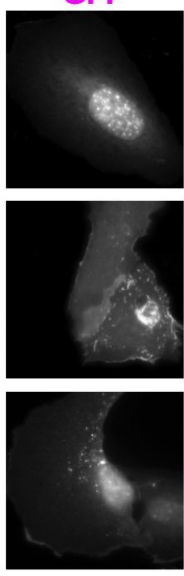

F-actin
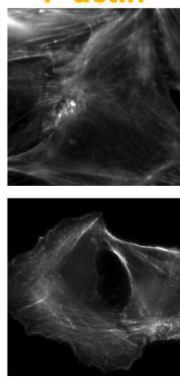

eHAP
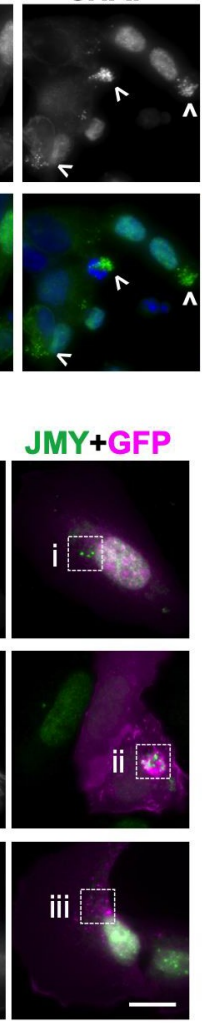

GFP
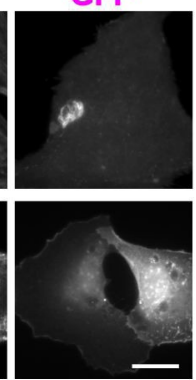
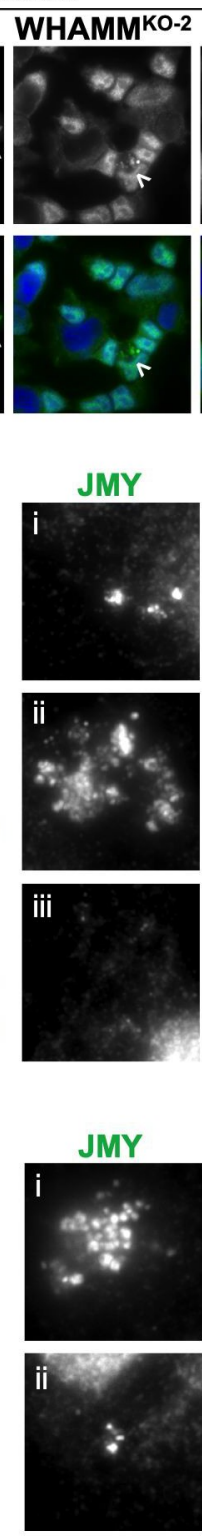

B
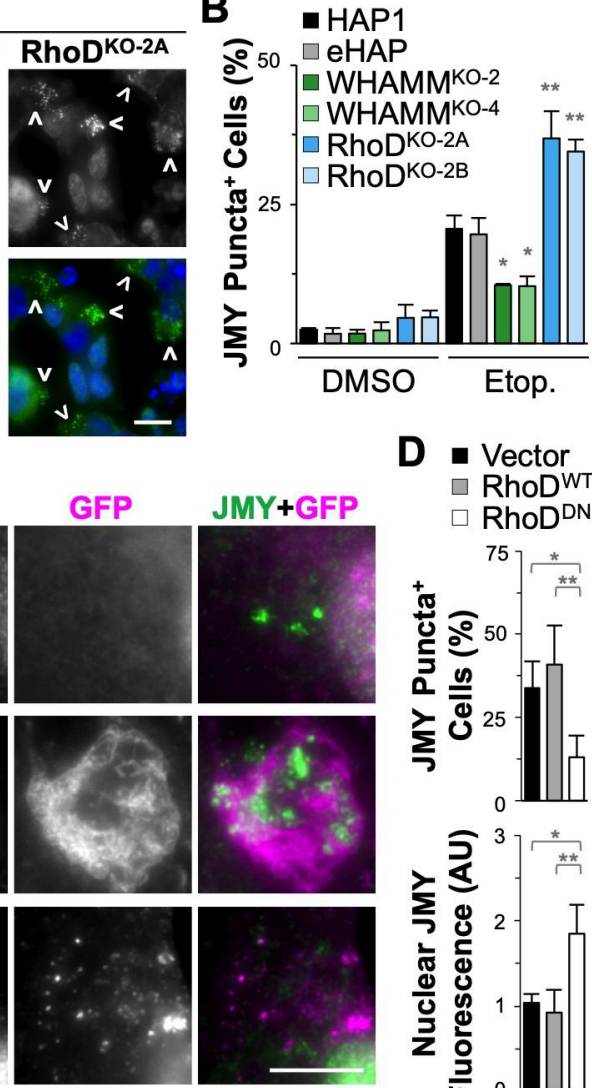

JMY+GFP

D - Vector

$\square$ RhoDWT

$\square$ RhoD $^{\mathrm{DN}}$
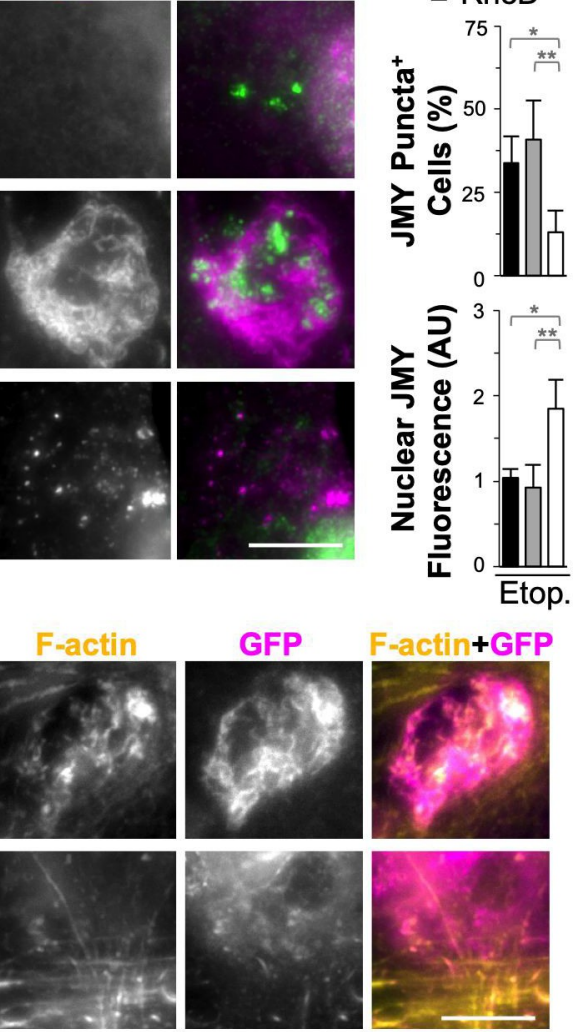

Fig 10. WHAMM and RhoD affect the organization of cytoplasmic territories containing JMY, cytochrome $c$, and Factin. (A) HAP1, eHAP, WHAMM ${ }^{\mathrm{KO}}$, and $\mathrm{RhoD}^{\mathrm{KO}}$ cells were treated with DMSO or $5 \mu \mathrm{M}$ etoposide for $6 \mathrm{~h}$ before being fixed and stained with a JMY antibody (green) and DAPI (DNA; blue). Arrowheads highlight examples of cytosolic JMY puncta. Scale bar, $25 \mu \mathrm{m}$. (B) The \% of cells with JMY puncta was calculated using ImageJ. Each bar represents the mean \% \pm SD from 2 experiments ( $n=170-346$ cells per bar). Significance stars refer to comparisons to parental cell lines. (C) U2OS cells transfected with plasmids encoding GFP (vector) or GFP-RhoD constructs $\left(\mathrm{RhoD}^{\mathrm{WT}}\right.$ and $\mathrm{RhoD}^{\mathrm{DN}}$ ) were treated with $10 \mu \mathrm{M}$ etoposide for $6 \mathrm{~h}$ before fixing and staining with a JMY antibody (green). GFP is shown in magenta. Scale bars, $25 \mu \mathrm{m}$, $10 \mu \mathrm{m}$. Magnifications (i-iii) represent examples of JMY localization. (D) The $\%$ of U2OS cells with JMY puncta was calculated in ImageJ and each bar represents the mean $\% \pm$ SD from 3-4 experiments ( $\mathrm{n}=107-201$ cells per bar). U2OS cells treated as in (C) were also stained with DAPI. Nuclear JMY fluorescence intensities were measured in ImageJ relative to those of the vector sample. Each bar represents the mean \pm SD from 3 experiments ( $n=105-186$ cells per bar). $\mathrm{AU}=$ Arbitrary Units. (E) U2OS cells treated as in (C) were stained with phalloidin to label F-actin (yellow). Magnifications (i,ii) represent examples of GFP-RhoD localizations. Scale bars, $25 \mu \mathrm{m}, 10 \mu \mathrm{m} .{ }^{*} \mathrm{p}<0.05,{ }^{* *} \mathrm{p}<0.01$ (ANOVA, Tukey post-hoc tests).

https://doi.org/10.1371/journal.pgen.1009512.g010 
contributions of actin assembly factors to apoptotic cell death are not well understood. Among the best-known cytoskeletal features of apoptosis are the actin filament rearrangements and disassembly that accompany changes in cell adherence and morphology $[7,8]$. Actin itself can be cleaved by caspases $[63,64]$, resulting in non-polymerizable fragments that promote apoptotic cellular phenotypes [65-67]. The actin turnover machinery has also been implicated in controlling apoptosis at multiple steps. Cofilin, which depolymerizes actin filaments [68], influences the early stages of apoptosis, as it translocates to mitochondria and may increase the release of cytochrome $c$ [69-71] and the localization of p53 [72]. Actin is additionally recruited to mitochondria at around the time of mitochondrial permeabilization [73-75]. During the later stages of apoptosis, the F-actin-severing protein gelsolin [76] is cleaved by caspases, resulting in a fragment with unregulated severing activity that drives depolymerization [77] and allows chromatin fragmentation [78]. In contrast to these described roles for actin disassembly proteins in apoptosis, less is known about the actions of the actin assembly machinery during cell death. Our results reveal intrinsic apoptotic functions for JMY, WHAMM, the Arp2/3 complex, and RhoD, and create a framework for understanding how actin nucleation factors and small G-proteins control pro-apoptotic and pro-survival processes.

WASP-family proteins have many well-recognized activities, but the extent to which they participate in cell death pathways is relatively underexplored. WAVE1 has been one of the most studied members, as it can affect the localization or modification of Bcl-2-family proteins. Several transient overexpression and depletion experiments suggest that WAVE1 limits mitochondrial permeabilization [20-23]. But in our initial knockout screen using BCR-ABLimmortalized human cells, the permanent loss of WAVE1 did not cause a consistent increase in the frequency of apoptosis, so the degree to which WAVE1 acts as an anti-apoptotic factor in a cell type specific manner requires further investigation.

In addition to WAVE1, JMY has been studied in the context of apoptosis. JMY was discovered as a cofactor that enhanced the transcriptional activity of p53 [24], and subsequent RNAi studies indicated that JMY has pro-survival $[32]$ or pro-death $[27,29,79]$ functions under different experimental circumstances. Our work advances the understanding of its pro-death role by demonstrating that cells with permanent deletions or transient depletions of JMY exhibit significant defects in apoptotic processes following DNA damage. In fact, inactivation of each WASP-family gene revealed that only cells lacking JMY, or its closest homolog WHAMM, had substantial deficiencies in their intrinsic apoptotic responses. WHAMM did not have any previously described roles in apoptosis, so the latter observation adds a third WASP-family member to the repertoire of actin assembly factors that can function in programmed cell death.

WHAMM and JMY comprise a subgroup within the WASP family, are approximately $50 \%$ similar to one another, and both promote anterograde membrane transport $[37,47,80]$ and autophagy $[32,81,82]$. Although the two proteins participate in similar cellular activities, they exhibit some key molecular differences. WHAMM has a conventional C-terminal WWCA domain that activates Arp2/3 complex-mediated actin assembly [37], whereas JMY has an extended WWWCA domain wherein the WCA produces Arp2/3-branched networks, and the WWW directly nucleates linear filaments [60]. WHAMM localizes to the ER and cis-Golgi and binds microtubules to mediate membrane tubulation and transport [37,47,83], while JMY acts later in the secretory pathway to promote trafficking away from the trans-Golgi [80]. WHAMM and JMY also both function in multiple aspects of autophagy. WHAMM binds to the phospholipid PI(3)P and stimulates the Arp2/3 complex to accelerate lipidation of LC3-family proteins during autophagosome biogenesis [82]; WHAMM additionally drives Arp2/3-dependent autophagosome movement [81] and autolysosome remodeling [84]. JMY binds to LC3 and polymerizes actin at autophagosomes during their maturation [32] and actin-based motility [28]. While it is reasonable to assume that the functions of WHAMM and 
JMY in secretion and autophagy help sustain cells during normal growth and allow them to adapt to conditions of nutritional stress, the fact that both factors also enable cell death indicates that they function as pivotal players in the cellular responses to multiple other stressors including genotoxic insults.

Following etoposide-induced DNA damage, parental HAP1 cells executed an immediate p53-dependent cell death program. In contrast, JMY or WHAMM knockout cells showed significant reductions in the terminal apoptosis phenotypes of phosphatidylserine externalization and membrane permeabilization. Further comparisons of JMY, WHAMM, and WHAMM/ JMY knockout cells revealed that an individual WHAMM deficiency results in partial apoptotic deficits, whereas JMY ablation, either alone or in conjunction with WHAMM, causes a more severe defect in apoptosis-one equivalent to a loss of $\mathrm{p} 53$.

Importantly, cells lacking JMY or WHAMM displayed inefficiencies and/or kinetic delays in multiple apoptotic processes, including the mitochondrial export of cyto $c$, caspase activation, and effector caspase cleavage of target proteins. These results indicate that both cytoskeletal regulators are key participants in a rapid, intrinsic, p53-dependent cell death pathway, with JMY acting as the more prominent contributor. They further suggest that JMY and WHAMM function at one or more steps in the apoptotic pathway that take place after the recognition of DNA damage and arrest of cell proliferation, including during transcriptional reprogramming, mitochondrial permeabilization, apoptosome assembly, and caspase cleavage/activation.

Under normal cell culture conditions, JMY is found predominantly in the cytosol [27,28], but in response to DNA damage, it accumulates in the nucleus while still maintaining a cytosolic presence [29,30]. At steady-state, WHAMM is mostly associated with cytoplasmic membrane-bound organelles, although it displays a nuclear localization in a small subpopulation of cells [37]. Such observations are consistent with the existence of both cytoplasmic and nuclear roles for these proteins in apoptosis. JMY was previously shown to interact with the stressresponse protein Strap, the acetyltransferase p300, and p53 [24,31]. p300 is one of many cofactors known to modify p53 to promote the transcription of genes necessary for initiating cell cycle arrest and stimulating pro-death pathways in response to cell damage [26,85-87]. While the precise function of JMY in a complex with Strap, p300, and p53 is unknown, co-overexpression of JMY with p53, or with p53 plus $\mathrm{p} 300$, augments $B A X$ transcription in several epithelial cell contexts $[24,29,79]$, and introduction of a JMY siRNA into p53-overexpressing cells limits $B A X$ induction [29]. However, our current work suggests that the activity of JMY in transcriptional regulation via p53 may not be the primary apoptotic driver following DNA damage.

p53 shuttles between the cytoplasm and nucleus, and although it has pro-apoptotic functions in the cytosol $[88,89]$, its most extensively characterized activities are as a nuclear transcription factor $[43,90,91]$. In our experiments, etoposide-induced increases in the overall abundance, nuclear accumulation, phosphorylation, and acetylation of p53 occurred in the presence or absence of JMY. Moreover, JMY inactivation had little effect on transcriptional upregulation of the p53 target $C D K N 1 A$, which encodes the key cell cycle inhibitor p21. In fact, JMY-deficient cells exhibited a prolonged arrest in response to DNA damage, indicating that JMY is not necessary for the gene expression changes that stop proliferation. These results collectively support the idea that JMY participates in only a subset of the p53-mediated transcriptional responses to genotoxic stress.

Given the speed and efficiency with which p53- and JMY-proficient parental cells underwent apoptosis, we hypothesized that they constitutively express a pool of potentially apoptotic factors that enable the cells to respond rapidly to DNA damage. Indeed, global and targeted gene expression profiling experiments implied that inactivation of $J M Y$ did not adversely affect the expression of common apoptosis regulators either before or after etoposide exposure. 
However, it was striking that the JMY knockout cells experienced a significant upregulation of RHOD, which encodes a small G-protein previously shown to interact with WHAMM $[45,46]$. RhoD has wide-ranging functions in regulating actin dynamics at the plasma membrane, endosomes, and Golgi, and in influencing cell proliferation [45-57]. While the selective pressures that led to greater RHOD expression in two out of the three JMY knockout cell lines are unknown, we nevertheless reasoned that increased RhoD levels may be part of a compensatory pro-survival mechanism that allows cells to better tolerate a permanent JMY mutation. Consistent with this possibility, RhoD depletion or deletion experiments resulted in more necrosis and enhanced apoptotic responses-the opposite phenotype of JMY- or WHAMM-depleted cells. These findings reveal complex relationships among two actin nucleation factors and one small G-protein during cell death and survival (S12 Fig).

Given that the best understood molecular behaviors of JMY and WHAMM reside in their abilities to promote actin assembly in the cell cytoplasm, we tested whether the Arp2/3 complex was also important for the execution of apoptosis. Indeed, RNAi-mediated depletion or pharmacological inhibition of the Arp2/3 complex also impaired apoptosis, and JMY truncations that cannot activate Arp2/3 failed to increase the apoptotic capacity of JMY knockout cells. Most notably, wild type and actin polymerization-deficient mutants of JMY were both able to congregate into discrete cytosolic structures, but only the polymerization-proficient protein generated distinct juxtanuclear zones containing actin filaments, active caspase-3, and cytochrome $c$. In light of these observations, we propose that JMY-mediated actin assembly is required for creating cytoplasmic territories that direct the activation of executioner caspase-3 by cytochrome $c$-containing apoptosomes (S12 Fig). The structural and biophysical properties of apoptosomes have begun to come into focus $[38,61,92]$, yet their cell biological characteristics remain less clear. Since JMY clusters form less frequently in $\mathrm{WHAMM}^{\mathrm{KO}}$ cells and with different frequencies depending on RhoD and its nucleotide-bound state, it will be important to gain a better understanding of the physical connections among RhoD, WHAMM, JMY, Arp2/3, and actin, and how they impact the organization and function of apoptosomes and caspases.

Continuing to define the roles of different elements of the actin assembly and regulatory machinery in cellular adaptations to endogenous or exogenous stress could provide new avenues for understanding tumorigenesis. The Arp $2 / 3$ complex and WASP-family members influence cell motility $[13,14]$, and elevated levels of nucleation factors are associated with increased metastasis $[93,94]$, indicating that such actin cytoskeletal proteins have proto-oncogenic features. Similarly, the functions of WHAMM and JMY in autophagy $[32,81,82]$ could enable cancer cells to better survive in diverse physiological environments and in response to chemotherapy $[95,96]$. However, our current results describing apoptotic requirements for JMY and WHAMM support the idea that these factors also possess key tumor-suppressive features. TP53 is well known as the most commonly mutated gene in human cancers, and mutations that inactivate $\mathrm{p} 53$ or other p53-associated proteins are linked to poor prognoses [9799]. Interestingly, JMY expression also appears to be lost in several B-cell lymphomas and invasive carcinomas [100]. Given the new positions of JMY and WHAMM as important players in p53-dependent apoptotic pathways, a greater understanding of how their actin nucleation, proto-oncogenic, and tumor-suppressive activities are coordinated will likely shed further light on how programmed cell death mechanisms are impacted by the cytoskeleton.

\section{Materials and methods}

\section{Ethics statement}

Research with biological materials in the Campellone Lab was approved by the UConn Institutional Biosafety Committee. This study did not include research with human subjects or live 
animals. Human cell lines were acquired from Horizon Genomics or the UC Berkeley cell culture facility as described below.

\section{Biological materials}

Cell lines are listed in S1 Table, nucleic acids are listed in S2 Table, and key reagents are listed in S3 Table. HAP1 cells are nearly-haploid fibroblast-like cells that contain an immortalizing BCR-ABL fusion and a single copy of all chromosomes except for a heterozygous 30Mb fragment of chromosome 15, which is integrated within the long arm of chromosome 19 [33,101]. This diploid portion encompasses 330 genes, including WHAMM. CRISPR/Cas9-engineered eHAP cells were derived from the HAP1 line and are fully haploid [35]. In the current study, CRISPR/Cas9-mediated recombination using guide RNAs against target genes resulted in frameshift and/or splicing mutations (S1 Table and S3 Fig) which were confirmed by DNA sequencing (Horizon Genomics). HAP1 cells were used for mutagenesis of JMY, WASL (encoding N-WASP), WASF1 (WAVE1), WASF2 (WAVE2), WASF3 (WAVE3), BRK1 (WAVE Complex), CCDC53 (WASH Complex), and CTTN (Cortactin), while eHAP cells were used for mutagenesis of WHAMM and RHOD. The latter two cell lines were made in an eHAP background due to the WHAMM diploidy in HAP1 cells, and because under normal culture conditions RHOD transcript was detectable in eHAP but not HAP1 cells (Horizon Genomics). One of the WHAMM mutant cell lines $\left(\mathrm{WHAMM}^{\mathrm{KO}-2}\right.$ ) was studied previously [82], and was used to make the WHAMM/JMY ${ }^{\mathrm{DKO}}$ cell lines. Attempts to generate WASH1 $\mathrm{KO}$ cells were unsuccessful, as all viable clones contained in-frame mutations (Horizon Genomics). HAP1 cell derivatives were cultured in Iscove's Modified Dulbecco's Medium (IMDM) supplemented with $10 \%$ fetal bovine serum (FBS) and penicillin-streptomycin. U2OS and HeLa cells (UC Berkeley cell culture facility) were cultured in Dulbecco's Modified Eagle's Medium (DMEM) supplemented with 10\% FBS and antibiotic-antimycotic. All cell lines were grown at $37^{\circ} \mathrm{C}$ in $5 \% \mathrm{CO}_{2}$. All assays were performed using cells that had been in active culture for 2-10 trypsinized passages.

\section{Transgene expression}

For JMY cloning (S2 Table), DNA fragments were amplified from cDNA templates by PCR, digested, and ligated into the BamHI and NotI restriction sites of pKC425 [102]. JMY ${ }^{\mathrm{WT}}$ contains amino acids 1-983 of murine JMY, JMY ${ }^{\Delta W W W}$ contains amino acids 1-856/934-983, and $J_{M Y}{ }^{\Delta C A}$ contains amino acids 1-941. For RhoD cloning (S2 Table), a BamHI-EcoRI restriction fragment from GST-RhoD [45] was inserted into the BglII and EcoRI sites of pKC-LAP-C1 [37]. RhoD ${ }^{\mathrm{WT}}$ contains amino acids $1-210$ of murine RhoD, and $\mathrm{RhoD}^{\mathrm{DN}}$ harbors a T31N mutation that was introduced by PCR-based site-directed mutagenesis. Plasmids were maintained in E.coli XL-1 Blue (Stratagene). For rescue studies, JMY ${ }^{\mathrm{KO}-1 \mathrm{~A}}$ cells cultured in 12-well plates were transfected with $2 \mu \mathrm{g}$ of linearized plasmid encoding GFP or GFP-JMY derivatives using LipofectamineLTX (Invitrogen). 24h later, the cells were transferred to media containing $1.5 \mathrm{mg} / \mathrm{mL}$ G418 for 12-16 days. Surviving colonies were collected, expanded in 24-well plates, 6-well plates, and ultimately T-25 flasks prior to cryopreservation. Upon reanimation, G418 concentrations were reduced stepwise to $1.0 \mathrm{mg} / \mathrm{mL}, 0.5 \mathrm{mg} / \mathrm{mL}$, and $350 \mu \mathrm{g} / \mathrm{mL}$ in 6 -well plates. The cell populations were subjected to experimental manipulations within 5 passages in media containing $350 \mu \mathrm{g} / \mathrm{mL}$ G418. For transient expression, U2OS cells were transfected in 6-well plates with 500ng of DNA prior to reseeding onto $12 \mathrm{~mm}$ glass coverslips in 24-well plates and fixing as described below. Transfection increased cell death in Fig 10. 


\section{Chemical treatments and RNA transfections}

Cells were treated with different concentrations of etoposide (Sigma Aldrich) diluted from an initial stock of 10mM in DMSO or with $100 \mu \mathrm{M}$ CK666 (Millipore) from a 100mM stock. Equivalent volumes of DMSO were used as controls. For RNA-seq experiments, the control condition consisted of regular media, while the treated condition consisted of media in which the etoposide powder was dissolved directly to $5 \mu \mathrm{M}$. For JMY rescue experiments, to be able to detect cleaved caspase- 3 in the $\mathrm{JMY}^{\mathrm{KO}}$ cell line, etoposide was dissolved to $10 \mu \mathrm{M}$. For RNAi experiments, cells were grown in 6-well plates for $24 \mathrm{~h}$, transfected with $40 \mathrm{nM}$ siRNAs (S2 Table) using RNAiMAX (Invitrogen), incubated in growth media for 24h, reseeded into 6-well plates and 24-well glass-bottom plates (MatTek), and incubated for an additional 24h. Cells cultured in 6-well plates were collected and processed for immunoblotting or RT-PCR, and cells cultured in 24-well plates were used in live fluorescence microscopy assays.

\section{RT-PCR and RNA-sequencing}

For RT-PCRs, approximately $10^{6}$ cells were seeded in 6-well plates, and for RNA-seq $2.5 \times 10^{6}$ cells were seeded in $6 \mathrm{~cm}$ dishes. After $24 \mathrm{~h}$ of growth, cells were subjected to control-, DMSO-, or etoposide-containing media changes and rinsed with phosphate buffered saline (PBS). RNA was isolated using TRIzol reagent (Ambion), followed by a chloroform extraction, isopropanol precipitation, and 75\% ethanol wash before resuspending RNA in water. For RT-PCRs, RNA was reverse transcribed into cDNA using Superscript III RT (Invitrogen) and subsequently amplified using Taq polymerase (New England Biolabs) and gene-specific primers (S2 Table). Primers were designed to amplify $\sim 230-460 \mathrm{bp}$ products from each cDNA template. After agarose gel electrophoresis, band intensities for $C D K N 1 A, W H A M M$, and $R H O D$ were quantified using ImageJ software [103] and normalized to $\beta$-ACTIN and/or GAPDH bands for each sample. For RNA-seq, Illumina cDNA library preparation was based on the Illumina TruSeq Stranded mRNA sample preparation guide. Total reads from RNA-seq were aligned with TopHat, and differential expression was calculated with the CuffLinks/CuffDiff program. Gene expression values were given as Fragments Per Kilobase of transcript per Million mapped reads (FPKM), differential expression was calculated as the Log2(FPKM ratio JMY ${ }^{\mathrm{KO}-}$ $\left.{ }^{1 \mathrm{~A}}: \mathrm{HAP} 1\right)$, and data from 3 independent experiments were merged. When comparing the transcriptomic changes that occurred in HAP1 or JMY ${ }^{\mathrm{KO}-1 \mathrm{~A}}$ lines upon etoposide treatment, differential expression was calculated as the Log2(FPKM Etoposide:Control) for each cell line and data from 2 independent etoposide experiments were merged. Volcano plots were generated by plotting the -Log10(q-value) against Log2(FPKM ratio) using Microsoft Excel software. The data summarized in this publication can be found in Supporting Information described below.

\section{Immunoblotting and quantification}

Detached cells were collected from 6-well plates and combined with adherent cells in PBS containing EDTA, centrifuged, washed with PBS, and centrifuged again to ensure collection of all live and dead material. Cell pellets were resuspended in lysis buffer (20mM HEPES pH 7.4, $100 \mathrm{mM} \mathrm{NaCl}, 1 \%$ Triton X-100, $1 \mathrm{mM} \mathrm{Na}_{3} \mathrm{VO}_{4}, 1 \mathrm{mM} \mathrm{NaF}$, plus $1 \mathrm{mM} \mathrm{PMSF}$, and $10 \mu \mathrm{g} / \mathrm{ml}$ each of aprotinin, leupeptin, pepstatin, and chymostatin), diluted in SDS-PAGE sample buffer, boiled, centrifuged, and subjected to SDS-PAGE before transfer to nitrocellulose membranes (GE Healthcare). Membranes were blocked in PBS + 5\% milk (PBS-M) before being probed with primary antibodies (S3 Table) diluted in PBS-M overnight at $4^{\circ} \mathrm{C}$ plus an additional $2-3 \mathrm{~h}$ at room temperature. Membranes were rinsed twice with PBS and washed thrice with PBS $+0.5 \%$ Tween-20 (PBS-T). Membranes were then probed with secondary antibodies 
conjugated to IRDye-800, IRDye-680, or horseradish peroxidase (S3 Table) and diluted in PBS-M. Membranes were again rinsed with PBS and washed with PBS-T. Blots were imaged using a LI-COR Odyssey Fc imaging system. Band intensities were determined using the Analysis tool in LI-COR Image Studio software, and quantities of proteins-of-interest were normalized to tubulin, actin, and/or GAPDH loading controls.

\section{Apoptosis and caspase activation assays}

For live fluorescence-based assays, approximately $2.5 \times 10^{5}$ cells were seeded into 24 -well glassbottom plates and allowed to grow for $24 \mathrm{~h}$ prior to DMSO or etoposide treatments. For endpoint apoptosis assays, Alexa488-AnnexinV (Invitrogen), Propidium Iodide (Invitrogen), and Hoechst (Thermo Scientific) were added directly to the media (S3 Table) and incubated for $15 \mathrm{~min}$ at $37^{\circ} \mathrm{C}$ in $5 \% \mathrm{CO}_{2}$. For caspase activation assays, CellEvent Caspase-3/7 Detection Reagent (Invitrogen) and Hoechst were added to the media and incubated for 30min. All live imaging was performed at $37^{\circ} \mathrm{C}$ as described below. For mitochondrial visualization in Fig 9, MitoTracker Red (Invitrogen) was added for 30min prior to fixation.

\section{Immunostaining assays}

For immunofluorescence microscopy, approximately $2.5 \times 10^{5}$ cells were seeded onto $12 \mathrm{~mm}$ glass coverslips in 24 -well plates and allowed to grow for $24 \mathrm{~h}$. After DMSO or etoposide treatments, cells were washed with PBS, fixed in $2.5 \%$ or $3.7 \%$ paraformaldehyde (PFA) in PBS for $30 \mathrm{~min}$, washed, permeabilized with $0.1 \%$ TritonX-100 in PBS, washed, and incubated in blocking buffer ( $1 \% \mathrm{FBS}+1 \%$ bovine serum albumin (BSA) $+0.02 \% \mathrm{NaN}_{3}$ in PBS) for a minimum of $15 \mathrm{~min}$. Cells were probed with primary antibodies (S3 Table) diluted in blocking buffer for $45 \mathrm{~min}$. Cells were washed and treated with AlexaFluor-conjugated secondary antibodies, DAPI, and/or AlexaFluor-conjugated phalloidin (S3 Table) for $45 \mathrm{~min}$, followed by washes and mounting in Prolong Gold anti-fade reagent (Invitrogen).

\section{Fluorescence microscopy}

All live and fixed images were captured using a Nikon Eclipse Ti inverted microscope with Plan Apo 100X/1.45, Plan Apo 60X/1.40, or Plan Fluor 20x/0.5 numerical aperture objectives using an Andor Clara-E camera and a computer running NIS Elements software. Live cell imaging was performed in a $37^{\circ} \mathrm{C}$ chamber (Okolab). All cells were viewed in multiple focal planes, and Z-series were captured at $0.2-0.4 \mu \mathrm{m}$ steps. Images presented in the figures represent one slice or two-slice projections. All images were processed and/or analyzed using ImageJ [103].

\section{Image processing and quantification}

The ImageJ Cell Counter plugin was used for live apoptosis or caspase-3/7 activation assays, and for fixed cytochrome $c$, cleaved caspase-3, or JMY staining assays by manually counting the total number of cells in the Hoechst or DAPI channel and the number of cells that were positive for AnnV fluorescence, AnnV fluorescence plus nuclear PI fluorescence, nuclear PI fluorescence, nucleic acid-associated DEVD reporter fluorescence, cytosolic non-mitochondrial cytochrome $c$ staining, clustered cleaved caspase-3 staining, and cytosolic punctate cytochrome $c$ or JMY staining. For analyses of nuclear $\gamma \mathrm{H} 2 \mathrm{AX}$, p21, JMY, or actin levels, the Threshold, Watershed, and Analyze tools were used in the DAPI channel to separate individual nuclei, and the ROI Manager Measure tool was used in the $\gamma \mathrm{H} 2 \mathrm{AX}, \mathrm{p} 21$, JMY, or actin channels to measure the mean fluorescence intensity per nucleus. To count the number of 
$\gamma \mathrm{H} 2 \mathrm{AX}$ foci per nucleus, the Find Maxima and ROI Manager Measure tools were used in the $\gamma \mathrm{H} 2 \mathrm{AX}$ channel. For analyses of total cellular p53, JMY, or actin levels, the Selection tool was used in the phalloidin channel to select individual cells, and the Measure tool was used in the p53, JMY, or actin channel to measure the mean fluorescence intensity per cell. For analyses of cytoplasmic JMY or actin levels, the nuclear intensity was subtracted from the total intensity for individual cells. Pixel intensity plots were generated using the Plot Profile tool. Lines were drawn through mitochondria- or JMY-rich regions after identification in the AIF/MitoTracker or JMY channels.

\section{Reproducibility and statistics}

All conclusions were based on observations made from at least 3 separate experiments and quantifications were based on data from 3-5 representative experiments, except where noted in the Figure Legends. To capture a breadth of apoptotic phenotypes, multiple fields-of-view containing cells at different densities were imaged. The sample size used for statistical tests was the number of times an experiment was performed, except where noted in the Legends. Statistical analyses were performed using GraphPad Prism software. Statistics on data sets with 3 or more conditions were performed using ANOVAs followed by Tukey's post-hoc test unless otherwise indicated. $\mathrm{P}$-values for data sets comparing 2 conditions were determined using unpaired t-tests unless otherwise noted. P-values $<0.05$ were considered statistically significant. Numerical data underlying graphs or summary statistics are shown in S1 and S2 Datasets.

\section{Supporting information}

\section{S1 Table. Cell Lines.}

(PDF)

\section{S2 Table. RNA and DNA.}

(PDF)

S3 Table. Immunofluorescence and immunoblotting reagents. (PDF)

S1 Fig. Analyses of WASP-family knockout cell lines uncover roles for JMY and WHAMM in apoptosis. (A) HAP1, WAVE1 ${ }^{\mathrm{KO}}$, WAVE2 ${ }^{\mathrm{KO}}, \mathrm{WAVE} 3^{\mathrm{KO}}, \mathrm{WAVE} \mathrm{Complex}^{\mathrm{KO}}\left(\mathrm{BRK} 1^{\mathrm{KO}}\right)$, $\mathrm{N}-\mathrm{WASP}{ }^{\mathrm{KO}}$, Cortactin $^{\mathrm{KO}}$, and WASH Complex ${ }^{\mathrm{KO}}\left(\mathrm{CCDC}^{\mathrm{KOO}}{ }^{\mathrm{K}}\right)$ cells were collected, lysed, and immunoblotted with different combinations of antibodies to WAVE1, WAVE2, N-WASP, Cortactin, WASH, and Strumpellin. Tubulin, actin, and GAPDH were used as loading controls. The relative quantities of WASP-family proteins in each cell line (shown beneath their respective blots) were determined by densitometry and normalization to the loading controls in these representative experiments confirming the WASP-family member deficiencies. (B) HAP1, $\mathrm{WAVE}^{\mathrm{KO}}{ }^{\mathrm{K}}, \mathrm{WAVE} 2^{\mathrm{KO}}, \mathrm{WAVE} 3^{\mathrm{KO}}$, and WAVE Complex ${ }^{\mathrm{KO}}$ cells were fixed and stained with phalloidin (F-actin; green) and DAPI (DNA; blue). Scale bar, 100 $\mu \mathrm{m}$. Note the rounder morphologies of the WAVE Complex ${ }^{\mathrm{KO}}$ cells compared to the other cells. (C) Parental (HAP1, eHAP) and WASP-family knockout $\left(\mathrm{JMY}^{\mathrm{KO}-1 \mathrm{~A}}, \mathrm{WHAMM}^{\mathrm{KO}-2}, \mathrm{~N}^{-W A S P}{ }^{\mathrm{KO}}, \mathrm{WAVE}^{\mathrm{KO}}\right.$, $\mathrm{WAVE}^{\mathrm{KO}}{ }^{\text {, WAVE}} 3^{\mathrm{KO}}$, WAVE Complex ${ }^{\mathrm{KO}}$, WASH Complex ${ }^{\mathrm{KO}}$, Cortactin $^{\mathrm{KO}}$ ) cells were treated with DMSO or $5 \mu \mathrm{M}$ etoposide for $6 \mathrm{~h}$ and stained with Alexa488-AnnexinV (AnnV; green), Propidium Iodide (PI; magenta), and Hoechst (DNA; blue). Scale bar, $100 \mu \mathrm{m}$. These panels depict some of the imaging data that was incorporated into the summary graph in Fig 1. (TIF) 
S2 Fig. Cells specifically lacking the WASP-family members JMY or WHAMM undergo less apoptosis following DNA damage. (A) Parental (HAP1, eHAP) and WASP-family knockout (JMY ${ }^{\mathrm{KO}-1 \mathrm{~A}}$, WHAMM ${ }^{\mathrm{KO}-2}$, WAVE1 ${ }^{\mathrm{KO}}$ ) cells were treated with DMSO or $5 \mu \mathrm{M}$ etoposide for $6 \mathrm{~h}$ and stained with Alexa488-AnnV (green), PI (magenta), and Hoechst (DNA; blue). Scale bar, $100 \mu \mathrm{m}$. These panels display the individual grayscale channels that comprise the merged images in Fig 1. (B-C) Representative examples of AnnV-negative/PI-negative $\left(\mathrm{AnnV}^{-} \mathrm{PI}^{-}\right)$non-apoptotic, $\mathrm{AnnV}$-positive/PI-negative $\left(\mathrm{AnnV}^{+} \mathrm{PI}^{-}\right)$early apoptotic, AnnV/PI double-positive $\left(\mathrm{AnnV}^{+} \mathrm{PI}^{+}\right)$late apoptotic, or AnnV-negative/PI-positive $\left(\mathrm{AnnV}^{-} \mathrm{PI}^{+}\right)$ necrotic cells are shown. Arrowheads in C highlight examples of hoechst-stained DNA condensation and nuclear fragmentation in HAP1 cells. Scale bars, $25 \mu \mathrm{m}$. (TIF)

S3 Fig. JMY, WHAMM, RhoD, and WHAMM/JMY knockout cell lines contain loss-offunction mutations derived from frameshifts or altered splicing. (A) HAP1 cells were CRISPR/Cas9 engineered using guide RNAs to the first or second exon of the JMY gene. A $17 \mathrm{bp}$ deletion in JMY ${ }^{\mathrm{KO}-1 \mathrm{~A}}$, a $10 \mathrm{bp}$ deletion in $\mathrm{JMY}^{\mathrm{KO}-1 \mathrm{~B}}$, and a $2 \mathrm{bp}$ deletion in $\mathrm{JMY}^{\mathrm{KO}-2}$ resulted in frameshifts and premature stop codons. (B) eHAP cells were treated with guide RNAs to the second or fourth exon of the WHAMM gene. A 10bp deletion in WHAMM ${ }^{\mathrm{KO}-2}$ and a 7 bp deletion in WHAMM ${ }^{\mathrm{KO}-4}$ resulted in frameshifts and premature stop codons. (C) eHAP cells were treated with guide RNAs to the second exon of the RHOD gene. A 22bp deletion in $\mathrm{RhoD}^{\mathrm{KO}-2 \mathrm{~A}}$ is predicted to result in defective splicing (not shown) and/or a frameshift (shown), while a 1 bp deletion in $\mathrm{RhoD}^{\mathrm{KO}-2 \mathrm{~B}}$ results in a simple frameshift and premature stop codon. (D) WHAMM ${ }^{\mathrm{KO}-2}$ cells were treated with guide RNAs to the first or second exon of the JMY gene. A 16bp deletion in WHAMM/JMY ${ }^{\mathrm{DKO}-1}$ and a 35bp deletion in WHAMM/ $\mathrm{JMY}^{\mathrm{DKO}-2}$ resulted in frameshifts and premature stop codons.

S4 Fig. Parental and knockout cell lines exhibit high levels of $\gamma \mathrm{H} 2 \mathrm{AX}$ expression and foci in response to DNA damage. (A) HAP1, eHAP, and knockout cell lines were treated with DMSO or $5 \mu \mathrm{M}$ etoposide for $6 \mathrm{~h}$ before immunoblotting with anti- $\gamma \mathrm{H} 2 \mathrm{AX}$ and anti-tubulin antibodies. (B) HAP1, eHAP, and JMY ${ }^{\mathrm{KO}}$ cells were treated with DMSO or etoposide, fixed, and stained with a $\gamma \mathrm{H} 2 \mathrm{AX}$ antibody (green), phalloidin (F-actin; magenta), and DAPI (DNA; blue). Representative images show increased nuclear $\gamma \mathrm{H} 2 \mathrm{AX}$ foci upon etoposide treatment. Scale bar, $25 \mu \mathrm{m}$. (C) Nuclear $\gamma \mathrm{H} 2 \mathrm{AX}$ fluorescence intensity was calculated using ImageJ ( $\mathrm{n}=48-70$ nuclei per sample from a representative experiment). (D) The number of $\gamma \mathrm{H} 2 \mathrm{AX}$ foci per nucleus was determined using Image ( $n=54-81$ nuclei per sample from a representative experiment). Significance stars are in reference to the etoposide-treated eHAP cell line. Fewer $\gamma \mathrm{H} 2 \mathrm{AX}$ foci were observed in etoposide-treated $\mathrm{RhoD}^{\mathrm{KO}}$ samples because of the loss of some dead cells prior to fixation to the slide. ${ }^{*} \mathrm{p}<0.05$ (ANOVA, Tukey post-hoc tests). (TIF)

S5 Fig. Transient WHAMM or JMY depletion in multiple cell lines results in less apoptosis. (A) eHAP or HAP1 cells were treated with control siRNAs or independent siRNAs for the WHAMM gene before collecting RNA and performing RT-PCR with primers for WHAMM and GAPDH. (B) The cells were treated with DMSO or $5 \mu \mathrm{M}$ etoposide for $6 \mathrm{~h}$ and stained with Alexa488-AnnV, PI, and Hoechst. The \% of AnnV-positive cells was calculated and each bar represents the mean \pm SD from 3 experiments ( $n=1,998-4,697$ cells per bar). Significance stars refer to comparisons to the siControl samples. (C) U2OS or HeLa cells were treated with control siRNAs or independent siRNAs for the JMY gene before immunoblotting with antibodies to JMY and tubulin. (D) The cells were treated with DMSO or $10 \mu \mathrm{M}$ etoposide for $6 \mathrm{~h}$ 
and stained with Alexa488-AnnV (green), PI (magenta), and Hoechst (blue). Scale bar, $100 \mu \mathrm{m}$. (E) The \% of AnnV-positive cells was calculated as in panel (B) $(n=476-866$ cells per bar). (F) JMY band intensities on immunoblots were normalized to tubulin bands and plotted against the \% of AnnV-positive cells. Each point represents the mean $\pm \mathrm{SD}$ from 3 images in a given experiment ( $n=69-440$ cells per point). The slopes in the linear trendline regression equations for etoposide-treated samples (U2OS: $\mathrm{Y}=38.31 \mathrm{X}-3.86$; HeLa: $\mathrm{Y}=35.16 \mathrm{X}+7.13$ ) were significantly non-zero $\left(\mathrm{p}<0.001, \mathrm{R}^{2}>0.74\right)$. $\mathrm{AU}=$ Arbitrary Units. ${ }^{* *} \mathrm{p}<0.01 ;{ }^{* * *} \mathrm{p}<0.001$ (ANOVA, Tukey post-hoc tests).

(TIF)

S6 Fig. Transient depletion of $\mathrm{p} 53$ results in less apoptosis in eHAP and WHAMM ${ }^{\mathrm{KO}}$ cells following DNA damage. (A) eHAP and WHAMM ${ }^{\mathrm{KO}-2}$ cells were treated with control siRNAs or independent siRNAs for the TP53 gene before immunoblotting with antibodies to p53 and tubulin. (B) The cells were treated with DMSO or $5 \mu \mathrm{M}$ etoposide for $6 \mathrm{~h}$ and stained with Alexa488-AnnV, PI, and Hoechst. The \% of AnnV-positive cells was calculated and each bar represents the mean \pm SD from 3 experiments ( $n=2,212-3,846$ cells per bar). (C) p53 band intensities on immunoblots were normalized to tubulin bands and plotted against the $\%$ of AnnV-positive cells. Each point represents the mean \pm SD from 3 fields-of-view in a given experiment ( $\mathrm{n}=576-1,509$ cells per point). The slopes in the linear trendline regression equations for etoposide-treated samples (eHAP: $\mathrm{Y}=35.44 \mathrm{X}+10.99$; $\mathrm{WHAMM}^{\mathrm{KO}}: \mathrm{Y}=13.28 \mathrm{X}$ $+11.81)$ were significantly non-zero $\left(\mathrm{p}<0.001\right.$, eHAP: $\mathrm{R}^{2}=0.87$; $\left.\mathrm{WHAMM}^{\mathrm{KO}}: \mathrm{R}^{2}=0.47\right)$. $\mathrm{AU}=$ Arbitrary Units. These studies accompanied the experiments in Fig $5 .{ }^{* *} \mathrm{p}<0.01$; ${ }^{* * *} \mathrm{p}<0.001$ (ANOVA, Tukey post-hoc tests).

S7 Fig. JMY is not required for p53 stabilization, nuclear accumulation, phosphorylation, or acetylation. (A) HAP1 and JMY ${ }^{\mathrm{KO}}$ cells were treated with DMSO or $5 \mu \mathrm{M}$ etoposide for $6 \mathrm{~h}$ before immunoblotting with antibodies to $\mathrm{p} 53, \mathrm{p} 53^{\text {phospho-S15 }}, \mathrm{p} 53^{\text {acetyl-K382 }}, \mathrm{p} 53^{\text {phospho-S46, }}$ GAPDH, and tubulin. (B) HAP1 and JMY ${ }^{\mathrm{KO}}$ cells were treated with DMSO or etoposide for $6 \mathrm{~h}$ before being fixed and stained with a p53 antibody (green) and DAPI (DNA; blue). Scale bar, $30 \mu \mathrm{m}$. (C) Cellular p53 fluorescence intensities were measured in ImageJ and the total p53 intensity was normalized to the HAP1 DMSO sample. Each bar represents the mean \pm SD from 3 experiments $(n=196-343$ cells per timepoint). AU = Arbitrary Units. (TIF)

S8 Fig. JMY-knockout cells undergo a prolonged p21-associated proliferation arrest instead of rapid apoptosis following DNA damage. (A-C) HAP1 and JMY ${ }^{\mathrm{KO}}$ cells were treated with DMSO or $5 \mu \mathrm{M}$ etoposide for $6 \mathrm{~h}$ before washout (triangles) and replacement with regular media. Samples were stained with Alexa488-AnnV, PI, and Hoechst at the indicated time points. In (A-B), the total \# of cells (live and dead) was counted in ImageJ and normalized to the \# at $0 \mathrm{~h}$ for each sample. The total \# of cells is displayed as the fraction of live AnnV-negative $\left(\mathrm{AnnV}^{-}\right)$or apoptotic $\mathrm{AnnV}$-positive $\left(\mathrm{AnnV}^{+}\right)$cells $(\mathrm{n}=1,461-9,108$ cells per bar for DMSO; $\mathrm{n}=1,415-2,992$ cells per bar for etoposide). Panels (A) and (B) depict the same data in two different formats. In (C), the \% of AnnV-positive cells was calculated and each point represents the mean $\pm S D$ from 3 experiments. Significance stars refer to comparisons among the etoposide-treated samples. $\mathrm{RU}=$ Relative Units. (D) HAP1 and JMY ${ }^{\mathrm{KO}}$ cells were treated with DMSO or etoposide for $6 \mathrm{~h}$ before collecting RNA and performing RT-PCR with primers for CDKN1A and GAPDH. Agarose gel band intensities were quantified in ImageJ, and values for CDKN1A were normalized to GAPDH and plotted in the adjacent bar graph. AU = Arbitrary Units. (E) Cells were treated with DMSO or etoposide for $6 \mathrm{~h}$ before being fixed and stained 
with a p21 antibody (green) and DAPI (DNA; blue). Scale bar, 30 $\mu$ m. (F) Nuclear p21 fluorescence intensity was measured in ImageJ, and each point represents the mean \pm SD from 3 fields-of-view in a representative experiment $\left(\mathrm{n}=216-418\right.$ cells per point). ${ }^{* *} \mathrm{p}<0.01$; ${ }^{* * *} \mathrm{p}<0.001$ (ANOVA, Tukey post-hoc tests). (TIF)

S9 Fig. Expression of RhoD is turned on in JMY-knockout cells, and etoposide treatment does not cause a differential upregulation of pro-apoptotic genes. (A) RNA collected from $\mathrm{HAP} 1$ and JMY ${ }^{\mathrm{KO}}$ cells was subjected to mRNA sequencing analysis. FPKM values for individual genes with expression differences in JMY ${ }^{\mathrm{KO}-1 \mathrm{~A}}$ vs HAP1 samples of at least 2-fold and with a significance q-value of $<0.05$ are shown in dark red (turned on), pink (up-regulated), light blue (down-regulated), or dark blue (turned off). Each bar represents the mean value $\pm \mathrm{SD}$ from 3 independent RNA samples per genotype. (B) RNA collected from HAP1 and JMY ${ }^{\mathrm{KO}}$ cells treated with $5 \mu \mathrm{M}$ etoposide for $6 \mathrm{~h}$ was subjected to mRNA sequencing analysis and comparisons to control samples from (A). FPKM values for individual genes with expression differences of at least 2 -fold and with a significance q-value of $<0.05$ in etoposide vs controltreated HAP1 (gray bars) or JMY ${ }^{\mathrm{KO}-1 \mathrm{~A}}$ (purple bars) samples are shown. Each bar represents the mean value $\pm \mathrm{SD}$ from 2 independent RNA samples per genotype. Bolded black gene names indicate a $>2$-fold expression difference in both HAP1 and JMY ${ }^{\mathrm{KO}}$ cells, purple gene names indicate a $>2$-fold expression difference in $\mathrm{JMY}^{\mathrm{KO}}$ cells only, and gray gene names indicate a $>2$-fold expression difference in HAP1 cells only. Stars indicate differences of $>2$ in Log2(FPKM) values between HAP1 and JMY ${ }^{\mathrm{KO}}$ cells, with IL8 (in one replicate) and CCL20 (in both replicates) upregulated more in HAP1 cells, and TNF, EGR1, JUN, PLK2, and DDIT4 upregulated more in JMY ${ }^{\mathrm{KO}}$ samples.

S10 Fig. Expression of genes encoding actin nucleation factors, cell cycle arrest proteins, canonical apoptosis regulators, and representative small G-proteins. RNA collected from HAP1 and JMY ${ }^{\mathrm{KO}}$ cells was subjected to mRNA sequencing analysis as in Fig 6. Data for several classes of gene products involved in apoptosis or cytoskeletal regulation are shown. For etoposide-treated samples, genes related to TNF or other signaling pathways are also included. (PDF)

S11 Fig. RhoD-deficient cells display more frequent cytochrome $c$ release, exhibit more caspase cleavage, and undergo more apoptosis following DNA damage. (A) JMY ${ }^{\mathrm{KO}-1 \mathrm{~A}}$ cells were treated with control siRNAs or independent siRNAs for the RHOD gene before performing RT-PCRs with primers to RHOD, GAPDH, and $\beta$-ACTIN. (B) Cells were treated with DMSO or $5 \mu \mathrm{M}$ etoposide for $6 \mathrm{~h}$ and stained with Alexa488-AnnV, PI, and Hoechst. The $\%$ of AnnV-positive cells was calculated and displayed as the fraction of AnnV-positive/PI-negative $\left(\mathrm{AnnV}^{+} \mathrm{PI}^{-}\right)$or AnnV/PI double-positive $\left(\mathrm{AnnV}^{+} \mathrm{PI}^{+}\right)$cells. Significance stars refer to comparisons of total $\mathrm{AnnV}^{+}$counts for siControl vs siRhoD samples. The \% of AnnV-negative/PI-positive $\left(\mathrm{AnnV}^{-} \mathrm{PI}^{+}\right)$necrotic cells was also quantified. Each bar represents the mean $\pm \mathrm{SD}$ from 3 experiments ( $\mathrm{n}=3,166-4,998$ cells per sample). (C) RHOD band intensities were normalized to $\beta$-ACTIN and plotted versus the $\%$ of AnnV-positive cells. Each point represents the mean \pm SD from 3 fields-of-view in a given experiment ( $n=670-1,919$ cells per point). (D) eHAP and $\mathrm{RhoD}^{\mathrm{KO}}$ cells were treated with DMSO or etoposide and stained with Alexa488-AnnV

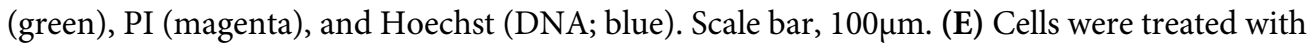
DMSO or etoposide, fixed, and stained with antibodies to detect cytochrome $c$ (Cyto $c$; green), AIF (Mito; magenta), and DAPI (DNA; blue). Scale bar, $25 \mu \mathrm{m}$. (F-G) Cells were treated with DMSO for $6 \mathrm{~h}$ or etoposide for 3 or $6 \mathrm{~h}$, and extracts were immunoblotted with antibodies to 
caspase-9 (Casp-9 ${ }^{\text {Pro }}$ and Casp- $9^{\text {Cleaved }}$ ), caspase-3 (Casp- $3^{\text {Cleaved }}$ ), and tubulin. (H) eHAP and $\mathrm{RhoD}^{\mathrm{KO}}$ cells were treated with DMSO or etoposide for $6 \mathrm{~h}$ and stained with caspase-3/7 green detection reagent (Cleaved DEVD; green) and Hoechst (DNA; blue), or fixed and stained with an antibody that recognizes active caspase-3 cleaved at Asp175 (Cleaved Casp-3; green) and DAPI (DNA; blue). Scale bars, $100 \mu \mathrm{m} .{ }^{*} \mathrm{p}<0.05,{ }^{* *} \mathrm{p}<0.01$ (ANOVA, Tukey post-hoc tests). (TIF)

S12 Fig. F-actin is reorganized in the cytosol of HAP1 cells in response to DNA damage. (A) HAP1 cells were treated with $5 \mu \mathrm{M}$ etoposide for $6 \mathrm{~h}$ before being fixed and stained with a JMY antibody (green), a cyto $c$ antibody (magenta), and DAPI (DNA; blue). Arrowheads and magnifications represent examples of juxtanuclear JMY and cyto $c$ puncta. Scale bars, $25 \mu \mathrm{m}$, $10 \mu \mathrm{m}$. (B) U2OS cells were treated with $10 \mu \mathrm{M}$ etoposide for $6 \mathrm{~h}$ before being incubated with MitoTracker (Mito; cyan), fixed, and stained with a JMY antibody (green), a cyto $c$ antibody (magenta), and phalloidin (F-actin; yellow). Arrowheads and magnifications depict clusters of JMY and cyto $c$ puncta in an F-actin territory. Scale bars, $25 \mu \mathrm{m}, 10 \mu \mathrm{m}$. (C) HAP1 and JMYKO cells were treated with $5 \mu \mathrm{M}$ etoposide for $6 \mathrm{~h}$ before being fixed and stained with a JMY antibody, DAPI, and either phalloidin to visualize F-actin or an actin antibody to visualize total actin. Nuclear and cytoplasmic F-actin, total actin, and JMY fluorescence intensities were measured in ImageJ and the total intensity was normalized to the HAP1 DMSO sample. Each bar represents the mean \pm SD from 2-4 experiments (F-actin: $n=106-163$ cells per bar; Total actin: $n=103-148$ cells per bar; JMY: $n=234-311$ cells per bar). Gray significance stars refer to comparisons of the cytoplasmic intensity to the DMSO samples and black significance stars refer to comparisons of the nuclear intensity to the DMSO samples. AU = Arbitrary Units. ${ }^{*} \mathrm{p}<0.05$, ${ }^{* *} \mathrm{p}<0.01$ (t-test). (D) Model for JMY, WHAMM, the Arp2/3 complex, F-actin, and RhoD in apoptosis. Line thickness reflects different degrees of apoptosis-related activities, line dashing represents a potential role for RhoD based on interactions shown in the literature. (TIF)

S1 Dataset. File containing the data underlying the summary graphs. (XLSX)

S2 Dataset. File containing the data underlying the RNA-seq figures. (XLSX)

\section{Acknowledgments}

We thank Bo Reese at the UConn Center for Genome Innovation for guidance with RNA-seq and analysis, Vanessa Vlaun for help with microscopy quantification, Frida Zink for help processing knockout cells, and L.T. Bear for support with experimental design. We also thank Katrina Velle, Aoife Heaslip, and Campellone Lab members for their comments on this paper.

\section{Author Contributions}

Conceptualization: Virginia L. King, Nathan K. Leclair, Kenneth G. Campellone.

Data curation: Virginia L. King, Nathan K. Leclair, Kenneth G. Campellone.

Formal analysis: Virginia L. King, Nathan K. Leclair, Kenneth G. Campellone.

Funding acquisition: Kenneth G. Campellone.

Investigation: Virginia L. King, Nathan K. Leclair, Alyssa M. Coulter, Kenneth G. Campellone. 
Methodology: Virginia L. King, Nathan K. Leclair, Alyssa M. Coulter, Kenneth G. Campellone.

Project administration: Kenneth G. Campellone.

Resources: Kenneth G. Campellone.

Supervision: Kenneth G. Campellone.

Validation: Virginia L. King, Nathan K. Leclair, Alyssa M. Coulter, Kenneth G. Campellone.

Visualization: Virginia L. King, Nathan K. Leclair, Kenneth G. Campellone.

Writing - original draft: Virginia L. King, Kenneth G. Campellone.

Writing - review \& editing: Virginia L. King, Nathan K. Leclair, Alyssa M. Coulter, Kenneth G. Campellone.

\section{References}

1. Kerr JF, Wyllie AH, Currie AR. Apoptosis: a basic biological phenomenon with wide-ranging implications in tissue kinetics. Br J Cancer. 1972; 26(4):239-57. https://doi.org/10.1038/bjc.1972.33 PMID: 4561027

2. Galluzzi L, Vitale I, Aaronson SA, Abrams JM, Adam D, Agostinis $P$, et al. Molecular mechanisms of cell death: recommendations of the Nomenclature Committee on Cell Death 2018. Cell Death Differ. 2018; 25(3):486-541. https://doi.org/10.1038/s41418-017-0012-4 PMID: 29362479

3. Dickens LS, Powley IR, Hughes MA, MacFarlane M. The 'complexities' of life and death: death receptor signalling platforms. Exp Cell Res. 2012; 318(11):1269-77. https://doi.org/10.1016/j.yexcr.2012. 04.005 PMID: 22542855

4. Tait SWG, Green DR. Mitochondrial regulation of cell death. Cold Spring Harb Perspect Biol. 2013; 5 (9): a008706. https://doi.org/10.1101/cshperspect.a008706 PMID: 24003207

5. von Karstedt S, Montinaro A, Walczak H. Exploring the TRAILs less travelled: TRAIL in cancer biology and therapy. Nat Rev Cancer. 2017; 17(6):352-66. https://doi.org/10.1038/nrc.2017.28 PMID: 28536452

6. Singh R, Letai A, Sarosiek K. Regulation of apoptosis in health and disease: the balancing act of BCL2 family proteins. Nat Rev Mol Cell Biol. 2019; 20(3):175-93. https://doi.org/10.1038/s41580-0180089-8 PMID: 30655609

7. Gourlay CW, Ayscough KR. The actin cytoskeleton: a key regulator of apoptosis and ageing? Nat Rev Mol Cell Biol. 2005; 6(7):583-9. https://doi.org/10.1038/nrm1682 PMID: 16072039

8. Desouza M, Gunning PW, Stehn JR. The actin cytoskeleton as a sensor and mediator of apoptosis. Bioarchitecture. 2012; 2(3):75-87. https://doi.org/10.4161/bioa.20975 PMID: 22880146

9. Campellone KG, Welch MD. A nucleator arms race: cellular control of actin assembly. Nat Rev Mol Cell Biol. 2010; 11(4):237-51. https://doi.org/10.1038/nrm2867 PMID: 20237478

10. Rottner K, Faix J, Bogdan S, Linder S, Kerkhoff E. Actin assembly mechanisms at a glance. J Cell Sci. 2017; 130(20):3427-35. https://doi.org/10.1242/jcs.206433 PMID: 29032357

11. Pollard TD, Blanchoin $L$, Mullins RD. Molecular mechanisms controlling actin filament dynamics in nonmuscle cells. Annu Rev Biophys Biomol Struct. 2000; 29: 545-76. https://doi.org/10.1146/ annurev.biophys.29.1.545 PMID: 10940259

12. Rotty JD, Wu C, Bear JE. New insights into the regulation and cellular functions of the ARP2/3 complex. Nat Rev Mol Cell Biol. 2013; 14(1):7-12. https://doi.org/10.1038/nrm3492 PMID: 23212475

13. Alekhina $O$, Burstein $E$, Billadeau DD. Cellular functions of WASP family proteins at a glance. J Cell Sci. 2017; 130(14):2235-41. https://doi.org/10.1242/jcs.199570 PMID: 28646090

14. Kabrawala S, Zimmer MD, Campellone KG. WHIMP links the actin nucleation machinery to Src-family kinase signaling during protrusion and motility. PLoS Genet. 2020; 16(3): e1008694. https://doi.org/ 10.1371/journal.pgen.1008694 PMID: 32196488

15. Derivery E, Sousa C, Gautier JJ, Lombard B, Loew D, Gautreau A. The Arp2/3 activator WASH controls the fission of endosomes through a large multiprotein complex. Dev Cell. 2009; 17(5):712-23. https://doi.org/10.1016/j.devcel.2009.09.010 PMID: 19922875

16. Jia D, Gomez TS, Metlagel Z, Umetani J, Otwinowski Z, Rosen MK, et al. WASH and WAVE actin regulators of the Wiskott-Aldrich syndrome protein (WASP) family are controlled by analogous structurally 
related complexes. Proc Natl Acad Sci U S A. 2010; 107(23):10442-7. https://doi.org/10.1073/pnas. 0913293107 PMID: 20498093

17. Schnoor M, Stradal TE, Rottner K. Cortactin: Cell Functions of A Multifaceted Actin-Binding Protein. Trends Cell Biol. 2018; 28(2):79-98. https://doi.org/10.1016/j.tcb.2017.10.009 PMID: 29162307

18. Kale J, Osterlund EJ, Andrews DW. BCL-2 family proteins: changing partners in the dance towards death. Cell Death Differ. 2018; 25(1):65-80. https://doi.org/10.1038/cdd.2017.186 PMID: 29149100

19. Opferman JT, Kothari A. Anti-apoptotic BCL-2 family members in development. Cell Death Differ. 2018; 25(1):37-45. https://doi.org/10.1038/cdd.2017.170 PMID: 29099482

20. Danial NN, Gramm CF, Scorrano L, Zhang C-Y, Krauss S, Ranger AM, et al. BAD and glucokinase reside in a mitochondrial complex that integrates glycolysis and apoptosis. Nature. 2003; 424 (6951):952-6. https://doi.org/10.1038/nature01825 PMID: 12931191

21. Cheng A, Arumugam TV, Liu D, Khatri RG, Mustafa K, Kwak S, et al. Pancortin-2 interacts with WAVE1 and Bcl-xL in a mitochondria-associated protein complex that mediates ischemic neuronal death. J Neurosci. 2007; 27(7):1519-28. https://doi.org/10.1523/JNEUROSCI.5154-06.2007 PMID: 17301160

22. Kang R, Tang D, Yu Y, Wang Z, Hu T, Wang H, et al. WAVE1 regulates Bcl-2 localization and phosphorylation in leukemia cells. Leukemia. 2010; 24(1):177-86. https://doi.org/10.1038/leu.2009.224 PMID: 19890377

23. Zhang Z, Wu B, Chai W, Cao L, Wang Y, Yu Y, et al. Knockdown of WAVE1 enhances apoptosis of leukemia cells by downregulating autophagy. Int J Oncol. 2016; 48(6):2647-56. https://doi.org/10. 3892/ijo.2016.3446 PMID: 27035872

24. Shikama N, Lee CW, France S, Delavaine L, Lyon J, Krstic-Demonacos M, et al. A novel cofactor for p300 that regulates the p53 response. Mol Cell. 1999; 4(3):365-76. https://doi.org/10.1016/s10972765(00)80338-x PMID: 10518217

25. Kastenhuber ER, Lowe SW. Putting p53 in Context. Cell. 2017; 170(6):1062-78. https://doi.org/10. 1016/j.cell.2017.08.028 PMID: 28886379

26. Hafner A, Bulyk ML, Jambhekar A, Lahav G. The multiple mechanisms that regulate $p 53$ activity and cell fate. Nat Rev Mol Cell Biol. 2019; 20(4):199-210. https://doi.org/10.1038/s41580-019-0110-x PMID: 30824861

27. Coutts AS, Boulahbel H, Graham A, La Thangue NB. Mdm2 targets the p53 transcription cofactor JMY for degradation. EMBO Rep. 2007; 8(1):84-90. https://doi.org/10.1038/sj.embor.7400855 PMID: 17170761

28. Hu X, Mullins RD. LC3 and STRAP regulate actin filament assembly by JMY during autophagosome formation. J Cell Biol. 2019; 218(1):251-66. https://doi.org/10.1083/jcb.201802157 PMID: 30420355

29. Coutts AS, Weston L, La Thangue NB. A transcription co-factor integrates cell adhesion and motility with the p53 response. Proc Natl Acad Sci U S A. 2009; 106(47):19872-7. https://doi.org/10.1073/ pnas.0906785106 PMID: 19897726

30. Zuchero JB, Belin B, Mullins RD. Actin binding to WH2 domains regulates nuclear import of the multifunctional actin regulator JMY. Mol Biol Cell. 2012; 23(5):853-63. https://doi.org/10.1091/mbc.E1112-0992 PMID: 22262458

31. Demonacos C, Krstic-Demonacos M, La Thangue NB. A TPR motif cofactor contributes to $p 300$ activity in the p53 response. Mol Cell. 2001; 8(1):71-84. https://doi.org/10.1016/s1097-2765(01)00277-5 PMID: 11511361

32. Coutts AS, La Thangue NB. Actin nucleation by WH2 domains at the autophagosome. Nat Commun. 2015; 6: 7888-. https://doi.org/10.1038/ncomms8888 PMID: 26223951

33. Kotecki M, Reddy PS, Cochran BH. Isolation and characterization of a near-haploid human cell line. Exp Cell Res. 1999; 252(2):273-80. https://doi.org/10.1006/excr.1999.4656 PMID: 10527618

34. Andersson BS, Collins VP, Kurzrock R, Larkin DW, Childs C, Ost A, et al. KBM-7, a human myeloid leukemia cell line with double Philadelphia chromosomes lacking normal c-ABL and BCR transcripts. Leukemia. 1995; 9(12):2100-8. PMID: 8609723

35. Essletzbichler P, Konopka T, Santoro F, Chen D, Gapp BV, Kralovics R, et al. Megabase-scale deletion using CRISPR/Cas9 to generate a fully haploid human cell line. Genome Res. 2014; 24 (12):2059-65. https://doi.org/10.1101/gr.177220.114 PMID: 25373145

36. Olbrich T, Mayor-Ruiz C, Vega-Sendino M, Gomez C, Ortega S, Ruiz S, et al. A p53-dependent response limits the viability of mammalian haploid cells. Proc Natl Acad Sci U S A. 2017; 114 (35):9367-72. https://doi.org/10.1073/pnas.1705133114 PMID: 28808015

37. Campellone KG, Webb NJ, Znameroski EA, Welch MD. WHAMM is an Arp2/3 complex activator that binds microtubules and functions in ER to Golgi transport. Cell. 2008; 134(1):148-61. https://doi.org/ 10.1016/j.cell.2008.05.032 PMID: 18614018 
38. Dorstyn L, Akey CW, Kumar S. New insights into apoptosome structure and function. Cell Death Differ. 2018; 25(7):1194-208. https://doi.org/10.1038/s41418-017-0025-z PMID: 29765111

39. Bock FJ, Tait SWG. Mitochondria as multifaceted regulators of cell death. Nat Rev Mol Cell Biol. 2020; 21(2):85-100. https://doi.org/10.1038/s41580-019-0173-8 PMID: 31636403

40. Green DR, Llambi F. Cell Death Signaling. Cold Spring Harb Perspect Biol. 2015; 7(12): a006080. https://doi.org/10.1101/cshperspect.a006080 PMID: 26626938

41. Julien O, Wells JA. Caspases and their substrates. Cell Death Differ. 2017; 24(8):1380-9. https://doi org/10.1038/cdd.2017.44 PMID: 28498362

42. Andrysik Z, Galbraith MD, Guarnieri AL, Zaccara S, Sullivan KD, Pandey A, et al. Identification of a core TP53 transcriptional program with highly distributed tumor suppressive activity. Genome Res. 2017; 27(10):1645-57. https://doi.org/10.1101/gr.220533.117 PMID: 28904012

43. Sullivan KD, Galbraith MD, Andrysik Z, Espinosa JM. Mechanisms of transcriptional regulation by $p 53$. Cell Death Differ. 2018; 25(1):133-43. https://doi.org/10.1038/cdd.2017.174 PMID: 29125602

44. Abbas T, Dutta A. p21 in cancer: intricate networks and multiple activities. Nat Rev Cancer. 2009; 9 (6):400-14. https://doi.org/10.1038/nrc2657 PMID: 19440234

45. Gad AKB, Nehru V, Ruusala A, Aspenström P. RhoD regulates cytoskeletal dynamics via the actin nucleation-promoting factor WASp homologue associated with actin Golgi membranes and microtubules. Mol Biol Cell. 2012; 23(24):4807-19. https://doi.org/10.1091/mbc.E12-07-0555 PMID: 23087206

46. Blom M, Reis K, Nehru V, Blom H, Gad AK, Aspenström P. RhoD is a Golgi component with a role in anterograde protein transport from the ER to the plasma membrane. Exp Cell Res. 2015; 333(2):20819. https://doi.org/10.1016/j.yexcr.2015.02.023 PMID: 25746724

47. Russo AJ, Mathiowetz AJ, Hong S, Welch MD, Campellone KG. Rab1 recruits WHAMM during membrane remodeling but limits actin nucleation. Mol Biol Cell. 2016; 27(6):967-78. https://doi.org/10. 1091/mbc.E15-07-0508 PMID: 26823012

48. Murphy C, Saffrich R, Grummt M, Gournier H, Rybin V, Rubino M, et al. Endosome dynamics regulated by a Rho protein. Nature. 1996; 384(6608):427-32. https://doi.org/10.1038/384427a0 PMID: 8945468

49. Tsubakimoto K, Matsumoto K, Abe H, Ishii J, Amano M, Kaibuchi K, et al. Small GTPase RhoD suppresses cell migration and cytokinesis. Oncogene. 1999; 18(15):2431-40. https://doi.org/10.1038/sj. onc.1202604 PMID: 10229194

50. Murphy C, Saffrich R, Olivo-Marin JC, Giner A, Ansorge W, Fotsis T, et al. Dual function of rhoD in vesicular movement and cell motility. Eur J Cell Biol. 2001; 80(6):391-8. https://doi.org/10.1078/01719335-00173 PMID: 11484930

51. Aspenström $P$, Fransson A, Saras J. Rho GTPases have diverse effects on the organization of the actin filament system. Biochem J. 2004; 377(Pt 2):327-37. https://doi.org/10.1042/BJ20031041 PMID: 14521508

52. Koizumi K, Takano K, Kaneyasu A, Watanabe-Takano H, Tokuda E, Abe T, et al. RhoD activated by fibroblast growth factor induces cytoneme-like cellular protrusions through mDia3C. Mol Biol Cell. 2012; 23(23):4647-61. https://doi.org/10.1091/mbc.E12-04-0315 PMID: 23034183

53. Nehru V, Voytyuk O, Lennartsson J, Aspenström $P$. RhoD binds the Rab5 effector Rabankyrin- 5 and has a role in trafficking of the platelet-derived growth factor receptor. Traffic. 2013; 14(12):1242-54. https://doi.org/10.1111/tra.12121 PMID: 24102721

54. Aspenström P. Atypical Rho GTPases RhoD and Rif integrate cytoskeletal dynamics and membrane trafficking. Biol Chem. 2014; 395(5):477-84. https://doi.org/10.1515/hsz-2013-0296 PMID: 24622787

55. Blom M, Reis K, Heldin J, Kreuger J, Aspenström P. The atypical Rho GTPase RhoD is a regulator of actin cytoskeleton dynamics and directed cell migration. Exp Cell Res. 2017; 352(2):255-64. https:// doi.org/10.1016/j.yexcr.2017.02.013 PMID: 28196728

56. Durkin $\mathrm{CH}$, Leite F, Cordeiro JV, Handa Y, Arakawa Y, Valderrama F, et al. RhoD Inhibits RhoCROCK-Dependent Cell Contraction via PAK6. Dev Cell. 2017; 41(3):315-29. e7. https://doi.org/10. 1016/j.devcel.2017.04.010 PMID: 28486133

57. Kyrkou A, Soufi M, Bahtz R, Ferguson C, Bai M, Parton RG, et al. RhoD participates in the regulation of cell-cycle progression and centrosome duplication. Oncogene. 2013; 32(14):1831-42. https://doi. org/10.1038/onc.2012.195 PMID: 22665057

58. Sadok A, Marshall CJ. Rho GTPases: masters of cell migration. Small GTPases. 2014; 5: e29710. https://doi.org/10.4161/sgtp.29710 PMID: 24978113

59. Ridley AJ. Rho GTPase signalling in cell migration. Curr Opin Cell Biol. 2015; 36: 103-12. https://doi. org/10.1016/j.ceb.2015.08.005 PMID: 26363959 
60. Zuchero JB, Coutts AS, Quinlan ME, Thangue NBL, Mullins RD. p53-cofactor JMY is a multifunctional actin nucleation factor. Nat Cell Biol. 2009; 11(4):451-9. https://doi.org/10.1038/ncb1852 PMID: 19287377

61. Bratton SB, Salvesen GS. Regulation of the Apaf-1-caspase-9 apoptosome. J Cell Sci. 2010; 123(Pt 19):3209-14. https://doi.org/10.1242/jcs.073643 PMID: 20844150

62. Yuan S, Akey CW. Apoptosome structure, assembly, and procaspase activation. Structure. 2013; 21 (4):501-15. https://doi.org/10.1016/j.str.2013.02.024 PMID: 23561633

63. Mashima T, Naito M, Fujita N, Noguchi K, Tsuruo T. Identification of actin as a substrate of ICE and an ICE-like protease and involvement of an ICE-like protease but not ICE in VP-16-induced apoptosis. Biochem Biophys Res Commun. 1995; 217(3):1185-92. https://doi.org/10.1006/bbrc.1995.2894 PMID: 8554575

64. Mashima T, Naito M, Noguchi K, Miller DK, Nicholson DW, Tsuruo T. Actin cleavage by CPP-32/apopain during the development of apoptosis. Oncogene. 1997; 14(9):1007-12. https://doi.org/10.1038/ sj.onc.1200919 PMID: 9070648

65. Kayalar C, Ord T, Testa MP, Zhong LT, Bredesen DE. Cleavage of actin by interleukin 1 beta-converting enzyme to reverse DNase I inhibition. Proc Natl Acad Sci U S A. 1996; 93(5):2234-8. https://doi. org/10.1073/pnas.93.5.2234 PMID: 8700913

66. Mashima T, Naito M, Tsuruo T. Caspase-mediated cleavage of cytoskeletal actin plays a positive role in the process of morphological apoptosis. Oncogene. 1999; 18(15):2423-30. https://doi.org/10.1038/ sj.onc.1202558 PMID: 10229193

67. Utsumi T, Sakurai N, Nakano K, Ishisaka R. C-terminal $15 \mathrm{kDa}$ fragment of cytoskeletal actin is posttranslationally $\mathrm{N}$-myristoylated upon caspase-mediated cleavage and targeted to mitochondria. FEBS Lett. 2003; 539(1-3):37-44. https://doi.org/10.1016/s0014-5793(03)00180-7 PMID: 12650923

68. Kanellos G, Frame MC. Cellular functions of the ADF/cofilin family at a glance. J Cell Sci. 2016; 129 (17):3211-8. https://doi.org/10.1242/jcs.187849 PMID: 27505888

69. Chua BT, Volbracht C, Tan KO, Li R, Yu VC, Li P. Mitochondrial translocation of cofilin is an early step in apoptosis induction. Nat Cell Biol. 2003; 5(12):1083-9. https://doi.org/10.1038/ncb1070 PMID: 14634665

70. Zhu B, Fukada K, Zhu H, Kyprianou N. Prohibitin and cofilin are intracellular effectors of transforming growth factor beta signaling in human prostate cancer cells. Cancer Res. 2006; 66(17):8640-7. https://doi.org/10.1158/0008-5472.CAN-06-1443 PMID: 16951178

71. Klamt F, Zdanov S, Levine RL, Pariser A, Zhang Y, Zhang B, et al. Oxidant-induced apoptosis is mediated by oxidation of the actin-regulatory protein cofilin. Nat Cell Biol. 2009; 11: 1241-6. https://doi.org/ 10.1038/ncb1968 PMID: 19734890

72. Liu T, Wang F, LePochat $P$, Woo JA, Bukhari MZ, Hong KW, et al. Cofilin-mediated Neuronal Apoptosis via p53 Translocation and PLD1 Regulation. Sci Rep. 2017; 7(1):11532. https://doi.org/10.1038/ s41598-017-09996-3 PMID: 28912445

73. Tang $\mathrm{HL}$, Le AH, Lung HL. The increase in mitochondrial association with actin precedes Bax translocation in apoptosis. Biochem J. 2006; 396(1):1-5. https://doi.org/10.1042/BJ20060241 PMID: 16536728

74. Wang C, Zhou GL, Vedantam S, Li P, Field J. Mitochondrial shuttling of CAP1 promotes actin- and cofilin-dependent apoptosis. J Cell Sci. 2008; 121(Pt 17):2913-20. https://doi.org/10.1242/jcs.023911 PMID: 18716285

75. Rehklau K, Gurniak CB, Conrad M, Friauf E, Ott M, Rust MB. ADF/cofilin proteins translocate to mitochondria during apoptosis but are not generally required for cell death signaling. Cell Death Differ. 2012; 19(6):958-67. https://doi.org/10.1038/cdd.2011.180 PMID: 22139132

76. McGough AM, Staiger CJ, Min JK, Simonetti KD. The gelsolin family of actin regulatory proteins: modular structures, versatile functions. FEBS Lett. 2003; 552(2-3):75-81. https://doi.org/10.1016/s00145793(03)00932-3 PMID: 14527663

77. Kothakota S, Azuma T, Reinhard C, Klippel A, Tang J, Chu K, et al. Caspase-3-generated fragment of gelsolin: effector of morphological change in apoptosis. Science. 1997; 278(5336):294-8. https://doi. org/10.1126/science.278.5336.294 PMID: 9323209

78. Chhabra D, Nosworthy NJ, dos Remedios CG. The N-terminal fragment of gelsolin inhibits the interaction of DNase I with isolated actin, but not with the cofilin-actin complex. Proteomics. 2005; 5 (12):3131-6. https://doi.org/10.1002/pmic.200401127 PMID: 16021605

79. Zuo W, Guo WS, Yu HC, Liu P, Zhang QD. Role of Junction-Mediating and Regulatory Protein in the Pathogenesis of Glucocorticoid-Induced Endothelial Cell Lesions. Orthop Surg. 2020. https://doi.org/ 10.1111/os.12680 PMID: 32363797 
80. Schlüter K, Waschbüsch $D$, Anft M, Hügging $D$, Kind $S$, Hänisch J, et al. JMY is involved in anterograde vesicle trafficking from the trans-Golgi network. Eur J Cell Biol. 2014; 93(5-6):194-204. https:// doi.org/10.1016/j.ejcb.2014.06.001 PMID: 25015719

81. Kast DJ, Zajac AL, Holzbaur ELF, Ostap EM, Dominguez R. WHAMM Directs the Arp2/3 Complex to the ER for Autophagosome Biogenesis through an Actin Comet Tail Mechanism. Curr Biol. 2015; 25 (13):1791-7. https://doi.org/10.1016/j.cub.2015.05.042 PMID: 26096974

82. Mathiowetz AJ, Baple E, Russo AJ, Coulter AM, Carrano E, Brown JD, et al. An Amish founder mutation disrupts a $\mathrm{PI}$ (3)P-WHAMM-Arp2/3 complex-driven autophagosomal remodeling pathway. Mol Biol Cell. 2017; 28(19):2492-507. https://doi.org/10.1091/mbc.E17-01-0022 PMID: 28720660

83. Shen Q-T, Hsiue PP, Sindelar CV, Welch MD, Campellone KG, Wang H-W. Structural insights into WHAMM-mediated cytoskeletal coordination during membrane remodeling. J Cell Biol. 2012; 199 (1):111-24. https://doi.org/10.1083/jcb.201204010 PMID: 23027905

84. Dai $A, Y u L$, Wang HW. WHAMM initiates autolysosome tubulation by promoting actin polymerization on autolysosomes. Nat Commun. 2019; 10(1):3699. https://doi.org/10.1038/s41467-019-11694-9 PMID: 31420534

85. Gu W, Roeder RG. Activation of p53 Sequence-Specific DNABinding by Acetylation of the p53 C-Terminal Domain. Cell. 1997; 90(4):595-601. https://doi.org/10.1016/s0092-8674(00)80521-8 PMID: 9288740

86. Gu W, Shi XL, Roeder RG. Synergistic activation of transcription by CBP and p53. Nature. 1997; 387 (6635):819-23. https://doi.org/10.1038/42972 PMID: 9194564

87. Barlev NA, Liu L, Chehab NH, Mansfield K, Harris KG, Halazonetis TD, et al. Acetylation of p53 activates transcription through recruitment of coactivators/histone acetyltransferases. Mol Cell. 2001; 8 (6):1243-54. https://doi.org/10.1016/s1097-2765(01)00414-2 PMID: 11779500

88. Erster S, Moll UM. Stress-induced p53 runs a transcription-independent death program. Biochem Biophys Res Commun. 2005; 331(3):843-50. https://doi.org/10.1016/j.bbrc.2005.03.187 PMID: 15865940

89. Green DR, Kroemer G. Cytoplasmic functions of the tumour suppressor p53. Nature. 2009; 458 (7242):1127-30. https://doi.org/10.1038/nature07986 PMID: 19407794

90. Riley $\mathrm{T}$, Sontag $\mathrm{E}$, Chen $\mathrm{P}$, Levine A. Transcriptional control of human p53-regulated genes. Nat Rev Mol Cell Biol. 2008; 9(5):402-12. https://doi.org/10.1038/nrm2395 PMID: 18431400

91. Beckerman R, Prives C. Transcriptional regulation by p53. Cold Spring Harb Perspect Biol. 2010; 2(8): a000935. https://doi.org/10.1101/cshperspect.a000935 PMID: 20679336

92. Zou H, Li Y, Liu X, Wang X. An APAF-1.cytochrome c multimeric complex is a functional apoptosome that activates procaspase-9. J Biol Chem. 1999; 274(17):11549-56. https://doi.org/10.1074/jbc.274. 17.11549 PMID: 10206961

93. Nürnberg A, Kitzing T, Grosse R. Nucleating actin for invasion. Nat Rev Cancer. 2011; 11(3):177-87. https://doi.org/10.1038/nrc3003 PMID: 21326322

94. Molinie N, Gautreau A. The Arp2/3 Regulatory System and Its Deregulation in Cancer. Physiol Rev. 2018; 98(1):215-38. https://doi.org/10.1152/physrev.00006.2017 PMID: 29212790

95. Levy JMM, Towers CG, Thorburn A. Targeting autophagy in cancer. Nat Rev Cancer. 2017; 17 (9):528-42. https://doi.org/10.1038/nrc.2017.53 PMID: 28751651

96. Poillet-Perez L, White E. Role of tumor and host autophagy in cancer metabolism. Genes Dev. 2019; 33(11-12):610-9. https://doi.org/10.1101/gad.325514.119 PMID: 31160394

97. Olivier M, Hollstein M, Hainaut P. TP53 mutations in human cancers: origins, consequences, and clinical use. Cold Spring Harb Perspect Biol. 2010; 2(1): a001008. https://doi.org/10.1101/cshperspect. a001008 PMID: 20182602

98. Kandoth C, McLellan MD, Vandin F, Ye K, Niu B, Lu C, et al. Mutational landscape and significance across 12 major cancer types. Nature. 2013; 502(7471):333-9. https://doi.org/10.1038/nature12634 PMID: 24132290

99. Mantovani F, Collavin L, Del Sal G. Mutant p53 as a guardian of the cancer cell. Cell Death Differ. 2019; 26(2):199-212. https://doi.org/10.1038/s41418-018-0246-9 PMID: 30538286

100. Adighibe O, Turley H, Leek R, Harris A, Coutts AS, La Thangue N, et al. JMY protein, a regulator of P53 and cytoplasmic actin filaments, is expressed in normal and neoplastic tissues. Virchows Arch. 2014; 465(6):715-22. https://doi.org/10.1007/s00428-014-1660-0 PMID: 25280461

101. Carette JE, Raaben M, Wong AC, Herbert AS, Obernosterer G, Mulherkar N, et al. Ebola virus entry requires the cholesterol transporter Niemann-Pick C1. Nature. 2011; 477(7364):340-3. https://doi.org/ 10.1038/nature10348 PMID: 21866103 
102. Campellone KG, Leong JM. Nck-independent actin assembly is mediated by two phosphorylated tyrosines within enteropathogenic Escherichia coli Tir. Mol Microbiol. 2005; 56(2):416-32. https://doi.org/ 10.1111/j.1365-2958.2005.04558.x PMID: 15813734

103. Schindelin J, Arganda-Carreras I, Frise E, Kaynig V, Longair M, Pietzsch T, et al. Fiji: an open-source platform for biological-image analysis. Nat Methods. 2012; 9(7):676-82. https://doi.org/10.1038/ nmeth.2019 PMID: 22743772 